\title{
AUDIO DESCRIPTION IN THE CHINESE COMMUNITY
}

\author{
by \\ Fei Xue \\ B.Mgt. Capital University of Economics and Business, 2011 \\ A thesis \\ Presented to Ryerson University \\ In partial fulfillment of the \\ Requirements for the degree of \\ Masters of Management Science \\ In the program of \\ Management of Technology and Innovation
}

Toronto, Ontario, Canada, 2013

@ Fei Xue 2013 
I hereby declare that I am the sole author of this thesis.

I authorize Ryerson University to lend this thesis to other institutions or individuals for the purpose of scholarly research.

Fei Xue

Date

I further authorize Ryerson University to reproduce this thesis by photocopying or by other means, in total or in part, at the request of other institutions or individuals for the purpose of scholarly research.

Fei Xue

Date 


\title{
Audio Description in the Chinese Community
}

\author{
Master of Management Science, 2013 \\ Fei Xue \\ Management o Technology and Innovation \\ Ryerson University
}

\begin{abstract}
ASTRACT
The motivation of this research is to apply audio description to films designed for or about the Chinese community. It aims to examine the differences and similarities of expectations and evaluations of audio description between the Chinese and Canadian communities. An integrated audio described film was produced for the film, 'Magical Coincidence'. Two phases of interviews were conducted among Chinese and Canadian participants. The results show that differences exist not only in nationalities, but also in genders. This research confirms the necessity of applying audio description to films for the Chinese community, and provides suggestions for the production process.
\end{abstract}




\section{ACKNOWLEDGEMENTS}

First and foremost, I would like to thank Dr. Deborah Fels, my thesis supervisor, for being so supportive, patient, and willing to take time out of her incredibly busy schedule to meet with me every week and guide me through this process. Without her support and aid I would not have been able to finish this thesis.

I would like to thank Keith Lock, director, for his participation, and taking the time to reply to all my questions on multiple occasions to provide inputs and insights into my thesis, and Chris Chin at the Reel Asian Film Festival.

I would like to thank my thesis committee, Ron Babin, Wendy Cukier, and Farid Shirazi for agreeing to review my thesis on such short notice.

I would also like to thank all the participants of my study from China and Canada.

I am grateful to the IMDC staff, especially Margot Whitfield, for her constant support, and patience with my millions of daily questions.

I want to thank Ryerson University, SSHRC and NSERC for funding my project. 


\section{Table of Contents}

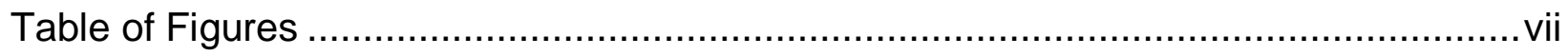

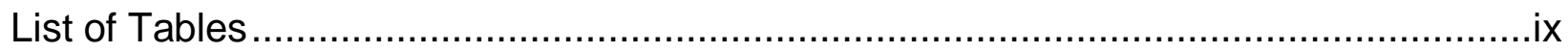

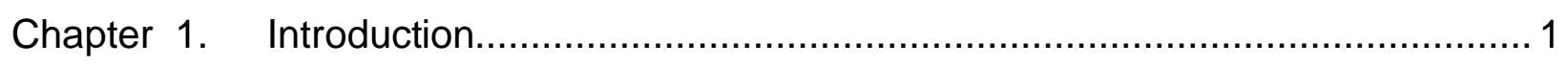

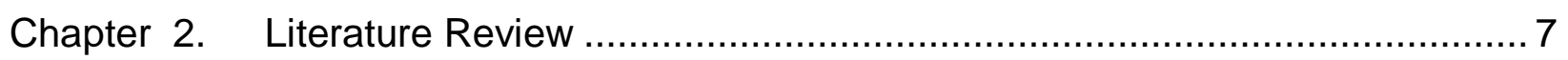

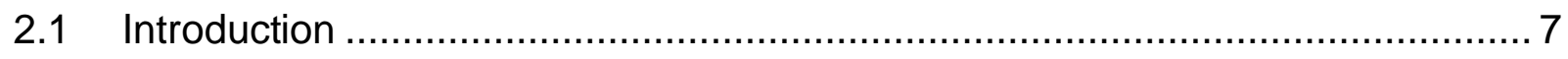

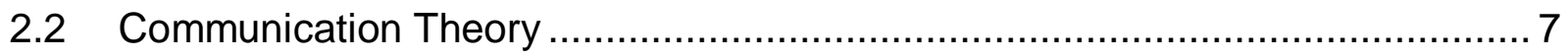

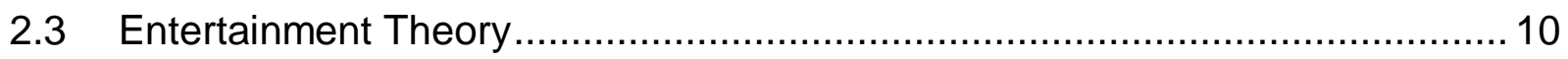

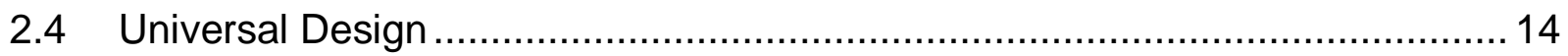

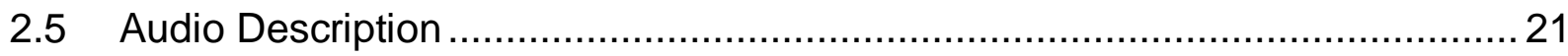

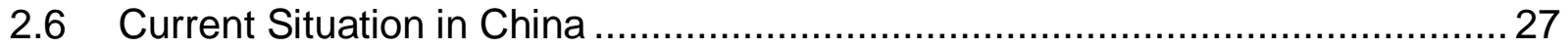

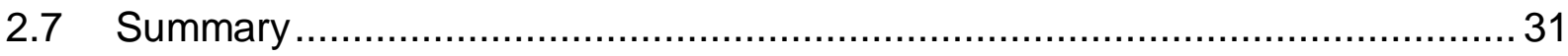

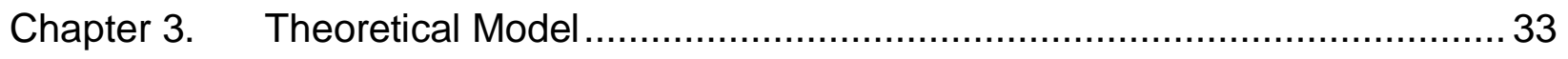

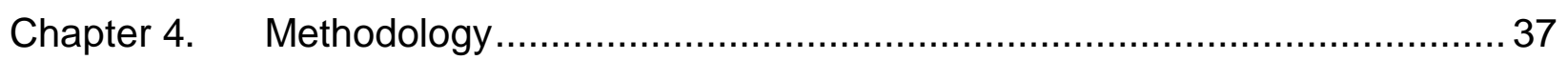

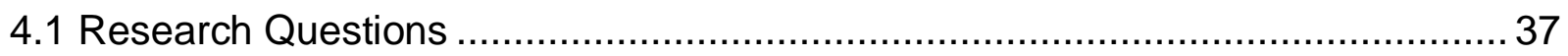

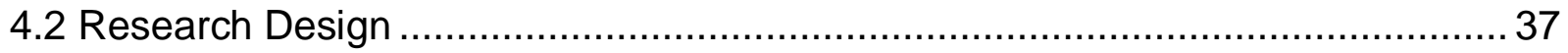

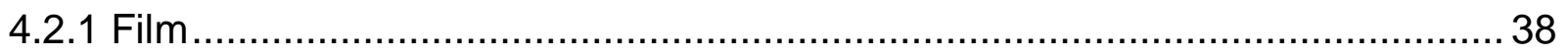

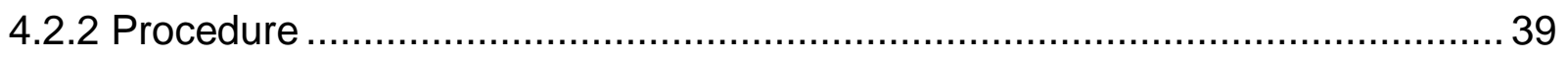

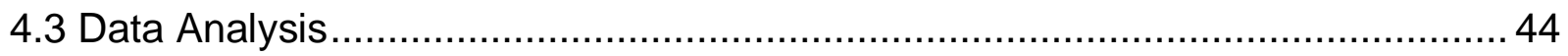




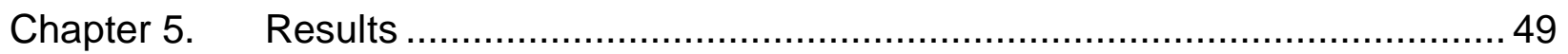

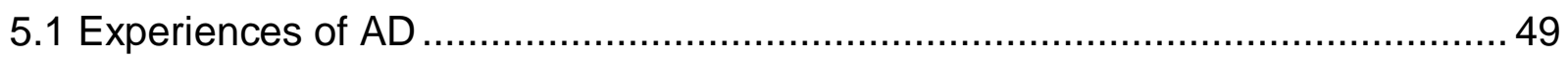

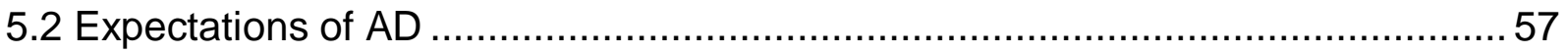

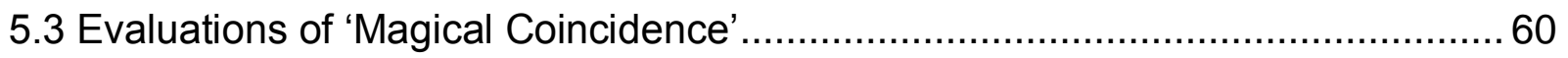

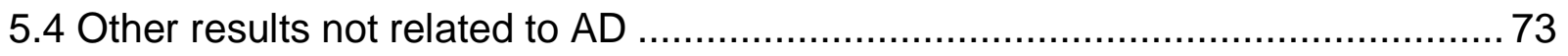

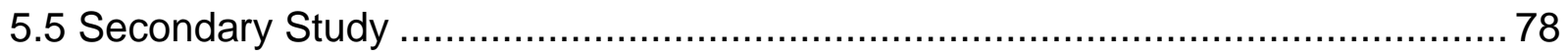

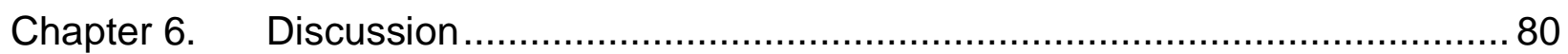

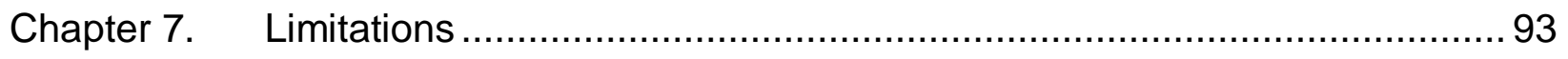

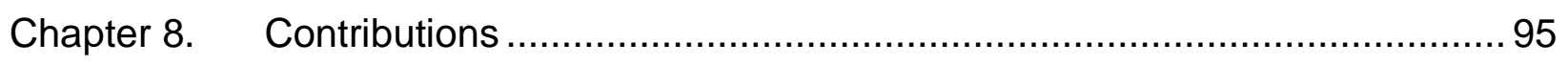

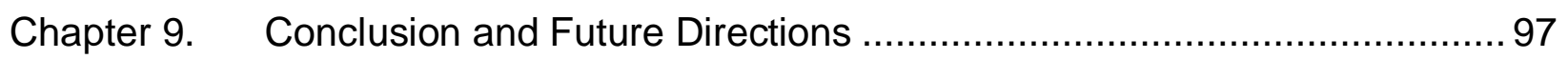

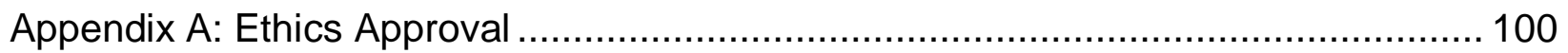

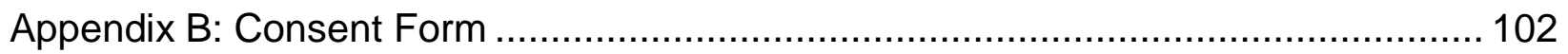

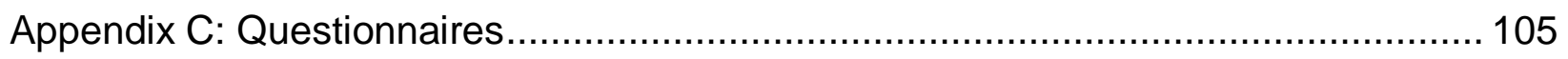

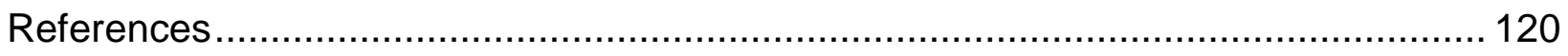




\section{Table of Figures}

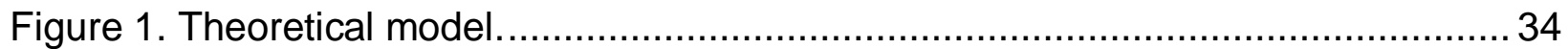

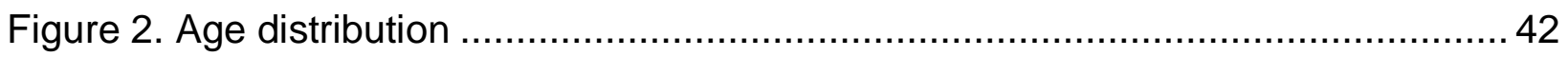

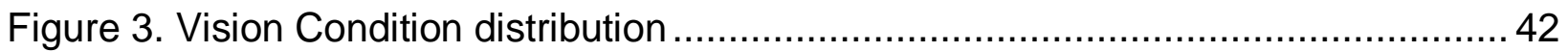

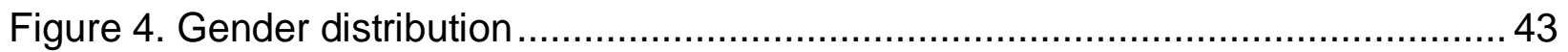

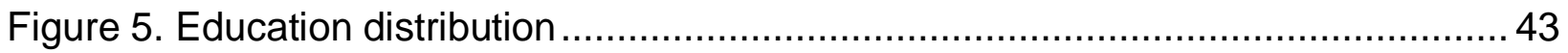

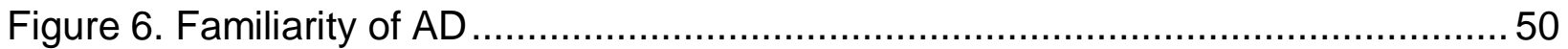

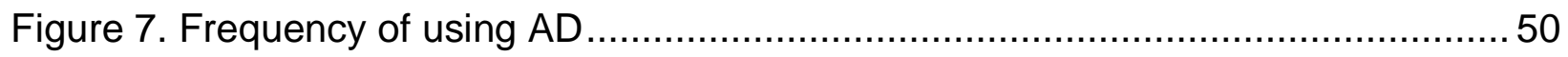

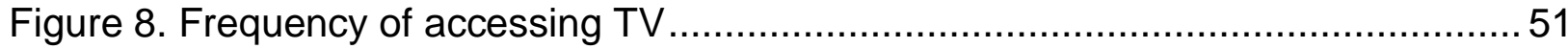

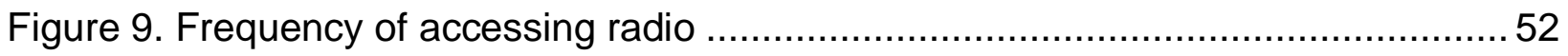

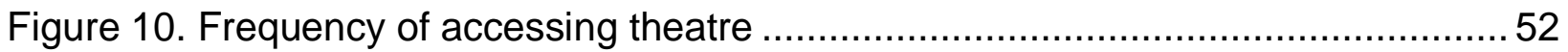

Figure 11. Ask for assistance when watch TV ...................................................... 53

Figure 12. Ask for assistance when watch movie................................................... 54

Figure 13. Ask for assistance when go to theatre ................................................... 54

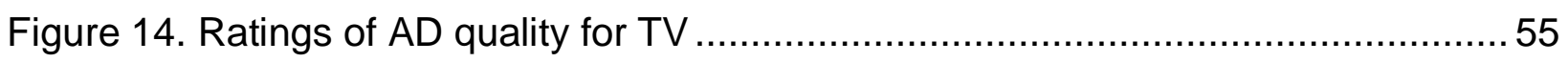

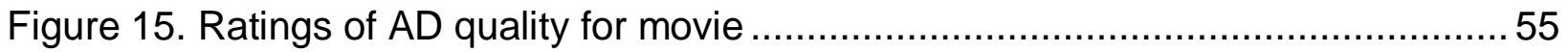

Figure 16. Ratings of AD quality for theatre shows ............................................... 56

Figure 17. Who usually describes for participants ................................................ 57

Figure 18. Factors that would influence participants' ratings of AD .............................6 60

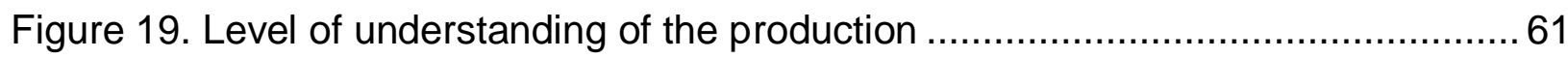

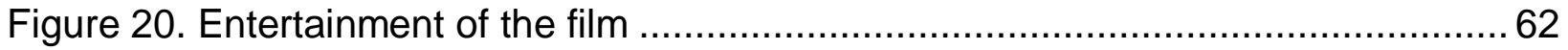

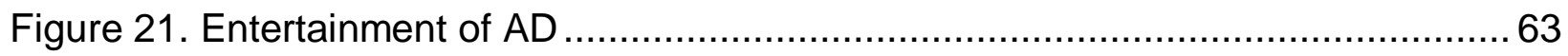

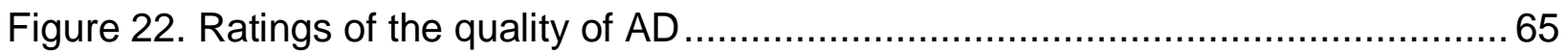


Figure 23. Comfortable discussing the production with a sighted partner or friend .......65

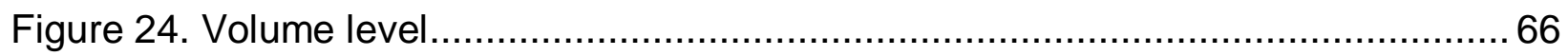

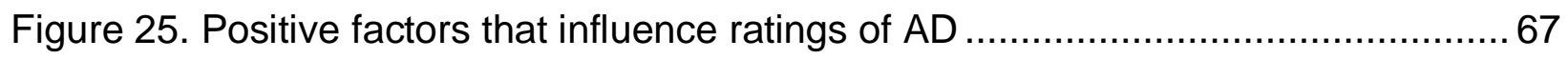

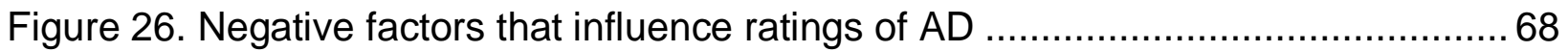

Figure 27. Quality of description for onscreen action/plot.......................................... 69

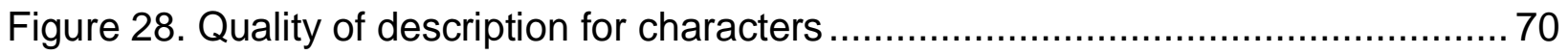

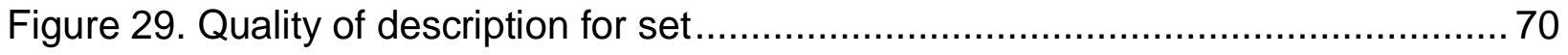

Figure 30. Quality of description for costumes .................................................. 70

Figure 31. Enough description for onscreen action/plot ....................................... 71

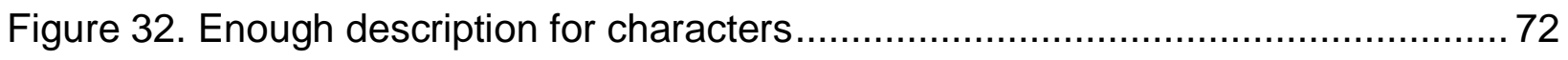

Figure 33. Enough description for costumes …................................................... 72

Figure 34. Enough description for set............................................................. 73

Figure 35. Enough description for costumes by gender ........................................... 76

Figure 36. Quality of description for costumes by gender ….................................... 76

Figure 37. Things that participants would like to do on their own ............................... 77

Figure 38. Things that participants would like to be helped with ................................ 78 


\section{List of Tables}

Table 1. Gagnon and Turner's classification of AD contents [18] ...............................24

Table 2. Similarities and differences of 'translation', 'representation', and 'performance' 30

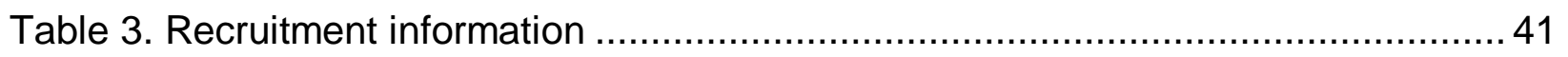

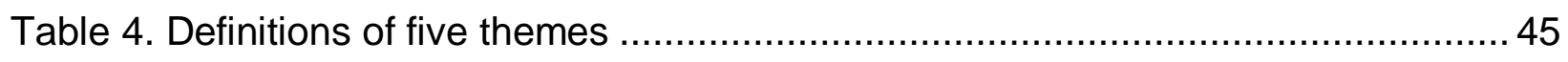

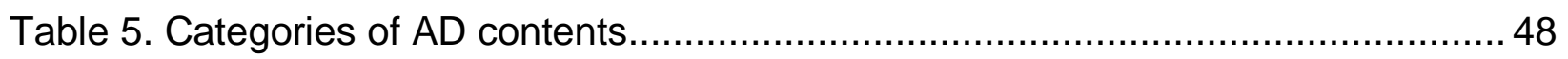

Table 6. Expected TV shows to be described (standard categories found on imdb.com) 58

Table 7. Expected movies to be described (standard categories found on imdb.com).. 58

Table 8. Expected theatre shows to be described (standard categories found on

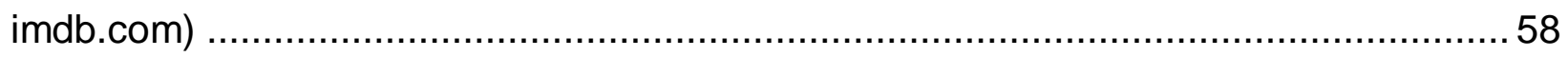

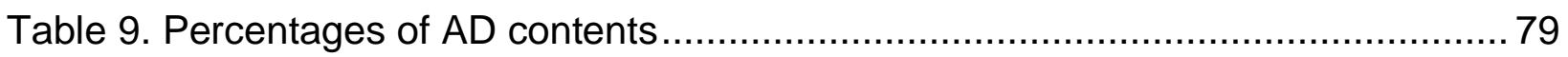




\section{Chapter 1. Introduction}

Entertainment is a fundamental aspect of human society as it makes an important contribution to the cultural development of that society. Access to some forms of entertainment and cultural expression, such as television, film, theatre, and other audiovisual entertainment media, can be limited to people with various disabilities. As a result, these individuals have more limited access to a vital aspect of a society's fabric, which can affect their participation as equal citizens.

Audio description (AD) is one technology that helps to offer better access to film, television, and theatre for people who are blind or low-vision (B/LV). It is defined as the aural description of visual stimuli via a secondary audio track, feed or onstage character or narrator [27].

There are various types and approaches in developing $A D$. Conventional $A D$ is produced by a third party after the production of the original work. Integrated AD is an unconventional way of producing $A D$. It has two distinguishing features: it is produced by the creative team and included from the beginning of the production process. Live $A D$ is generated for live events such as fashion shows. First-person AD is described by the main character in the show and is from the protagonist's perspective. Integrated AD is employed in this research. It is considered to be one example of universal design because it not only provides access to a larger population than the target one, but is also managed, designed, and executed from within the production process. AD is 
targeted at people who are B/LV, but it may also be useful to sighted people when their eyes are occupied such as when driving or cooking.

A large number of organizations provide $A D$ services in countries such as Canada, the United States (US), Australia, and the United Kingdom (UK), but provide them mostly in one language - English. As a result, foreign films and/or people residing in those countries who speak different languages are likely unable to benefit from AD. This means that people who are B/LV may have restricted access to non-English cultural artefacts, which are often so important to people living in multi-cultural and diverse societies. Chinese AD is rarely available in either Canada or China, particularly in mainland China, where AD is still a new concept to most people. In Toronto, the Chinese population is about 283,075 or $11.4 \%$. The World Health Organization [77] estimates that about $4.75 \%$ of the world's population is $B / L V$ and therefore it is estimated that there are about 13,446 (283,075 times $4.75 \%)$ B/LV Chinese people in Toronto (assuming that the population structure of Chinese immigration is random). This means that there are 13,446 people in Toronto who have little or no access to entertainment in their native language. To further study this topic, this research aims to examine the use of and experience of $A D$ in the Chinese community and to collect suggestions in producing $A D$ for directors and describers with regard to cultural differences between the Chinese and Canadian communities.

There are several organizations providing $A D$ services to blind communities in China and Canada. In Beijing, there are three to five non-profit organizations that provide AD 
for films. They recruit volunteers who receive a short informal training session and then are able to orally describe films for B/LV people. One theatre called the Heart \& Eye Theatre has announced on their website that they provide AD service on a weekly basis [78]. Their services are very popular among Chinese blind community although they do not have a standard principle or guideline for creating AD. In the current stage, some professional guidelines of producing $A D$ are needed.

Among the Chinese speaking people who have immigrated to Canada, it is more difficult for B/LV people in the Chinese community to access AD for Chinese film or television. To date, all AD is provided in English, but most B/LV Chinese in Toronto can only understand Mandarin or Cantonese [79].

In Canada, AD is regulated by the Canadian Radio, Television and Telecommunications Commissions [76]. The regulation says that the commission "...requires broadcasters to provide $A D$ for all in-house production...broadcasters are required to provide at least four hours per week of described programming." [76, para. 5]. In 2011, Media Access Canada released a guide to create accessible digital media. This particular guide focuses on the AD process and provides examples and best practice, which offers a useful benchmark for $A D$ quality. Provision of $A D$ increases access to video content for B/LV people. Some of the rules mentioned in this guide and other standards for inclusive digital environments serve as instructions for the creative team in this research. 
To come up with the whole research process, the procedure of creating AD for film and choosing which elements to include should be clarified. There are three elements in the process of creating AD: 1. People (describer, script writer, director, and audiences), 2. Place (cinema and recording studio), and 3. Technology (AD recording system and headset). First, the film directors should agree to add $A D$ to their films, and the script writers then write the script for AD. The original script writer of the film is the best candidate for writing the script for $A D$. Second, $A D$ is conveyed from the describer to the audiences through a secondary audio track or a live describer. Third, the process of adding $A D$ to films also needs audiences' participation, opinions, and feedback. Fourth, cinemas are the places where audiences use $A D$, and recording studios are the places for describers to produce AD. Fifth, an AD recording system and headset are needed to convey the information from describer to audiences. The interaction between these three elements completes the production process of $A D$. To apply $A D$ in the Chinese community, the only different element is that the audiences are Chinese. The describer and script writer should take this into consideration that the audiences may have different opinions and expectations of AD.

Although there already exists a variety of research on $A D$, a few studies have been reported in the Chinese community. The application of $A D$ is more popular in Taiwan and Hong Kong than in mainland China [16]. There is some training for AD hosted by universities in Hong Kong and Taiwan, but they mainly focus on the training of linguistic skills. Unlike previous works, this research would investigate people's feedback from a cultural perspective. The research questions are as follows: 
1. How are the expectations of AD between the Chinese and Canadian communities different?

2. How do the evaluations of integrated AD differ between the Chinese and Canadian communities for "Magical Coincidence"?

"Magical Coincidence" is the audio described film that is developed for participants to evaluate. It is a 20-minute long romantic comedy with some cross-cultural elements. There are three languages used in this film: the majority is in English, and there are five places in Mandarin and two places in Italian. It tells a romantic story between a Canadian woman who can speak English and Mandarin, and an Asian male who can speak English and Italian. These characters are brought together by chance circumstances involving mushrooms containing mysterious messages purchased by a Chinese-speaking vegetable seller and the character's quest to discover the message's meaning and origins from an Italian-speaker mushroom grower. There are some cultural confusions between the two main character: the Asian male could not understand when the Canadian woman speaks Mandarin, and the Canadian woman could not understand when the Asian male speaks Italian.

The contents of this thesis are arranged as follows: Chapter 2 is literature review, in which the theoretical basis, current situation, and previous studies are introduced. Chapter 3 is the theoretical model proposed by the researcher including descriptions of each process. Chapter 4 clarifies the methodology employed in this research. Research questions, research design, and data analysis are included in this chapter. Chapter 5 
displays all the results of this research. Chapter 6 is the discussion of the results and offers some explanation to the research questions. Chapter 7 states the limitations of this research. Chapter 8 illustrates the contributions. Chapter 9 introduces some future directions for studies in this field and concludes the thesis. At the end of this thesis, appendixes and references are attached. 


\section{Chapter 2. Literature Review}

\section{$2.1 \quad$ Introduction}

In this chapter, the theoretical foundation of this research is introduced first. Three fields of theory are discussed: communication theory, entertainment theory, and universal design. Then, the main issue in this research is examined: AD. The methodologies, results, and purpose of previous research on AD are presented. This chapter also discusses the differences and similarities between this research and prior studies. Next, the special issue of this research, the Chinese community, is clarified. The last part is arranged in the following sequence: the current situation of Chinese blind community, the government's efforts for accessibility, the Chinese film theory, and AD in China. Finally, a conclusion of this chapter and a preliminary introduction to next chapter are presented. In next chapter, a model of producing integrated $A D$ is proposed based on other research and the special process in this research.

\subsection{Communication Theory}

With the digital era brought by various types of high-tech media, society has been transferring from a cultural-debating public to a cultural-consuming public [40]. During the period when Habermas developed the structural transformation of the public sphere, newspaper was the leading media. It provided the government a channel to announce its political stance and convey its standpoint to the public [41]. Also, it was controlled by economic and communicational institutions [42]. The mediating public sphere is 
between the ruling class and private individuals. It is open to all citizens and constituted by an exchange of information and ideas [44]. Unlike newspaper, which limits the public's ability to express their opinions in the public sphere, "digitization together with social and cultural changes has accelerated the demise of public service broadcasting to public service communication which no longer has boundaries between nations or communities" [45]. Broadcast media and computers are used to inform and enlighten individuals rather than to manipulate them [49]. Georgina Born announced in her paper that it was the public broadcaster's duty to construct a public sphere that enriches the cultural, political, and moral stance. Interactions in communication break the limitations associated with the nation state and its political culture. Face-to-face interactions are another important source of communication [49]. Although none of these articles discusses the blind communities' participation in the public sphere or their contribution to cultural and social development, 'the public' they have mentioned includes the blind communities. Habermas stimulated scholars' interests in communication studies and his works set a milestone in connecting citizens with the powerful [43].

Media provides channel and contributes to the development of the public sphere. For example, television has three aspects: an industry, sets of audio-visual texts, and a sociocultural experience [47]. Films are another type of media that convey information and establish communication in society, and through which we can expand the current public sphere [48]. Media can be constructed through different approaches in order to reflect different governments and markets [51]. Many people have claimed their points to be 'beyond Habermas', because there emerged many new forms of the public screen 
that produce new modes of intelligence, knowledge, politics, and rhetoric [52]. People with special needs in the public sphere have the same rights to access the public screen as other people, and they can contribute to the expansion of culture and the revolution of society. But those people usually do not have equivalent access to the public screen and sometimes they are excluded from the public sphere and their contribution is little. Multiple inputs from diverse individuals comprise the public sphere we have now, and B/LV people's inputs are very important.

Communication theories are mutually relevant. One of the traditions of communication theory is semiotics which focuses on the presentation and transmission of meaning, the gaps between subjectivities that can be bridged, and the use of shared systems of signs [53]. In order to complete the transmission of meaning, shared systems of signs are required to be established. The transmission of meaning bridges the gaps between subjectivities. A general semiotic theory is considered powerful according to its capacity to offer an appropriate formal definition or every sort of sign-function, whether it has already been described and coded or not [55]. Communication theory studies how people convey ideas for themselves and to one another, whether through words, food, clothing, objects, or in other ways. Semiotics has paid a great deal of attention to describing how people convey meanings and thus has developed a vocabulary, which is the shared system of signs, people can borrow from [56]. People communicate with each other to convey meaning and to justify their senses of existence [54]. If a person could not participate in a discussion with a social group, he or she is not able to communicate with others in that social group and might feel excluded and isolated. B/LV 
people need to participate in communicating with others in the social group and to justify their senses of existence.

\subsection{Entertainment Theory}

Dolf Zillmann [37] has done some empirical research on entertainment. He established a set of theories in the field of entertainment and wished "to describe and explain what entertainment is, how it works, what it does to the audience, and to answer the question of why the audience is so attracted to it" [37, p132]. There are several representative theories he proposed in the field of entertainment: mood-management and selective exposure theory, affective-disposition theory which is based on the theory of empathy, and excitation-transfer theory which is based on the three-factor theory of emotion. Mood-management and selective-exposure theory explains why and how the audience seeks entertainment. It is expected that people would maintain and foster their positive moods and alter negative moods by selecting media products [37]. Affective-disposition theory leads media users to hope for a positive outcome and fear a negative outcome for their preferred protagonist. Excitation-transfer theory lets the audience gain relief and positive experience after the protagonist encounters a stressful event.

Entertainment theory studies users and media products in the process of perceiving entertainment. Who the users are and where they consume the entertainment should be taken into consideration in media presence research [70]. In entertainment theory, another topic is to understand users' preferences in perceiving entertainment. Voderer [37] mentioned that females and males do not have the same preference in selecting 
media products. The author also indicated that interactive media is a special medium since it includes the uses' impact on the media [37]. Meaningfulness is what media users are searching for when seeking and selecting entertainment.

Vorderer proposed a model of entertainment motivation based on entertainment theory which features the enjoyment of consuming media products [38]. Enjoyment is defined as a pleasant experiential state in the entertainment experience which includes physiological, cognitive, and affective components [67]. This model describes media contents in two dimensions: enjoyment and appreciation. Appreciation is influenced by three factors: relatedness, competence, and autonomy, and it is more difficult to satisfy. Enjoyment is influenced by comprehension and pleasure, and is more intuitive in consuming media. The questionnaires of my research are designed to follow the principles of how people consume media products which is explained in entertainment theory. For example, participants are required to answer questions like 'how entertaining is the film?' and 'do you think enjoyment is important in evaluating the quality of AD?'

In the studies of entertainment, some scholars argue that the soundtrack of television should perform some specific functions: 1 . The soundtrack should provide sufficient plot or informational continuity even when the image is not visible; 2 . There must be a sense that anything which is really important will be queued by the soundtrack; 3 . There must be recognizable continuity in the type of sound and material presented throughout individual programs or over succeeding programs; 4 . The sound itself must provide desired information, events, or emotions from time to time during the flow [39]. Those functions give us some hints in developing AD. AD language should also have 
informational continuity, and a distinctive voice that could be recognized of the describer is desired. Similar voices in AD could confuse users and lead to misunderstanding or distraction.

AD has some features that are similar to film narratives since they both describe films. Previous research has studied how people describe films and made comparisons between different countries. The Pear Tree Project is one of the studies that aim to find out preferences of film narratives in different countries, so that a preliminary guideline could be proposed in applying AD in different countries [3]. The results shows that the Americans tended to describe from a film perspective using words like "the scene now turns to a boy", and the Chinese tended to describe from a critical perspective with more social, moral, and psychological interpretations. For example, the Chinese described a scene using words like "the boy picks up the basket of pears carefully in case the man catches him". The Chinese and the Americans grouped clauses into sentences almost identically, and their sequence of events, narrative action description, and descriptive clauses were almost the same. The Chinese included more chronological details in their description such as first, second, and etc. Relative clauses were used when they first mention a new character [2][3][15]. For example, "a boy wearing a white T-shirt shows up". These results may give us some guidance on developing AD in the Chinese community. For example, in choosing what should be described in $A D$, more chronological details should be included if the findings of Chinese preference of film narratives were followed. One limitation of the Pear Tree Project is that it applies the results of preferences on film narratives to producing $A D$ guidelines, and does not make 
any explanations regarding why. AD and film narratives have some characteristics in common, but they are two totally different concepts. Another limitation is that there were no blind participants included, and they did not discuss anything related to the blind community. Although this project is not a reasonable guideline for $A D$, it does have some implications, such as including more chronological details in Chinese $A D$, that future researchers could focus on when studying the content and language of AD.

One of the most popular standpoints in the field of $A D$ is that $A D$ is a translation from audio to visual elements. The simultaneous transmission of image, verbal language and sound, and the complex semiotic interaction comprise an audio described film [6]. There are several areas of research on translated products in film studies: film adaptation, the screenplay, subtitling, and audio-visual translation. A film adaptation is the transfer of a written work, in whole or in part, to a feature film [75]. A screenplay is the original work in the process of producing film. It is "a story told with pictures, dialogue and description, and placed within the context of dramatic structure" [80]. When foreign films were not dubbed but subtitled, which translates characters' foreign language into native language in the captions showed on the screen, audio describers had to include all the subtitles in the AD script and read the subtitles in AD. This is defined as audio subtitling. Results from previous studies of audio subtitling showed that: 1 . Different voices should be employed in audio subtitling; 2. Connections between the original soundtrack and the audio subtitling may affect audiences' perception; 3 . Songs should be kept in the original language if necessary, and important lyrics should be audio subtitled by a different describer other than the audio describer; 4 . If a film includes more than one 
language, only the major language should be dubbed in the original work and others should be left audio subtitled to make sense [8]. The concept of audio-visual translation is developed on the definition of language translation. From the linguistic perspective of translation, there exist three kinds of translation: intralnguistic, interlinguistic, and intersemiotic. Intralinguistic translation represents the translation between verbal signs in the same language. Interlinguistic translation is the translation between different languages. Intersemiotic translation is the translation between verbal and nonverbal signs in the same language. If $A D$ is classified from the linguistic point of view, it could be defined as intersemiotic translation, which translates visual signs into verbal signs. Some researchers define $A D$ as audio-visual translation based on the definition of intersemiotic translation [6]. Both audio and visual media products are entertainment, and entertainment theory applies to all kinds of media products. The four translated products discussed in this paragraph are independent media products or a part of other entertainment, so entertainment theory applies on AD. Similar to studies based on entertainment theory, studies in $A D$ reception should include the enjoyment level of users, people's perception, motivation, and preference of using.

\subsection{Universal Design}

Universal design was initially proposed by the Center for Universal Design at North Carolina State University to guide the design process, to evaluate existing or new designs, and to teach students and practitioners about how to produce AD [63]. It is concerned with the issue of accessibility, which is the right of all citizens to obtain and maintain access to a society-wide pool of information resources and interpersonal 
communication facilities [81]. Some designs include accessibility after the production process which is called 'reactive adaptation'. Contrary to reactive adaptation, which is a post-production that emerges to meet special needs, universal design is a proactive approach in the early phases of design [62]. There are a few confusing terms that appear similar to 'universal design': accessible design, adaptable design, and transgenerational design. Accessible design meets the requirements of people with disabilities. Adaptable design adds modifications to meet individual needs.

Transgenerational design considers the changes that happen to people as they age. Universal design is always accessible and it integrates accessibility from the beginning of the design process. It requires the least from users compared with products that do not follow universal design, because it applies to the change in the environment rather than the change in the user [57]. Universal design takes users' needs into consideration [58] and is intended to break barriers to independence and decrease exclusions [60]. The participation of users in design and test processes is crucial because designers often overlook the special needs of various users. The designers should also have advice about social and ethical issues. Legislation by the government or organizations could increase awareness of the rights of people with disabilities to encourage the application of universal design [59]. Accessible design is legally mandated whereas universal design is not [61]. There are seven principles of universal design as outlined by [63]. After introducing each principle, how AD meets the regulations of universal design is discussed as follows: 
PRINCIPLE ONE: Equitable Use [63]

The design is useful and marketable to people with diverse abilities.

Guidelines:

1a. Provide the same means of use for all users: identical whenever possible; equivalent when not.

1b. Avoid segregating or stigmatizing any users.

1c. Make provisions for privacy, security, and safety equally available to all users. 1d. Make the design appealing to all users.

Some research has shown that $A D$ has a viable market [34]. $A D$ provides individuals who are $B / L V$ equivalent access to information and entertainment without any help from other sighted peers. In addition, AD is a useful tool for sighted individuals who do not have full access to entertainment media. For example, it can be used when sighted individuals devote their visual attention to sewing or when they are watching a sports game from a long distance in a stadium.

PRINCIPLE TWO: Flexibility in Use

The design accommodates a wide range of individual preferences and abilities. Guidelines:

2a. Provide choice in methods of use.

2b. Accommodate right- or left-handed access and use.

2c. Facilitate the user's accuracy and precision.

2d. Provide adaptability to the user's pace. 
This principle stresses that universal design should provide options for users to access products or services which do not require additional adaptations. The users of AD include the audience and media producer. Usually B/LV individuals use AD to access entertainment media. Various types of AD could be produced to meet audiences with various needs. For example, a more detailed version of $A D$ could be provided online or on another soundtrack if enough funding and time are available.

PRINCIPLE THREE: Simple and Intuitive Use

Use of the design is easy to understand, regardless of the user's experience, knowledge, language skills, or current concentration level.

Guidelines:

3a. Eliminate unnecessary complexity.

3b. Be consistent with user expectations and intuition.

3c. Accommodate a wide range of literacy and language skills.

$3 d$. Arrange information consistent with its importance.

3e. Provide effective prompting and feedback during and after task completion.

$A D$ is relatively easy to launch and turn off. Theatre-goers just need to turn on the headsets or set to AD soundtrack if it is recorded in DVD format. If the users are accessing $A D$ online, a screen reader could help them turn on the AD soundtrack. Additionally, AD guidelines require the language used to be informative and easy to understand [64]. 
PRINCIPLE FOUR: Perceptible Information

The design communicates necessary information effectively to the user, regardless of ambient conditions or the user's sensory abilities.

Guidelines:

4a. Use different modes (pictorial, verbal, tactile) for redundant presentation of essential information.

4b. Maximize "legibility" of essential information.

4c. Differentiate elements in ways that can be described (i.e., make it easy to give instructions or directions).

4d. Provide compatibility with a variety of techniques or devices used by people with sensory limitations.

This principle states that important information should be distinguishable and legible. In this research, the AD script was written by the director, and he was also the describer. The AD content basically represents what the director wants to communicate with the audience through this film. This maximizes the understanding of the AD users. Conventional $A D$ also follows this principle to convey important information in a distinguishable and legible way.

PRINCIPLE FIVE: Tolerance for Error

The design minimizes hazards and the adverse consequences of accidental or unintended actions. 


\section{Guidelines:}

5a. Arrange elements to minimize hazards and errors: most used elements, most accessible; hazardous elements eliminated, isolated, or shielded.

5b. Provide warnings of hazards and errors.

5c. Provide fail safe features.

5d. Discourage unconscious action in tasks that require vigilance.

$A D$ is usually recorded before it is actually conveyed to users except live AD. This minimizes hazards and the adverse consequences of accidental or unintended actions because describers or AD produces always proofread before recording and check after recording. This principle also applies to the equipment in theatre. The volume of wireless receivers should be adjustable so that users are not disturbed by loud volume levels or puzzled by low volume levels.

\section{PRINCIPLE SIX: Low Physical Effort}

The design can be used efficiently and comfortably and with a minimum of fatigue.

Guidelines:

6a. Allow user to maintain a neutral body position.

6b. Use reasonable operating forces.

6c. Minimize repetitive actions.

6d. Minimize sustained physical effort. 
In the theatre, $A D$ users only need to put on headsets or turn on the AD soundtrack to use AD. Technical matters ensure that the whole system is functional. As for the physical efforts of describers, they only need to look at the screen and click a few buttons to record AD. So AD needs little physical effort from describers and audiences. The script writer in this research is the director, so he understands the film and did not need to watch the film several times before writing. That saves a lot of time in the process and minimizes the physical and cognitive efforts.

PRINCIPLE SEVEN: Size and Space for Approach and Use Appropriate size and space is provided for approach, reach, manipulation, and use regardless of user's body size, posture, or mobility. Guidelines:

7a. Provide a clear line of sight to important elements for any seated or standing user. 7b. Make reach to all components comfortable for any seated or standing user. 7c. Accommodate variations in hand and grip size.

$7 d$. Provide adequate space for the use of assistive devices or personal assistance.

This guideline does not specifically apply to $A D$ because it is not a physical entity. $A D$ users would have equal size and space as other people in theatres. Different users need different cognitive efforts to use AD. For example, users with some background knowledge of the production need less cognitive efforts than those who are less familiar. AD guidelines have established several principles to provide users an easy and friendly environment. 
Overall, $A D$ fits with some of the seven principles of universal design. $A D$ in this research is produced by the creative team of the media production and is considered from the beginning of the production. User feedback and requirement are included in developing AD.

\subsection{Audio Description}

There are many definitions of $A D$ by various researchers. Snyder argued that $A D$ is the visual made verbal [1]. Many people perceived AD as audiovisual translation [6]. They call the process 'transadaptation' [4]. They conceived AD as a narration that provides a verbal description of the visual elements, and asserted that the language should be objective and interpretive [4]. Snyder pointed out that the language used in AD should be from the director's perspective and should maintain a certain degree of objectiveness. He also stated that words in AD should be succinct, vivid, and imaginative [1]. But, how could 'imaginative' be 'objective'? The objectiveness Snyder argued might means nonemotional or non-interpretive, and imagination made $A D$ vivid and interesting. If the director's perspective is followed, the describer would imagine the meaning conveyed by the film as the director intended, but no one could assure the imagination is objective. Orero [7] has done research that compares the audio describer to the language translator, and she found a gap between media accessibility and translation. She claimed that there were three levels of watching films: physical, mental, and psychological. These three levels range from objective to interpretive in nature. She concluded that AD should avoid being superficial (objective), and convey richer information [7]. 
$A D$ helps $B / L V$ people perceive visual elements [25]. Similarly, auditory-vision sensory substitution is a technology that helps B/LV people to 'see via ears'. Tactile-vision substitution is a technology that allows B/LV people to 'see via skin receptors' [20]. Sensory substitution is a stimuli transformation from one sensory modality to another. It is not literally 'sensory' or 'substitution'. It is a supplementation system that activates the motivation of people with disabilities in perception [21]. AD could be considered an incomplete sensory substitution which partially transfers visual stimuli to verbal stimuli. There is some research that collects blind or blindfolded participants' feedback on a sensory substitution device called The vOICe. It is a sensory substitution system that converts visual views into an auditory representation [22]. Blind participants perceived edges, contrast, and acuity without fine details in the first few years of using the device; then they can perceive depth and movement, even colors, after having some experience with the device [22]. Results showed that users with more experience with a substitution device perform more accurately [71]. Also, their perception with the device passed from deductive to intuitive and immediate with their learning progress [72]. For $A D$ users with more experience, it would be easier and intuitive to use AD.

The content and language of $A D$ are also popular fields in studying AD. Piety investigated the language system of AD. She studied four audio described films and found four structural components: insertions, utterances, representations, and words. Insertion was defined as a contiguous stretch of description that was uninterrupted by other significant audio content. Utterance was defined as the unit of language that was actually spoken, and it can be as long as the insertion itself or much shorter. 
Representations were defined from the perspectives of meaning and communication. Words used in AD were a restricted set of words used in spoken or written discourses, and usually in present tense. She also stated that there was little need for special language in AD because B/LV people consume the same speech, and consumers of $A D$ were cognitively active [9]. Some researchers did a contrastive study on $A D$ language between different countries and found some specific suggestions that could offer implications for future generations of $A D$ in the respective countries [13].

Salway [10] analyzed AD scripts for 91 films, and the results showed that there were statistically significant differences of commonly occurring phrases and temporal information in a corpus of $A D$ scripts and a general language sample. He classified the frequent words into: character's appearance, characters' focus of attention, characters' interpersonal interactions, changes of location of characters and objects, and characters' emotional states [10]. Frequently used words in each category were listed in the results, and another finding was that some temporal information was not described but presented through description of costumes and settings.

In my research, the classification of words in the AD script also included the content that were classified in Salway's paper, but was categorized differently: character, setting, costume, and action. The classification used in my research was based on Turner's definition [18], and was more suitable in our research. Gagnon et al. [18] did an analysis on the frequency of words in $A D$ and developed a refined typology of descriptions (Table 1) based on the paper by Turner and Colinet [18] and added the categories 
'credits' and 'video description'. Fels [19] also did research on the frequency of words in the AD of 'Death Comes to Town'. They found that participants want more information of all types especially the information of characters [19].

Table 1. Gagnon and Turner's classification of AD contents [18]

\begin{tabular}{ll}
\hline Video description typology & Presence (\%) \\
\hline Action & $36-45$ \\
Information about the attitude of characters & $1-4$ \\
Decor & $4-12$ \\
Lighting & $0-1$ \\
Spatial relationships between characters & $1-3$ \\
Facial and corporal expressions & $2-7$ \\
Clothing & $1-3$ \\
Weather & $0-1$ \\
Movement of the characters & $7-22$ \\
Physical description of the characters & $1-5$ \\
Indicators of proportions & 0 \\
Occupation, roles of the characters & $3-18$ \\
Setting & $7-9$ \\
Description of sound & 0 \\
Temporal indicators & $1-3$ \\
Textual information included in the image & $1-2$ \\
Appearance of titles & $1-4$ \\
Credits & $1-4$ \\
Video description & $0-1$ \\
\hline
\end{tabular}

There is also research on the comparison of language between AD and screenplays. Screenplays and $A D$ describe events in similar ways using similar language [12] but that $A D$ is more sensitive in choosing contents because it is time-limited [11]. Some researchers found that it costs less time and money to generate AD from screenplays since AD script writer could take some actors' lines and description of actions directly from the screenplay script $[11,12]$. 
The integration of users in the production of $A D$ continuously improves the quality of $A D$. Many researchers have done reception studies to collect users' feedback on AD. Chmiel and Mazur [14] conducted research on the reception of AD in Poland in 2012. They recruited 33 participants to watch three clips of film with $A D$, and there were two kinds of $A D$ for each regarding character naming, facial expressions, interpretation, metaphors, intertextuality, detailed description, identification of characters, and explicitation. Their results showed that participants prefer detailed description and character identification. They thought interpretation and explication seemed to facilitate comprehension. Szarkowska and Jankowska [23] introduced the production of text-tospeech (TTS AD), a synthetic system that converts text to speech, to voice over for foreign films and presented $20 \mathrm{~B} / \mathrm{LV}$ audiences' feedback of the TTS AD. The results showed that "TTS AD is acceptable for the majority of the visually impaired viewers interviewed with a surprisingly high number of people also accepting it as a permanent solution" [23, p93]. Fels et al. [19] have conducted several reception studies in the last few years. In one study, they asked $24 \mathrm{~B} / \mathrm{LV}$ participants to watch eight episodes of a television show. They found that there was a correlation between the entertainment level of the show and that of the $A D$; there was an inverse correlation between enjoyment of the show and level of distraction. They also recommend that the entertainment level of the show and AD should be in the same stylistic manner, otherwise the $A D$ is not properly produced in accordance with the show. If users thought the $A D$ distracted them, their ratings of the entertainment level of the show and the $A D$ would be relatively low. In another reception study, the results showed that a comfortable environment and good understanding of the production had positive 
impacts on the ratings of AD [28]. In 2009, Fels et al. [25] introduced integrated (unconventional) $A D$ in another research. The authors suggested that the conventional $A D$ does not provide equivalent access to $B / L V$ audiences since it presents what is seen rather than what is meant to be seen. Integrated AD is produced with the director's intention included so that this intention dominates the decision-making of $A D$. The results showed that $B / L V$ audiences thought the emotional and interpretive $A D$ had more entertainment value.

There are some results from several studies which showed that the integration of the describers into the show (e.g. to let the describers take on a character on the show) could help them learn to understand B/LV people's needs and provide a better entertainment experience $[27,29,31,32]$. First-person narrative $A D$ is another type of AD which is usually done by a main character in the show. In 2006, Fels et al. [26. 33। did a comparison of first-person narrative AD with the conventional third-person AD on 7 sighted and 7 blind viewers' engagement and entertainment levels of an animated comedy. The AD was carried out during the creation of the production and the creative team was involved. The results showed that the participants found the first-person $A D$ to have more entertainment value, but was less informative and trustworthy. The users found the experience of first person narrative interesting although they were most comfortable with the conventional AD.

Live $A D$ is produced for live shows [82]. It requires lots of cognitive and physical efforts from the describer since there are some uncontrollable variables, such as time spacing 
and improvisation, in live situation. Although live description is difficult and stressful, it is still doable if proper tools are developed [30]. In 2010, Fels et al. [35] did research on live $A D$ for a fashion show. The description was entertainment-focused rather than information-focused. The results showed that most audiences enjoyed the style of the description. The verbal description had some additions to the description script. Excitement and personal interest comments by a subjective matter expert were desirable in live description.

In UK, the Broadcasting Act 1996 requires the Independent Television Commission to draw up guidelines on how digital programme services should promote sensory impaired people's understanding and enjoyment [64]. It provides detailed guidelines on how to produce $A D$ with different focuses for various programme categories. It introduces how to decide what should be described and how to describe it [64]. In Canada, accessible media is regulated by CRTC [76]. In 2011, some researchers in Canada developed a guideline for AD that is more updated and applicable [65].

\subsection{Current Situation in China}

There are about 17 million B/LV people in China [74]. The government and blind organizations have established some regulations to manage accessibility. However, physical and perceptual accessibility are still problematic in most areas in China because the developing country is still focusing on economic development and little attention is paid to the blind community. Still, the government and organizations contribute to provide some services for B/LV people [74]. Before the digital library was 
established, there were several physical libraries or rooms provided to meet special needs of $B / L V$ people [73].

The "authoritarian capitalism" of mass media in China is market-oriented but controlled by the government. The emergence of internet, which is considered a "public sphere" in China since it could be used to express "public opinion", is gradually changing this situation. It is reported that the popular television show has changed from political to entertaining in China. The average person's daily viewing time of television amounted to nearly 3 hours in 2006, comprised of mostly entertainment content. China's TV broadcasting sector has been under rather strict supervision, primarily by the State Administration of Radio, Film, and Television [66]. Despite some highly popular talent shows, TV dramas had remained the preferred TV genre. Audiences' favorite genres of dramas included historical subject matter and dynasty dramas. The trend was also influenced by foreign media [66]. There did not exist a system of Chinese film theory that was developed in China. The theories that were broadly adopted were imported from Western countries, and heavily influenced by political factors [68]. As a result, there were many exotic elements in Chinese film such as film narrative style and characters' clothing. However, Chinese film still has some domestic characteristics and features inherited from Chinese poetry, ancient music, and drama [69].

There are several organizations providing AD service to B/LV people in larger cities in China (e.g. Heart \& Eye Theatre). But little research was conducted in mainland China. In Hong Kong and Taiwan, some scholars in the translation entertainment fields did 
research on $A D$. $Y$ et al. [16] conducted a 30-hour AD training session in Hong Kong to stimulate students' interests in AD and to further explain people's reference of language using in narratives. Some exercises were conducted to describe different kinds of entertainment, and the description was in English and Cantonese. The results were not published in this paper [16]. In Taiwan, Yaly [16] has done research on AD. In one of her papers, she discussed whether AD is translation or representation. From her point of view, whether $A D$ belongs to translation or representation depends on the similarity of expression of visual and verbal elements. She considered 'translation' as communication featuring audiences' needs, which was cited from the Dynamic Equivalence by Nida, 1964. She applied the translation guideline in China, "Xin Da Ya" (信達雅), on AD: 1. 'Xin', faithfulness, means the describer conveys information correctly; 2. 'Da', expressiveness, argues the accuracy and accessibility of the description; 3. 'Ya', elegance, implies the aesthetic value of the description. She pointed out that in some respects 'translation' was treated as 'adaptation' because the style of the original work was maintained. 'Translation' was creative work involving intersemiotic transformation, and so was AD. The author defined 'representation' as a sense-making practice which is the portrayal of important and specific characters while abandoning the rest. She also argued that 'representation' and 'performance' are symbiotic, and 'performance' could be classified as 'emotional representation'. She also stated that 'representation' included interpretation of the original medium, but that visual medium in AD had already represented the meaning, so there was no need to interpret in verbal medium. She argued that the faithfulness of the 'partial representation' in AD could only be tested by subjective recognition of individuals. In 'representation', there 
was no original meaning before the construction. But in the cases of $A D$, the original meaning existed in the film scripts or the films themselves. She concluded that if asymmetric meanings cannot be conveyed from the original version to the translated version, then $A D$ is 'representation' rather than 'translation', which includes reconstruction, interpretation, and creation. The common characteristic of 'translation' and 'representation' is that they rely on the substance. Compared to 'representation', 'performance' is over-exaggerated with subjective emotions and interpretation, and is focused on the script writers' intentions. Moreover, she stated that AD was a 'translation' to sighted people who preferred a visualized symbol system, and it was a 'representation' or 'performance' to B/LV people who preferred a verbalized symbol system [17]. The three main concepts she discussed in her paper have some similarities and differences. The three concepts all convey information from one symbol system to another. 'Translation' is limited by the original meaning. 'Representation' presents the asymmetric information that cannot be 'translated'. 'Performance' is expressed by the creative team with their subjective interpretation. The similarities and differences of the three definitions are listed in Table 2. AD can be classified to either one of these definitions and lies in the overlapped areas of the three definitions.

Table 2. Similarities and differences of 'translation', 'representation', and 'performance'

\begin{tabular}{|l|l|l|l|}
\hline & Similarities & Differences & \multicolumn{2}{|l|}{ translate all contents } \\
\hline Translation & \multirow{2}{*}{$\begin{array}{l}\text { Convey information from on } \\
\text { symbol system to another }\end{array}$} & \begin{tabular}{l} 
limited by the original meaning \\
Representation \\
\cline { 3 - 4 } that cannot be translated
\end{tabular} & $\begin{array}{l}\text { represent important and } \\
\text { specific contents }\end{array}$ \\
\cline { 3 - 4 } Performance & & $\begin{array}{l}\text { creative with subjective } \\
\text { interpretation }\end{array}$ & interpret emotionally \\
\hline
\end{tabular}


Yaly et al. [24] also conducted other studies on AD that tested various factors:

frequencies of accessing media, frequent contacts, film narratives, and reception study. She found that acquired B/LV people have more possession and higher frequency of using of auditory media and less possession and lower frequency of use of visual media than congenitally blind people. The most frequent contacts of B/LV people were family members, relatives, and neighbors. The majority of the participants rarely visited their family members or friends, but they usually called them and chat. She also concluded that whether the describer's and the director's intentions were the same would influence the audience's understanding of $A D$ [24]. In my research, the describer is the film director, so that the AD presents the production as the director intended which has positive impact on audience's understanding.

\subsection{Summary}

In this chapter, two general theories are introduced: communication theory and entertainment theory. These two parts draw our attention to the general questions--why do we need to communicate? How do we perceive entertainment? Communication theory demonstrates that people communicate with each other to exchange ideas, to be included in the public sphere, and to contribute to the society. Due to accessibility issue, B/LV people need some tools to communicate equivalently. Entertainment theory states that people consume entertainment media to perceive enjoyment. B/LV people have the same rights to enjoy media products. Entertainment theory can also be employed in the application of AD. Second, universal design is discussed, which is the basic principle of applying AD. Principles in universal design should be followed in the production of AD. 
Third, previous studies on AD done by various researchers are presented. Since there are no studies conducted in the Chinese community, this research introduces a new field in $A D$ research. Fourth, since this research focuses on applying $A D$ in Chinese community, the current situation in China including the Chinese blind community, Chinese entertainment theory, and Chinese AD are established. This part discusses the current issues of $A D$ in the Chinese community, and illustrates the positive impacts of applying AD. In next chapter, a model of generating AD based on the literature mentioned above is proposed. 


\section{Chapter 3. Theoretical Model}

Previous studies had explained the process of producing various types of AD. The generation of AD from screenplay script was described in [12]. Orero [15] explained how conventional $A D$ was developed. Fels and her colleagues had conducted several $A D$ studies using integrated approach $[25,27,28,29,31]$. Also, the process of producing live description was introduced in [30, 35]. However, this previous research did not provide a visual representation of these processes. There were three concepts in the process that were used from film theory and language theory; adaptation is film terminology [75] and narration and translation are linguistic terminologies [5]. Combining all of the concepts from $A D$ research and from film theory/practice literature, the researcher organized those processes they defined and generated the theoretical model in Figure 1. This model is supported by entertainment theory and universal design. Entertainment theory states that media products should express director's intention, and this framework describes how the director controls the process [37]. This model also shows how AD was included in the early phases of the design as stated in universal design [63]. Taking the terms and processes from film and from audio description/translation discussed in the literature review, the researcher has developed a framework to explain this research approach by combining these existing concepts (see Figure 1). 


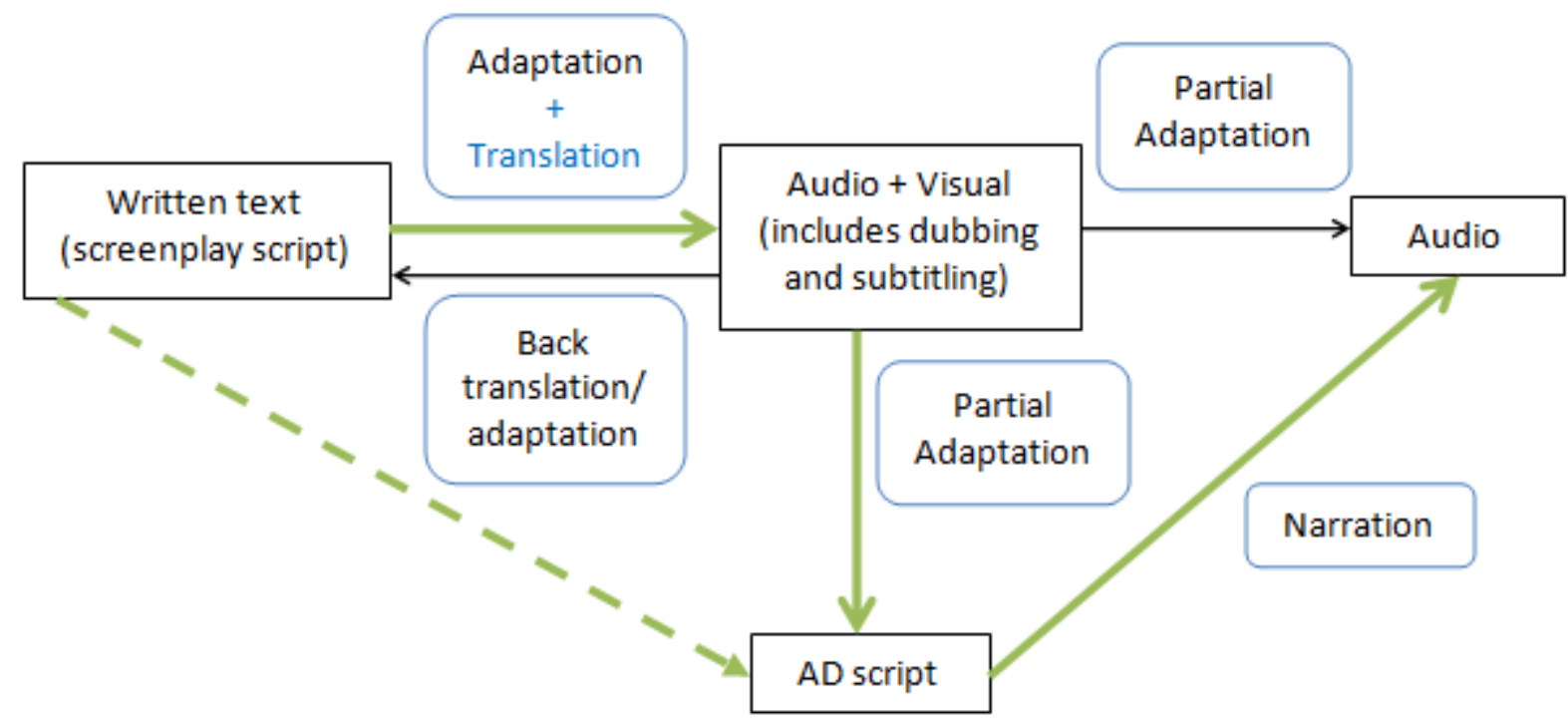

Figure 1. Theoretical model. Black square boxes represent main production processes, blue rounded boxes represent actions taken to complete a process, lines with arrows represent procedures, dotted lines represent possible/optional procedures, and thicker green lines/dotted lines represent the production process of this research.

As shown in Figure 1, the first main production process for film or television is the written text or script of the film, which is also known as the screenplay script [80]. The next main stage of the film-making production process is the translation/adaptation of the script into audio/visual representation of that script that is the actual film or television product. This would include any language dubbing or subtitling that would accompany the original production. The arrow from written text to film indicates that film is generated from the written text through adaptation and translation. A film adaptation is the transfer of a written work, in whole or in part, to a film [75]. Inter-linguistic translation is an interpretation of verbal signs by means of some other language [5]. This is often needed when making a film consumable by audiences who do not speak the same language (subtitling or dubbing) or for people who are deaf or hard of hearing (captioning). 'Translation' is labeled in bolded and blue in this model because it does not 
represent the translation between written text and the film, but the translation of the original subtitling or dubbing. A back translation/adaptation from the film to a text version is possible and may occur when a film is made first and then an accompanying book is written later (e.g., Full Monty, [84]). The box labeled audio is the post production version of $A D$. An $A D$ script could be generated from the film, the screenplay or both. The processes from film to $A D$ script and from film to $A D$ are labeled as partial adaptation because adaptation is defined as the transfer between a written work, a film, and other formats of the production in film terminology, and 'partial' means only parts of the production is adapted (e.g. the visual part of the film is adapted to audio elements and the audio part is remained). The dotted line joining the written script and the AD script represents the influence of screenplay on the AD script. This may occur depending on whether the describer has access to the original script. If an AD script is produced then the describer would use that script to record the AD. This process is described as narration because it is defined as a message that tells the particulars of an act or occurrence or course of events, presented in writing, drama, cinema, or as a radio or television show [83].

This model combines language translation terminology and film terminology, and the generation of $A D$ is defined from a combined perspective. Different paths represent different approaches in developing $A D$. For example, usually an $A D$ script is partially adapted from the film by a third party, and a post-production version of AD is narrated by a describer. Some live AD is developed directly from a film to $A D$. The approach used in this research follows the green lines. The AD was created and described by the 
director/script writer of this film, so the production started from the screen play script. The film was generated through adaptation and translation (e.g. there were some foreign languages in the original script) from the screen play script. Next, the director wrote the AD script from the film, which was defined as partial adaptation. Although he did not develop the AD script directly from the screenplay, it would be influenced by the screenplay. Finally, the $A D$ was recorded from the $A D$ script, and this process was narration. The whole process was distinct since the creative team was included and it started from the screen play script.

In next chapter, the research questions and methodology employed in this research are discussed. 


\section{Chapter 4. Methodology}

\subsection{Research Questions}

This research aims to examine the use of and experience of $A D$ in the Chinese community and to collect suggestions in producing AD for directors and describers with regard to cultural differences between the Chinese and Canadian communities. To achieve the goals, two research questions are proposed as follows:

[1] How are the expectations of AD between the Chinese and Canadian communities different?

[2] How do the evaluations of integrated AD differ between the Chinese and Canadian communities for "Magical Coincidence"?

\subsection{Research Design}

The primary goal of this research is to study the differences of attitudes to AD between the Chinese and Canadian communities. The attitudes could be divided into two parts: expectations of $A D$ and evaluation of actual $A D$. The evaluations are based on an $A D$ film that uses the integrated approach (the description is written, produced and delivered by the director of the film).

For measures of attitude there were two phases. Phase one took place before participants watched the AD film, and the pre-questionnaire focused on expectations 
and experiences of $A D$. Phase two was conducted after watching the AD film, and the post-questionnaire was comprised of evaluation questions. Participants were required to answer one questionnaire in each phase.

\subsubsection{Film}

An audio described film was produced by its director before participants were recruited in this research. After providing responses to the pre-questionnaire, the participants were asked to watch the film and provide their evaluation of the $A D$ and the film.

Researchers from the Inclusive Media Design Centre's (IMDC) worked with an Asian film director, Keith Lock, to produce the AD for his film. The film was a 20-minute-long romantic comedy, called "Magical Coincidence", and it was first shown in the 2012 Reel Asian International Film Festival in Toronto. Only the audio described version was released to public.

The film was produced by the Lock's creative team, and the director agreed to integrate $A D$ into this film at part of the scriptwriting phase. Researchers at IMDC provided demonstrations and suggestions to the director about $A D$ and considerations for an $A D$ script and the corresponding film. The director was the scriptwriter for his film as well as for the AD script. In addition, the director performed as the describer and recorded the $A D$ himself with technical assistance from an audio editor. The main language of the film was English, but there were 50 seconds in Chinese and Italian. 
The director also uploaded a video version to the Internet for those participants who did not have the chance to go to the theatre. However, the original website, to which the video was uploaded, was not accessible to B/LV people because there was not keyboard equivalent or alt text equivalent for the 'play' button which had to be 'clicked' to activate. A screen reader, a device used by blind individuals to access computer, was unable to read the 'play' button and notify a blind users of its existence. As a result the video was uploaded to the IMDC web server for this study. This video could play automatically once the web page was opened. Participants had three options to watch the film: 1. Go to the theatre in person; 2. Watch the film online at IMDC website or the original website; 3 . Meet with the researcher and watch the film from the researcher's device. After the AD film was produced and ready for watching, the researcher began recruiting participants.

\subsubsection{Procedure}

Prior to participant recruitment, an ethics application was submitted to and approved by the Ryerson Ethical Board (REB) (see Appendix A). Participants were first contacted with a short research proposal through personal contacts and email lists provided by blind organizations. If they were interested in participating, an information form introducing more detailed information including study summary and study process was provided. After being informed about the study, if participants were willing to participate, they were asked to sign the consent form for the study (see Appendix B). The format of signature was flexible due to their vision conditions. 
Data were collected through a pre-study (Phase one) and post-study (Phase two) questionnaire (see Appendix C). The pre-questionnaire had 22 questions that asked about participants' expectations and experience of AD (16 forced-choice/Likert scale question, 4 open ended, 2 other). The post-questionnaire had 11 questions about participants' evaluations of the respective film's AD (8 forced-choice/Likert scale questions, 2 opened and 1 other). Questions on demographics, negative/positive factors, and evaluations were taken from previous research on $A D$, and questions on expectations were proposed on the basis of the research questions.

There were three ways of completing questionnaires: 1 . Answer online and send them back to the researcher; 2 . Answer through phone calls; 3 . Answer in person at places that were convenient for participants. Participants could choose the most convenient method.

Only B/LV adults were recruited in this study. Participants were self-identified as B/LV; no eye examination was carried out to assess vision levels. Three groups of participants were recruited in phase one and two groups were recruited in phase two. These groups were categorized by nationality (native Chinese, Chinese Canadian, and non-Chinese), see Table 3 for the participant distribution in various categories. The results of this research were presented to the director, and his comments were included in the results chapter to explain or support some conclusions. 
Table 3. Recruitment information

\begin{tabular}{|l|l|l|l|l|l|l|l|}
\hline Group & Nationality & Region & $\begin{array}{l}\text { Recruitment } \\
\text { Source }\end{array}$ & $\begin{array}{l}\text { Native } \\
\text { Language }\end{array}$ & $\begin{array}{l}\text { Recruitment } \\
\text { Date }\end{array}$ & $\begin{array}{l}\text { Phase } \\
\text { One }\end{array}$ & $\begin{array}{l}\text { Phase } \\
\text { Two }\end{array}$ \\
\hline 1 & $\begin{array}{l}\text { Native } \\
\text { Chinese }\end{array}$ & $\begin{array}{l}\text { China Blind } \\
\text { Berijing, } \\
\text { China }\end{array}$ & $\begin{array}{l}\text { Person's } \\
\text { Association; China } \\
\text { Disabled Persons' } \\
\text { Federation; word } \\
\text { of mouth }\end{array}$ & Mandarin & $\begin{array}{l}2012.8- \\
2012.9\end{array}$ & 10 & 0 \\
\hline 2 & $\begin{array}{l}\text { Chinese } \\
\text { Canadian }\end{array}$ & $\begin{array}{l}\text { Toronto } \\
\text { Canada }\end{array}$ & $\begin{array}{l}\text { Christian Aid \& } \\
\text { Relational } \\
\text { Evangelism Inc.; } \\
\text { CNIB; word of } \\
\text { mouth }\end{array}$ & $\begin{array}{l}\text { Mandarin/ } \\
\text { English }\end{array}$ & $\begin{array}{l}2012.11- \\
2013.3\end{array}$ & 15 & 13 \\
\hline 3 & Non-Chinese & $\begin{array}{l}\text { Toronto } \\
\text { Canada }\end{array}$ & $\begin{array}{l}\text { Alliance for Blind } \\
\text { Canadians and } \\
\text { Pathfinders; CNIB; } \\
\text { word of mouth }\end{array}$ & English & $2012.11-$ & 15 & 13 \\
\hline
\end{tabular}

Ten native Chinese participants were recruited from mainland China. Fifteen Chinese participants and fifteen non-Chinese participants were recruited in Toronto (Table 3). All ten native Chinese participants and fifteen Chinese Canadians volunteered to take part in the phase one questionnaire. Thirteen of fifteen non-Chinese participants took part in the phase one questionnaire. Thirteen out of fifteen Chinese Canadians and thirteen non-Chinese participants finished the phase two questionnaire. Participants who answered the phase two questionnaire were the same ones from group 2 and 3 who answered the phase one questionnaire. There were two Chinese Canadians who participated in the phase one questionnaire but did not complete the phase two questionnaire due to personal reasons. In the non-Chinese group, one participant did not complete the phase one questionnaire because she came to the theatre to watch the AD film and she did not have enough time to answer all questions before the film started. Two non-Chinese participants withdrew halfway due to personal reasons so they did not finish the phase two questionnaire. 
Age, gender, level of vision impairment, and highest level of education were demographic questions asked at the beginning of the phase one questionnaire. The distribution of age, gender, level of vision impairment and education levels for all three groups can be seen in Figures 2-5. Figure 2 shows the distribution of ages for all three groups.

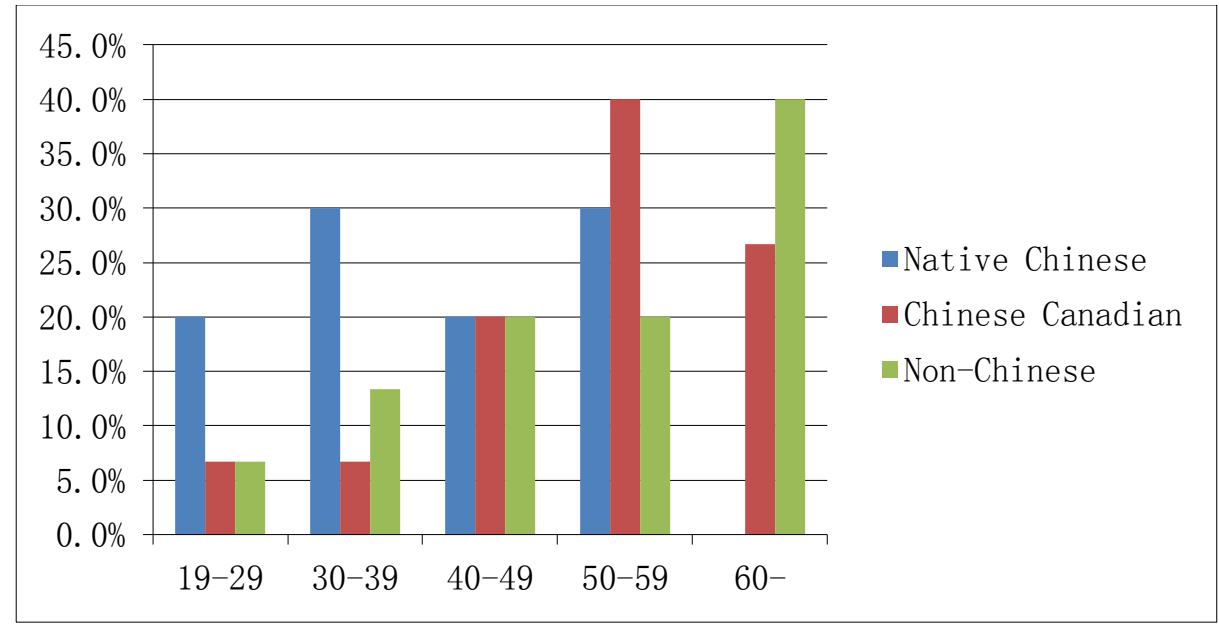

Figure 2. Age distribution

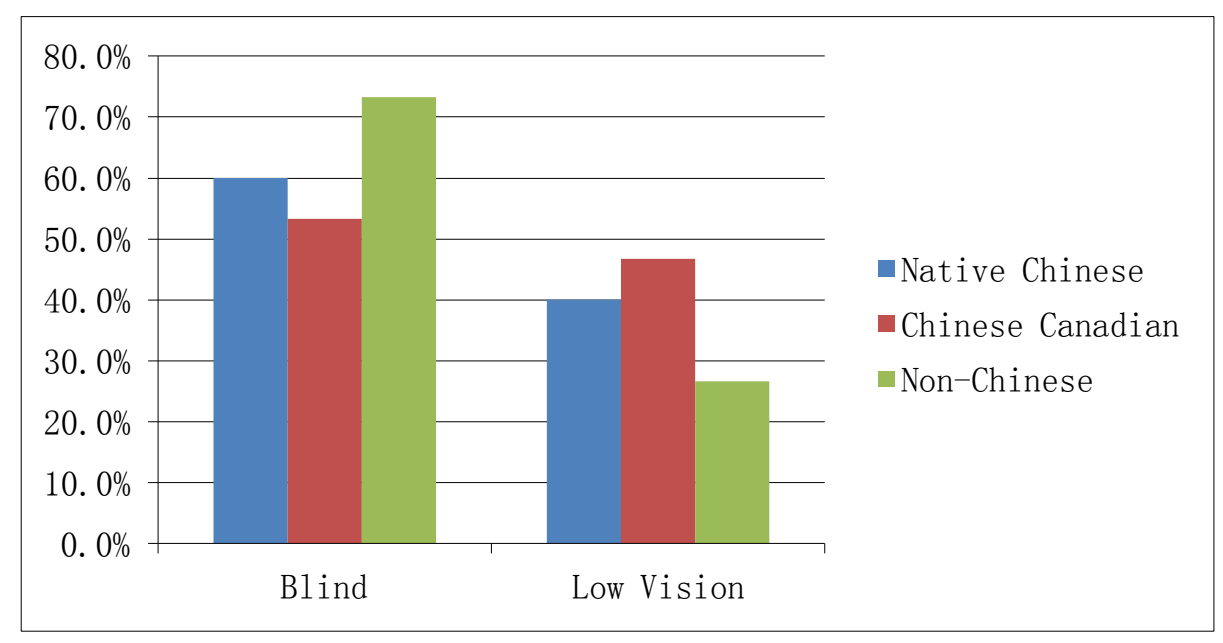

Figure 3. Vision Condition distribution 


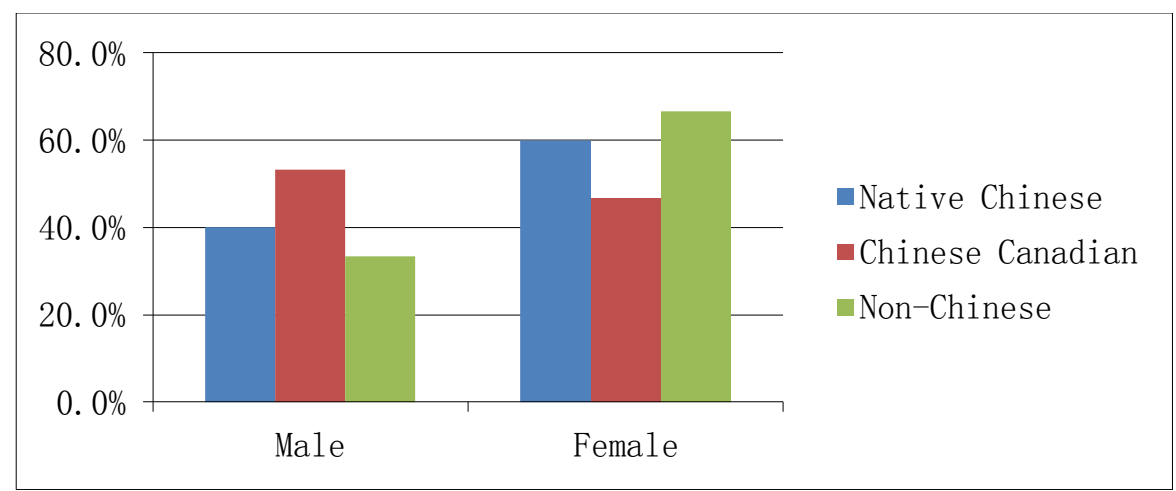

Figure 4. Gender distribution

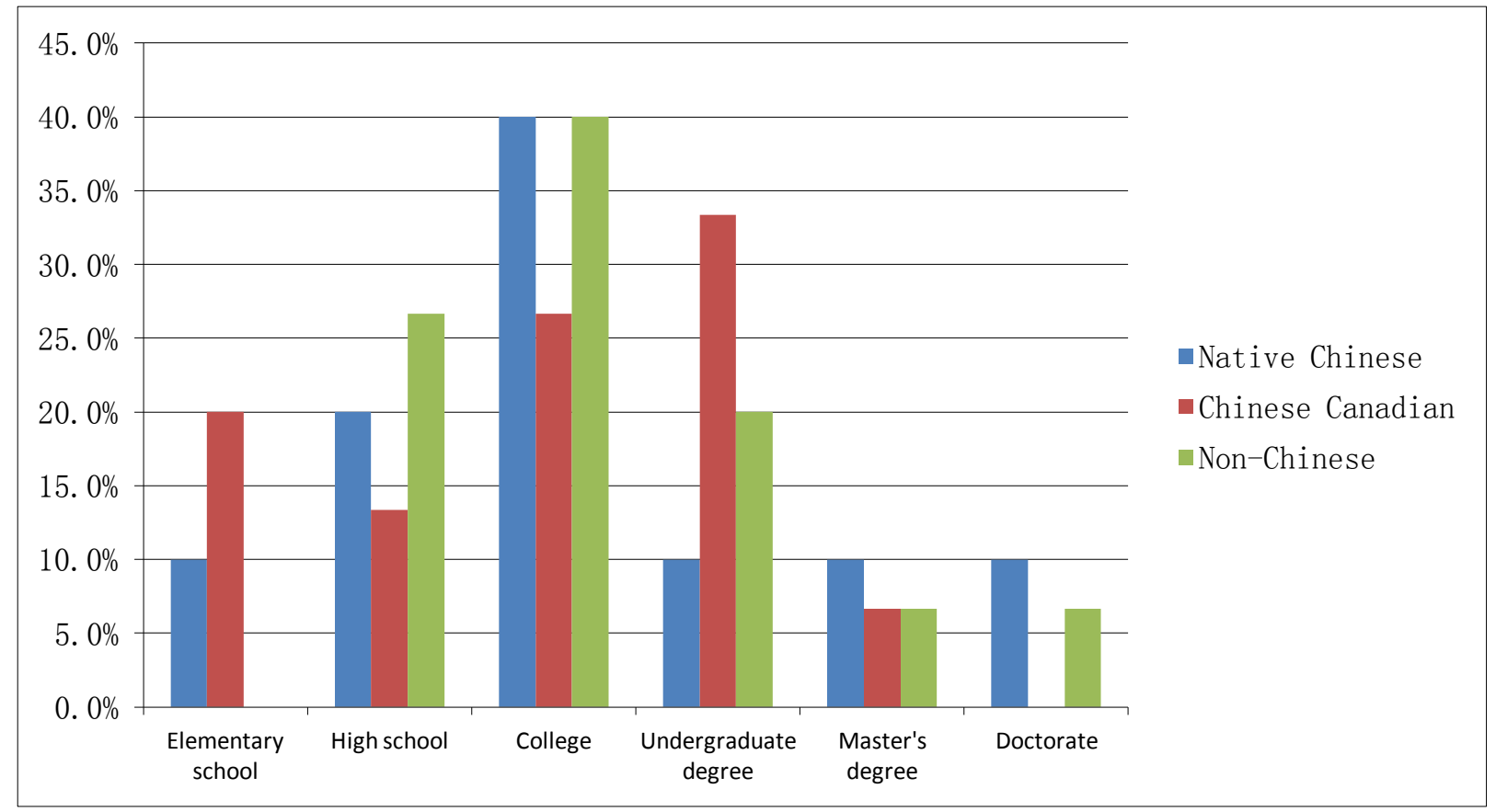

Figure 5. Education distribution

From the three graphs above, it can be concluded that: 1 . there were more blind participants $(62.5 \%)$ than low vision participants (37.5\%) in all three groups; 2 . the level of education among all groups was fairly highly with most participants' highest level of education being college or undergraduate education; 3. on average there were $42.5 \%$ male and $57.5 \%$ female. The distribution of participants was diversified for age, vision condition, gender, and education. 


\subsection{Data Analysis}

In this study, nationality and gender were independent variables, and other variables were dependent. Nationality was controlled to guarantee the research had the same sample size in each group on average.

The small sample size (13 in each group on average) did not meet the normality assumptions for parametric statistical analyses, so nonparametric tests were used for quantitative data. For questions in the phase one questionnaire, there were 3 independent groups categorized by different nationalities (native Chinese, Chinese Canadian and non-Chinese), and the dependent variables were ordinal, so KruskalWallis was applied to compare differences. For questions in phase two questionnaire, there were 2 independent groups of participants, and the dependent variables were ordinal, so Mann-Whitney was applied. Descriptive analysis was used to complement the non-parametric analyses. Frequency Charts and percentages were employed to display the distribution and trends of the data.

In analyzing qualitative data, participants' comments were treated as supporting material for results of other data, or analyzed with descriptive methods. Thematic analysis [36] was employed for questions about participants' preference for being helped. Post hoc, the researcher first defined five themes from participants' responses (see Table 4), then randomly selected $20 \%$ of the comments. Two independent raters then coded these comments to assess inter-rater reliability. As there were only enough comments in two themes, ICC was only conducted for these two themes. For both 
themes, the ICC values were greater than 0.95 and thus the researcher continued to code the remaining responses alone.

Table 4. Definitions of five themes

\begin{tabular}{|c|c|c|}
\hline No. & Themes & Definitions \\
\hline 1 & $\begin{array}{l}\text { Issues related } \\
\text { to } A D\end{array}$ & Have access to and understand media and AD. \\
\hline 2 & Daily activities & $\begin{array}{l}\text { Other issues that are not related to AD, such as reading, writing, working, } \\
\text { grocery shopping, traveling around, etc., or when a participant refers to } \\
\text { "everything". }\end{array}$ \\
\hline 3 & $\begin{array}{l}\text { Access to } \\
\text { services }\end{array}$ & $\begin{array}{l}\text { Services provided by government or organizations, such as financial } \\
\text { services, legal services, and going to the hospital. }\end{array}$ \\
\hline 4 & $\begin{array}{l}\text { Issues related } \\
\text { to technology }\end{array}$ & Issues related to computers and technology. \\
\hline 5 & $\begin{array}{l}\text { Unable to do } \\
\text { anything or no } \\
\text { help }\end{array}$ & $\begin{array}{l}\text { When participants say they are unable to do anything (negative), or they } \\
\text { don't need any help (positive). }\end{array}$ \\
\hline
\end{tabular}

For multiple permitted answer questions, weighted matrix or frequency charts were employed to show what the most chosen options were. For example, questions about participants' preferences to have $A D$ for a variety of television, movies, and theatre genres were listed as multiple possible options. Participants were asked to choose three shows from each kind of entertainment (television, movie, and theatre) and rank them as 1,2, and 3. A weighted matrix was employed to obtain the first, second, and third most preferred entertainment types to be described. Different weights ( 3 for rank 1, 2 for rank 2 , and 1 for rank 3 ) were assigned to different rankings $(1,2$, and 3$)$ since the importance of the options were supposed to decrease evenly. Weights were multiplied by the number of responses in each ranking, and then the total score of each option was calculated. Finally, the option that received the highest score would be the most desired type to be described. 
In the question regarding important factors that would affect participants when rating the quality of $A D$, a frequency chart was employed. Participants were supposed to choose three from all twelve factors listed in this question. The total score of each option was calculated, and the option with the highest score was considered the most important factor.

Questions about participants' preferences of being helped when they were accessing entertainment in the phase one questionnaire were confusing to some participants. These three questions in the initial version of the questionnaire asked about the participants' frequency of accessing entertainment with other people. The format of the questions was confusing, and the original intention was to investigate whether participants would like to be helped when accessing entertainment. After interviewing a few participants, the options of these questions were modified as follows for later interviews: 1. Never watch with others, 2. Watch with others but don't ask for assistance, 3. Watch with others and request their assistance. In the coding stage, the few responses to the initial version of the questionnaire were coded into the modified categories. For example, if they chose "sometimes, frequently, or always watch with others and requested assistance", the response would be coded into category 3. "Never watch entertainment and never watch with others" would be coded into category 1 "Sometimes, frequently, or always watch with others and don't ask for assistance" would be coded into category 2. After the reorganization of the construction of questions, the data were easier to analyze and the results were more understandable. 
In the question regarding who described entertainment for participants when accessing it, six kinds of describers were listed in this question. Similar to the question about level of assistance participants required, the initial version of the questionnaire asked how frequently each kind of person described entertainment for participants. The researcher was more concerned about who was describing rather than how often so that interviews/questionnaire was changed and participants' were only required to answer the question about who usually described entertainment for them.

Although this research was focused mainly on cultural differences between nationalities among issues related to $A D$, other topics were mentioned during the interviews. The researcher discovered that some female participants mentioned costumes in their comments, so gender preferences for description were also compared post hoc. While it may seem obvious that there is a gender difference in preferences for $A D$, however, there is little or no research in this area.

To analyse the structure of the AD script for specific AD types, the researcher used definitions listed by Gagnon and Turner [18]. They outlined 19 categories of AD description in Table 1, however, several categories were combined to better fit the specific show (see Table 5). 
Table 5. Categories of AD contents

\begin{tabular}{|l|l|}
\hline Category of Phrases & Content of categories \\
\hline Onscreen Action/Plot & Action, movement of the characters. \\
\hline Characters & $\begin{array}{l}\text { Information about the attitude of characters, spatial relationships between } \\
\text { characters, facial and corporal expressions, physical description of the } \\
\text { characters, occupation, roles of the characters. }\end{array}$ \\
\hline Costumes & Clothing. \\
\hline Set & $\begin{array}{l}\text { Decor, lighting, weather, setting, description of sound, temporal indicators, } \\
\text { textual information included in the image. }\end{array}$ \\
\hline Language Translation & Language translation. \\
\hline
\end{tabular}




\section{Chapter 5. Results}

\subsection{Experiences of AD}

Participants' prior experiences of $A D$ were investigated in phase one. As expected nonChinese participants had more access to AD than Chinese Canadian participants, and native Chinese participants had the lowest access. There was a statistically significant difference in familiarity with $A D$ among different nationalities $(H(2)=9.950, p=0.007)$, with a mean rank of 27.85 for native Chinese, 22.23 for Chinese Canadians and 13.87 for non-Chinese. Non-Chinese participants were more familiar with $A D$ than Chinese Canadian participants, and Chinese Canadian participants were more familiar with $A D$ than native Chinese participants (Figure 6). Although there was no significant difference in the frequency of using $A D$ among nationalities, the frequency was ranked from the most to the least as: Non-Chinese participants, Chinese Canadian participants, and Native Chinese participants. Fifty percent of native Chinese participants had never used AD, $53.3 \%$ of Chinese Canadian participants had used AD several times, and $66.7 \%$ of non-Chinese participants had used AD frequently (Figure 7). 


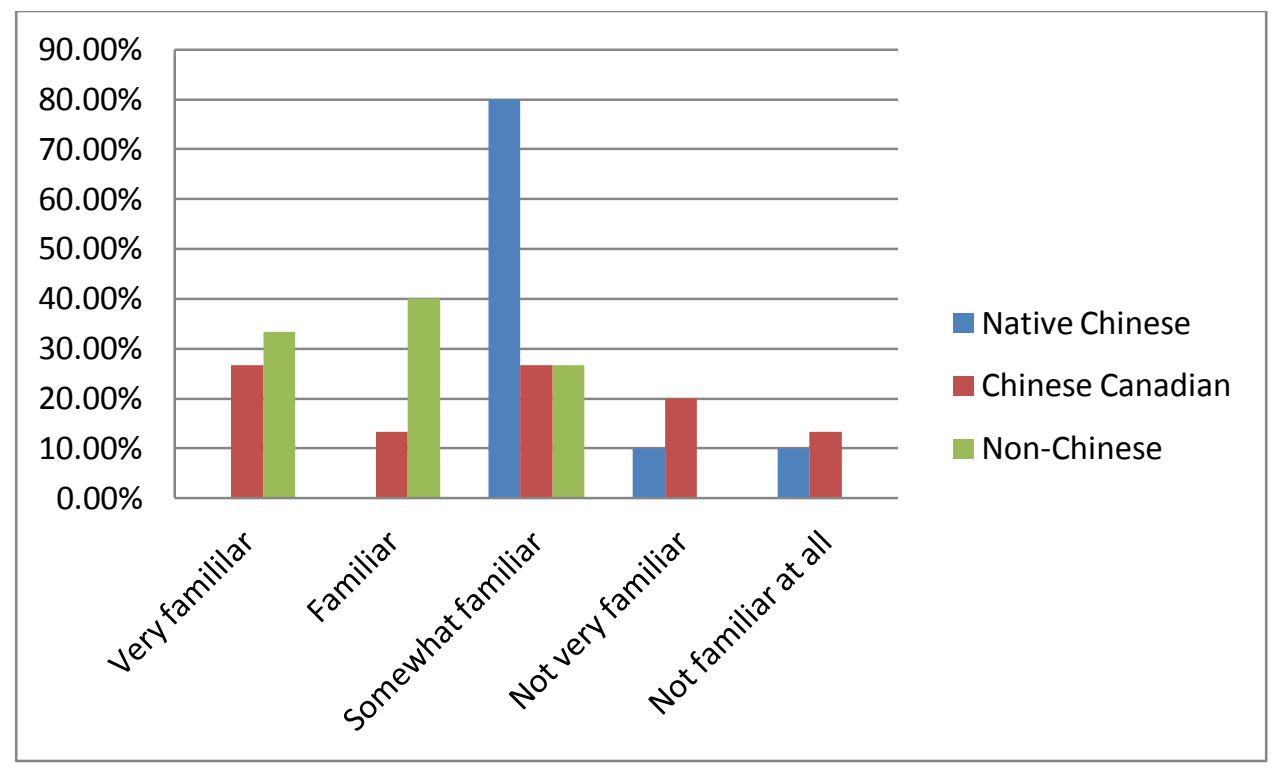

Figure 6. Familiarity of AD

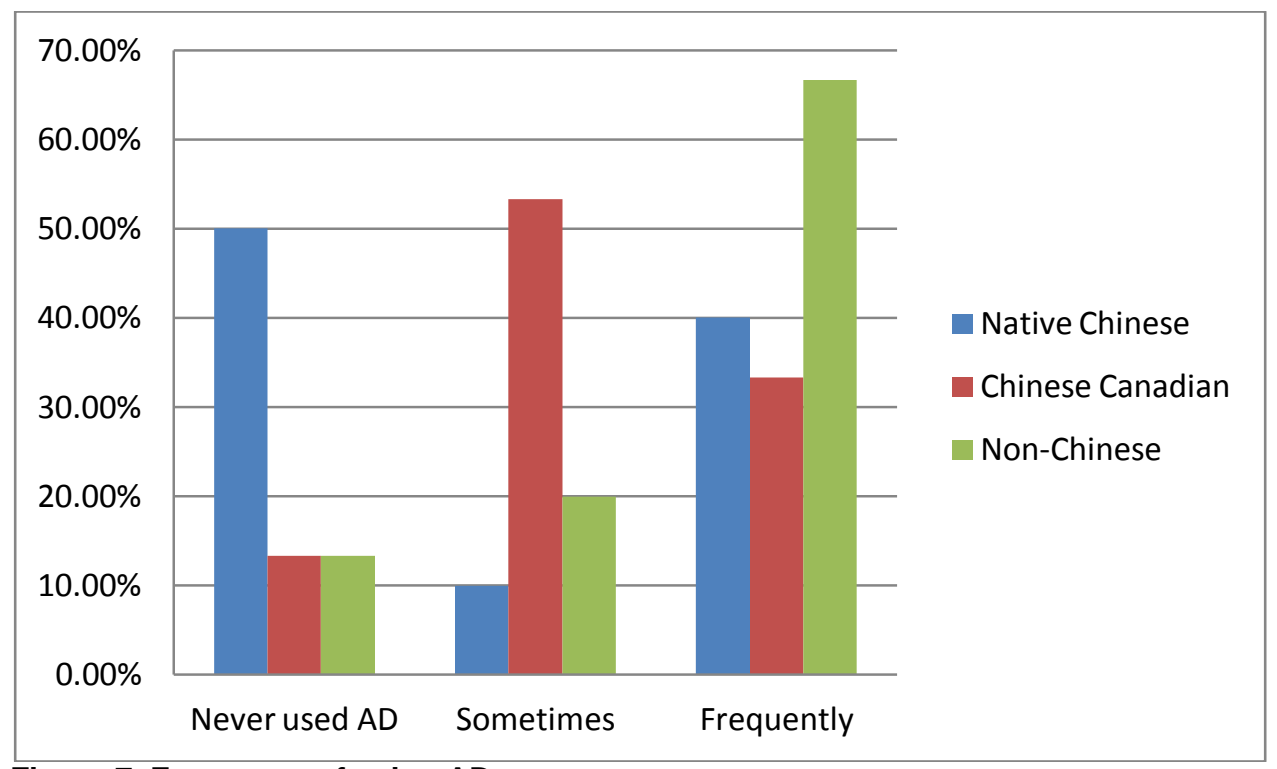

Figure 7. Frequency of using AD

Whether the participants had access to entertainment would influence their access to $A D$, so the frequency of accessing different kinds of entertainment was examined (Figures 8-10). Sixty percent of native Chinese participants, 53\% of Chinese Canadian participants, and $33 \%$ of non-Chinese participants had daily access to television, and $90 \%, 86.7 \%$, and $66.7 \%$ of participants in those groups, respectively, listened to radio 
on a daily basis. Sixty percent of native Chinese and Chinese Canadian participants had never been to a theatre, and $75 \%$ of non-Chinese participants went to a theatre once every several months. Some participants mentioned that they also had access to other kinds of entertainment that were not listed in the question, such as karaoke, movies from CNIB, entertainment from the internet, and walking in parks.

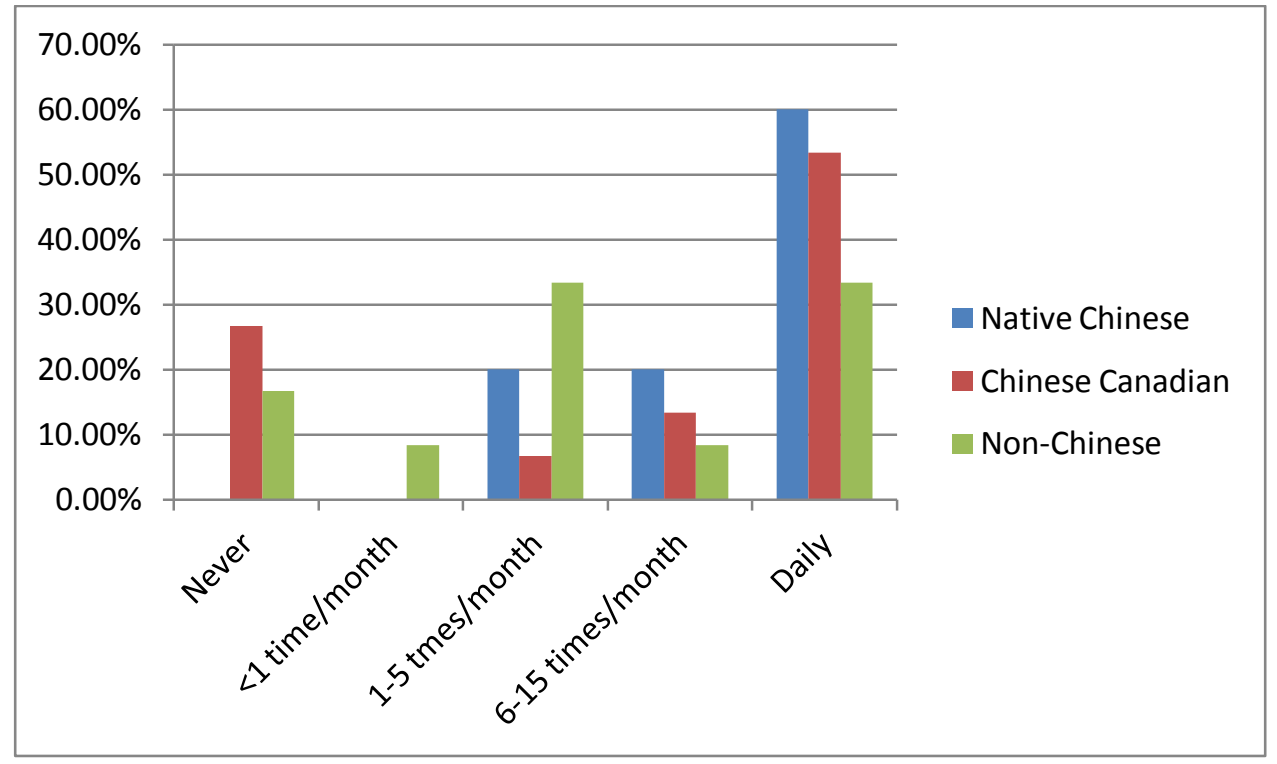

Figure 8. Frequency of accessing TV 


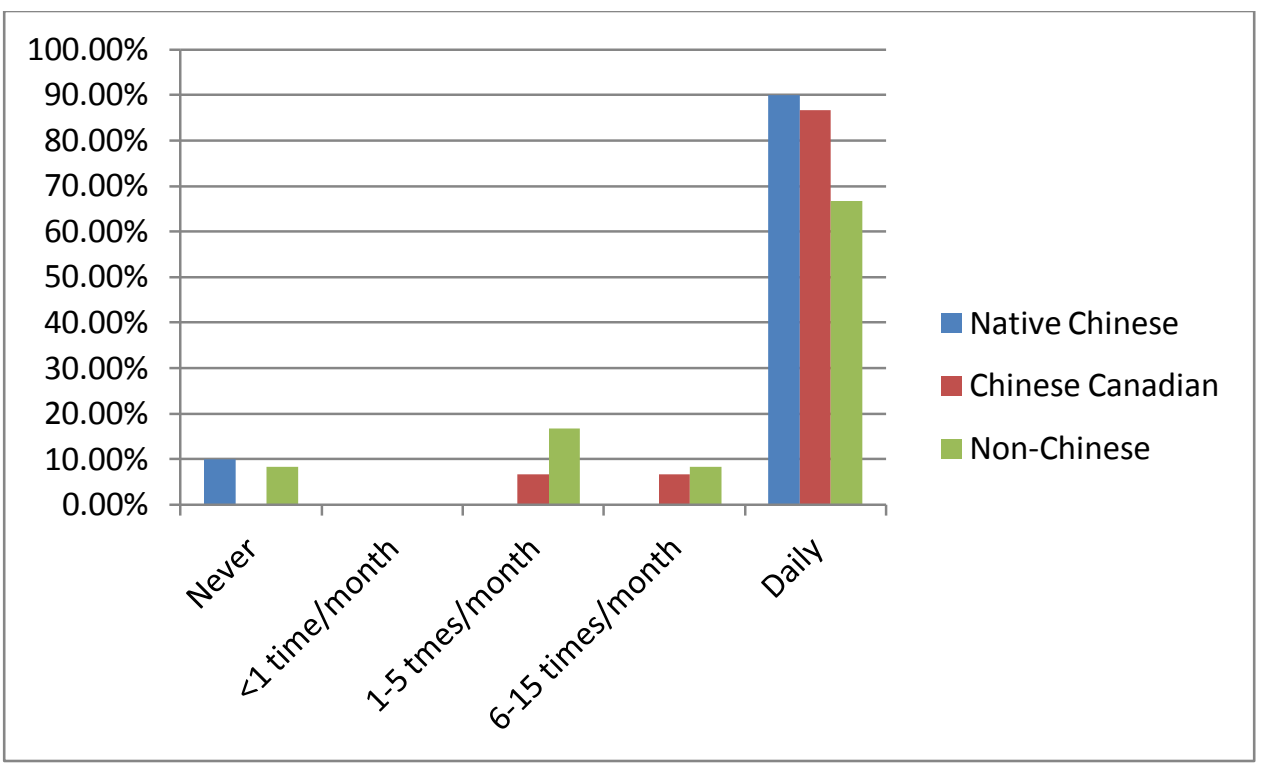

Figure 9. Frequency of accessing radio

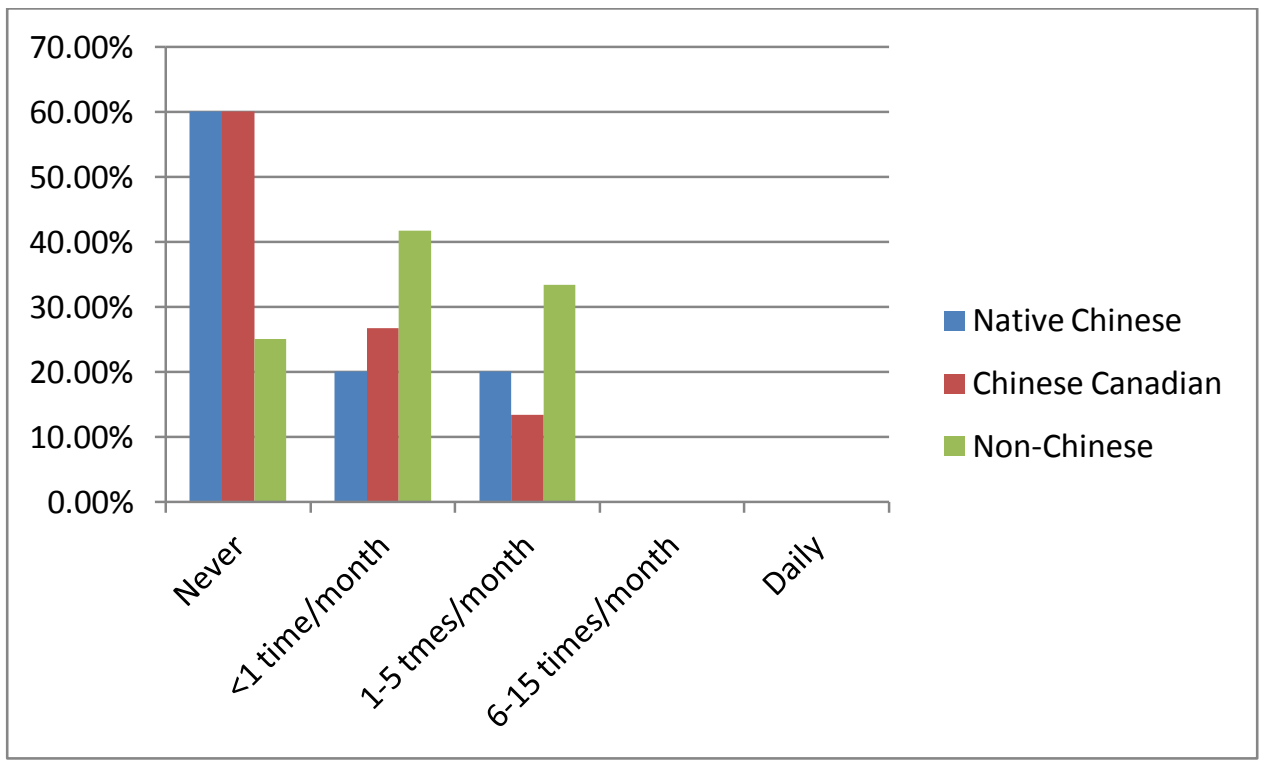

Figure 10. Frequency of accessing theatre

As shown in Figures 11 to 13, seventy percent of native Chinese participants liked to watch television with other people and requested their assistance, and $46.7 \%$ of Chinese Canadian participants never watched television with others. Seventy-seven percent of non-Chinese participants liked to watch television with others, half of whom 
asked for assistance while other half did not. The percentages of each group that liked to watch movies with other people and requested assistance were: $80 \%, 46.7 \%$, and $61.5 \%$. Fifty percent of native Chinese, sixty percent of Chinese Canadian, and forty-six percent of non-Chinese participants had never been to theatre with other people. One participant mentioned that she thought that always asking for assistance made her look "stupid". After watching shows for over 40 years on her own, she was used to watching shows without having description of visual elements and she could enjoy the show without any help.

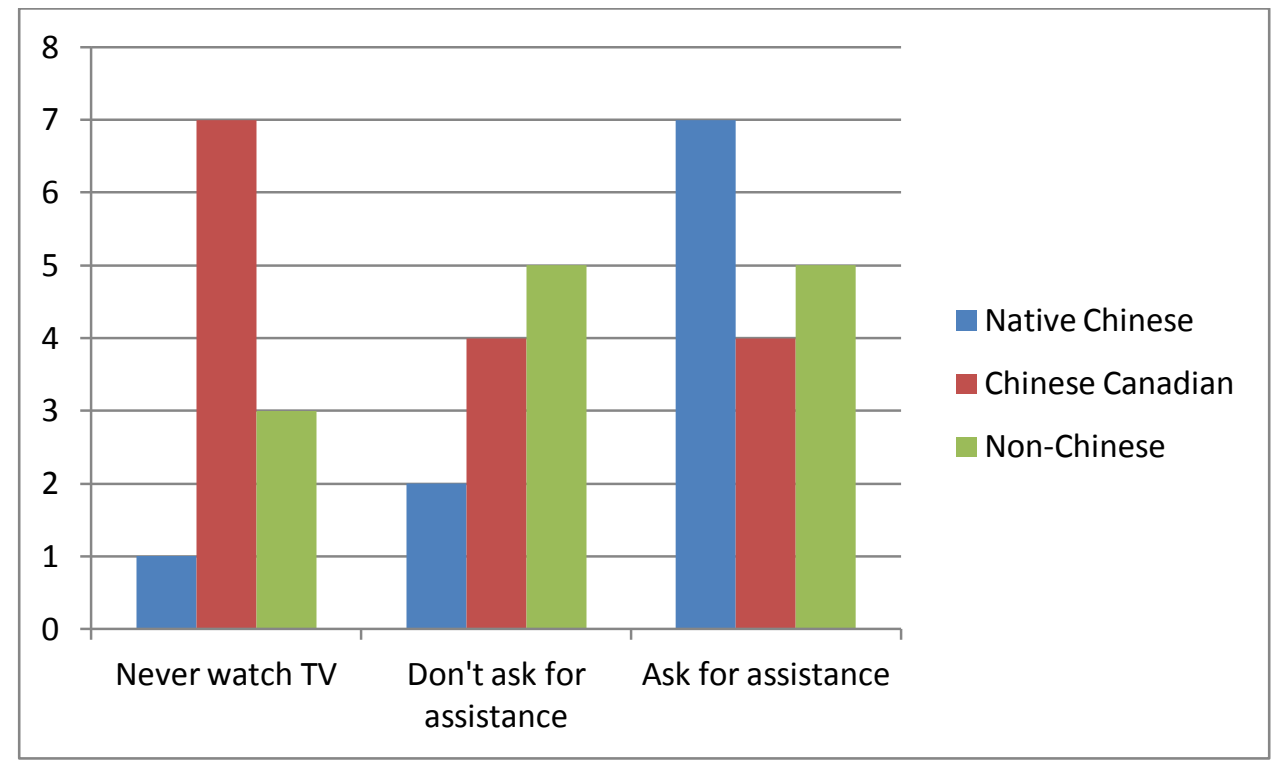

Figure 11. Ask for assistance when watch TV 


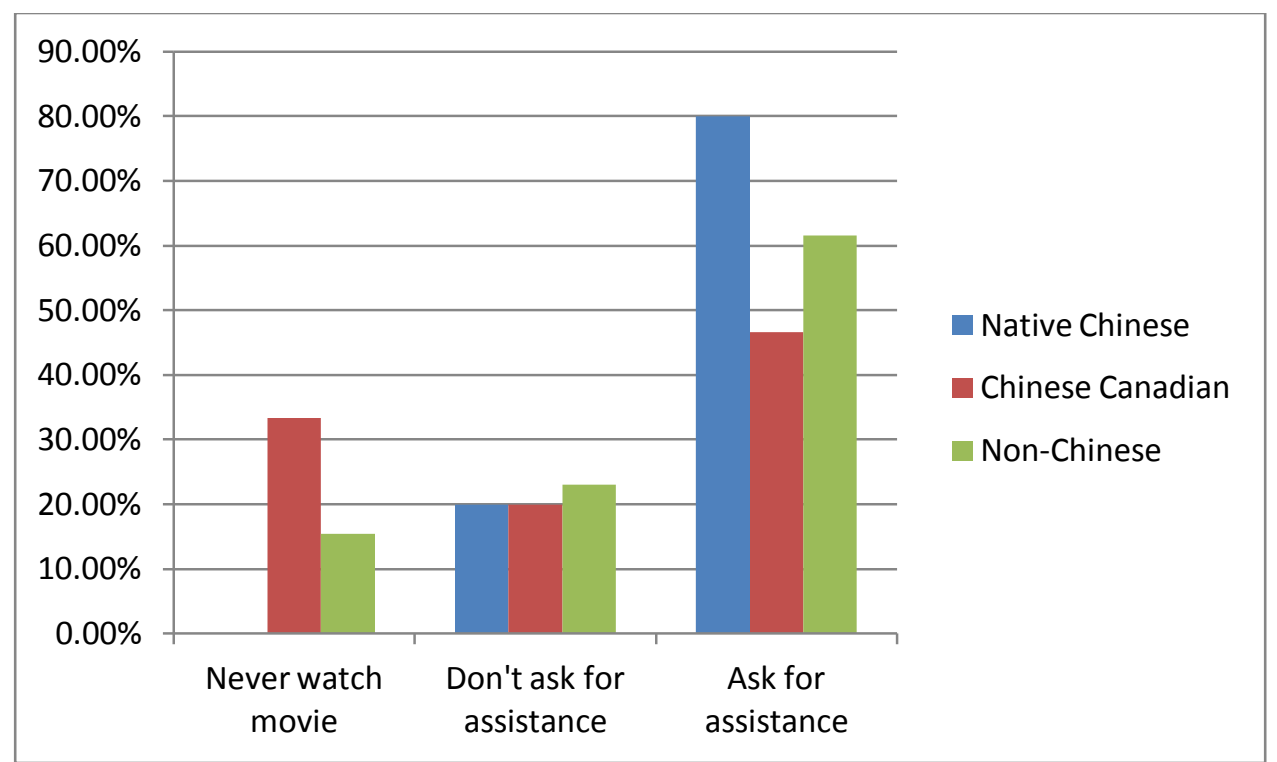

Figure 12. Ask for assistance when watch movie

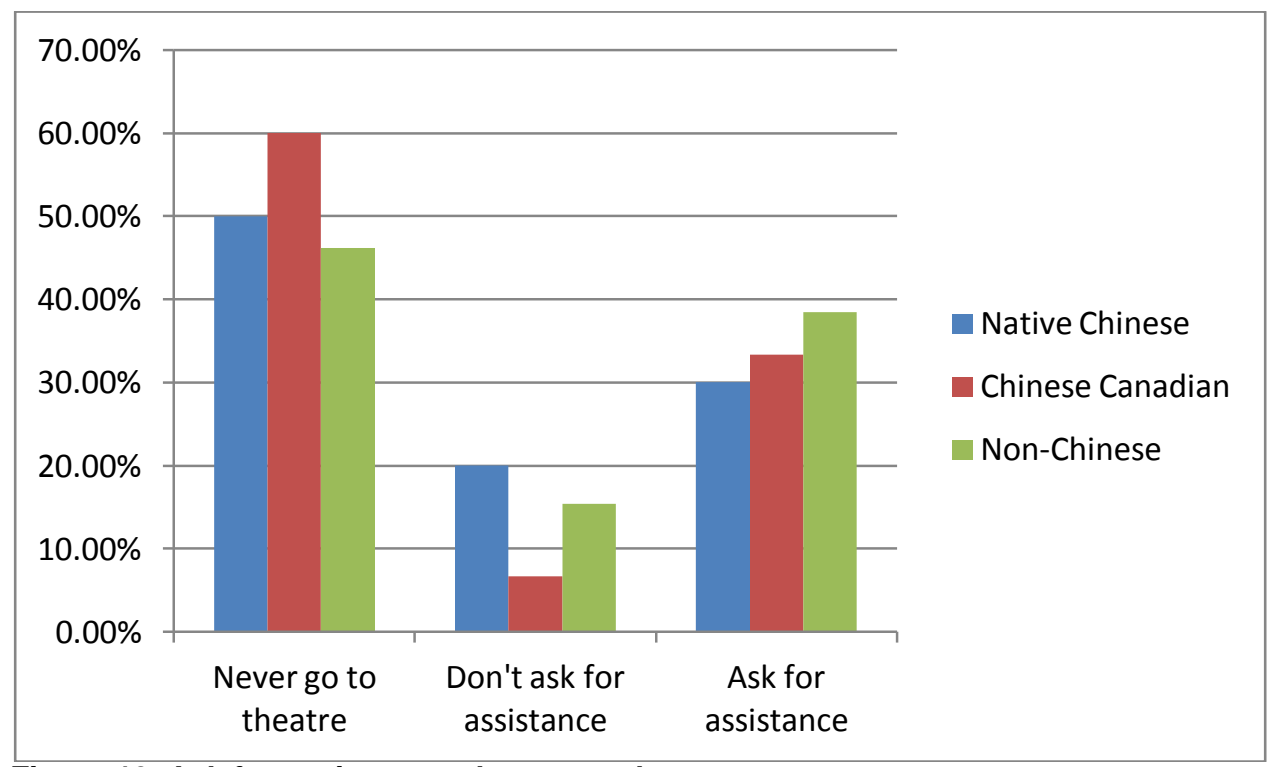

Figure 13. Ask for assistance when go to theatre

Among the participants who had used AD before, they rated the quality of $A D$ for television shows, movies, and theatre shows. Participants' responses were dispersed from 'very poor' to 'very good'. For the quality of $A D$ for those three kinds of shows, see Figures 14-16. Regardless of the group, most participants said that they had rare access to shows with $A D$, and it was usually unavailable when they wanted it. Some 
Chinese Canadian participants said they did not have access to $A D$ in their native language in Canada. The three figures below illustrate the distribution of responses on the quality of $A D$ for the three kinds of shows:

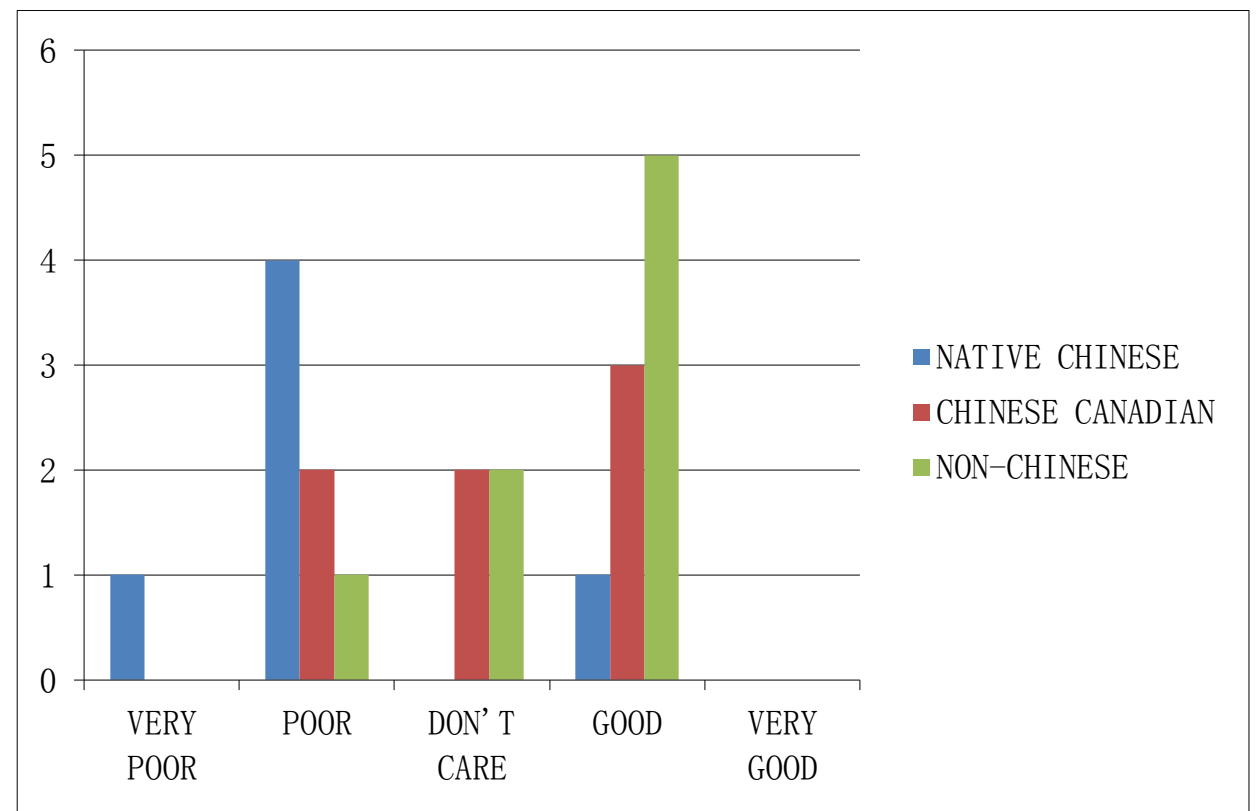

Figure 14. Ratings of AD quality for TV

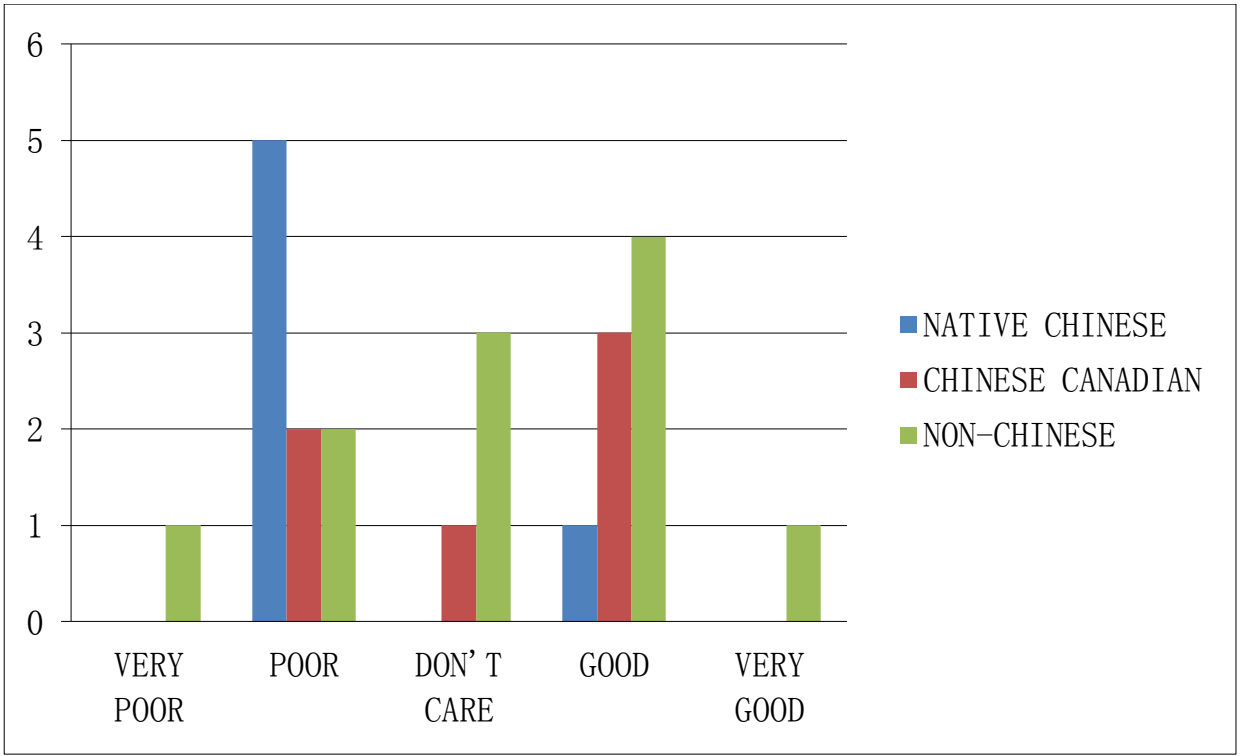

Figure 15. Ratings of AD quality for movie 


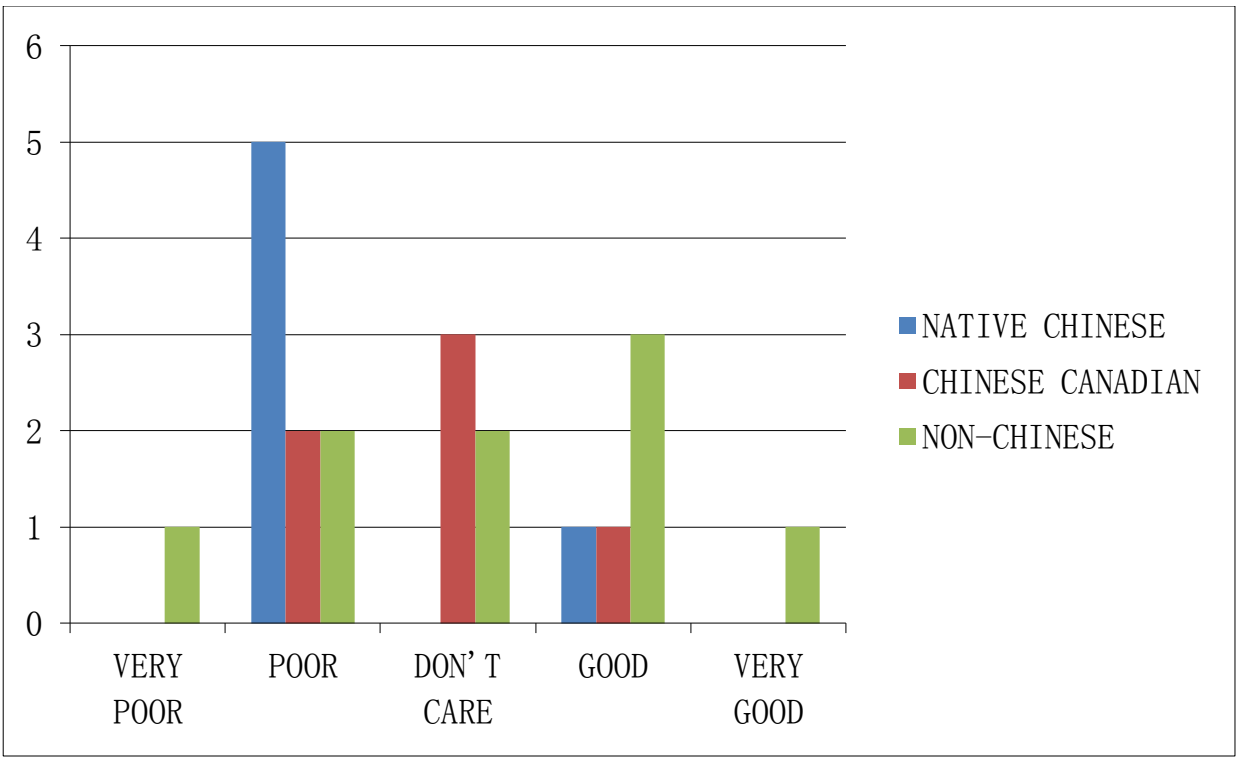

Figure 16. Ratings of $A D$ quality for theatre shows

Aural description was given to participants in their daily life. Six kinds of 'describer' were listed in the questionnaire. Friends, relatives, and partners were the three most chosen ones (33.87\% of participants chose 'Friends', $22.58 \%$ chose 'Relatives', and $20.97 \%$ chose 'Partner or Spouse'). Figure 17 shows all of the different categories and the frequency of selection among the three groups: 


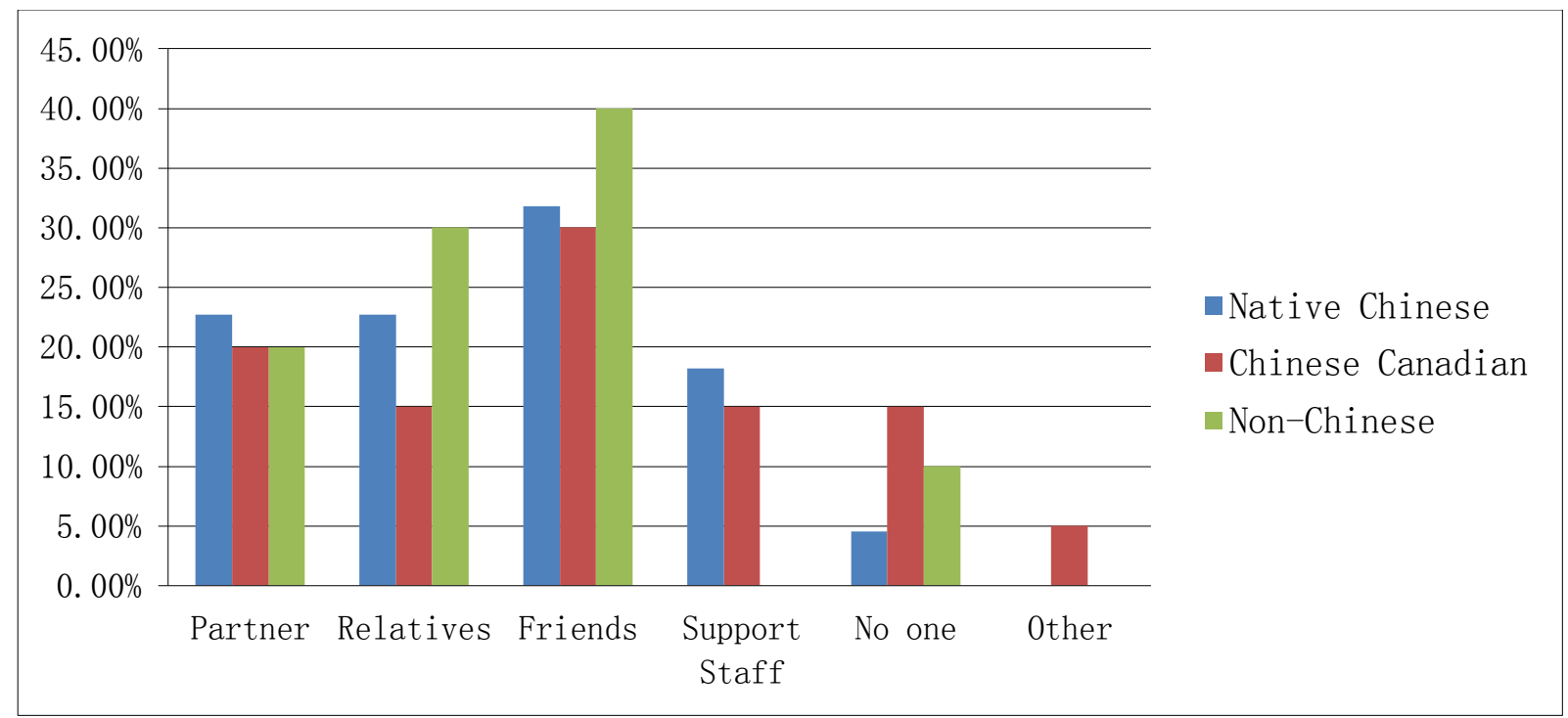

Figure 17. Who usually describes for participants

The participants had different experiences with $A D$, and participants who lived in Toronto, Canada had more access to AD than participants who lived in Beijing. Also, it seemed that participants relied on friends most often or assistance for describing events in their daily life.

\subsection{Expectations of AD}

Participants were asked which types of entertainment experiences they expected to be described and the important factors that would influence their ratings of AD. There were three kinds of entertainment regarding participants' expected shows to be described: television, movies, and theatre shows. The weighted results are shown in Tables 6-8. The numbers shown in bold are the three most expected types of entertainment for participants in each group. 
Table 6. Expected TV shows to be described (standard categories found on imdb.com)

\begin{tabular}{|l|l|l|l|l|l|l|l|l|}
\hline $\begin{array}{l}\text { Nationality/TV } \\
\text { shows }\end{array}$ & News & $\begin{array}{l}\text { Docum- } \\
\text { entaries }\end{array}$ & Dramas & $\begin{array}{l}\text { Situation } \\
\text { Comedies }\end{array}$ & Comedies & Mysteries & $\begin{array}{l}\text { Reality } \\
\text { Shows }\end{array}$ & Other \\
\hline Native Chinese & $\mathbf{1 4}$ & $\mathbf{9}$ & 6 & $\mathbf{2 1}$ & 6 & 3 & 2 & 0 \\
\hline $\begin{array}{l}\text { Chinese } \\
\text { Canadian }\end{array}$ & 9 & $\mathbf{2 3}$ & $\mathbf{1 9}$ & 2 & $\mathbf{1 0}$ & 9 & 5 & 6 \\
\hline Non-Chinese & 1 & $\mathbf{2 1}$ & $\mathbf{1 6}$ & 2 & $\mathbf{1 7}$ & 13 & 2 & 4 \\
\hline
\end{tabular}

Table 7. Expected movies to be described (standard categories found on imdb.com)

\begin{tabular}{|l|l|l|l|l|l|l|l|l|}
\hline $\begin{array}{l}\text { Nationality/ } \\
\text { Movie } \\
\text { genres }\end{array}$ & Dramas & $\begin{array}{l}\text { Docum- } \\
\text { entaries }\end{array}$ & Comedies & Tragedies & Actions & Mysteries & Horrors & Other \\
\hline $\begin{array}{l}\text { Native } \\
\text { Chinese }\end{array}$ & $\mathbf{1 3}$ & 12 & $\mathbf{1 4}$ & 0 & $\mathbf{1 3}$ & 6 & 2 & 0 \\
\hline $\begin{array}{l}\text { Chinese } \\
\text { Canadian }\end{array}$ & $\mathbf{1 4}$ & 10 & $\mathbf{1 5}$ & 5 & $\mathbf{1 9}$ & 9 & 7 & 3 \\
\hline $\begin{array}{l}\text { Non- } \\
\text { Chinese }\end{array}$ & $\mathbf{1 0}$ & 4 & $\mathbf{9}$ & 7 & $\mathbf{1 5}$ & 7 & 4 & 4 \\
\hline
\end{tabular}

Table 8. Expected theatre shows to be described (standard categories found on imdb.com)

\begin{tabular}{|l|l|l|l|l|l|l|}
\hline $\begin{array}{l}\text { Nationality/Live } \\
\text { venues }\end{array}$ & Music Concerts & Dance & Plays & Circus & Opera & Other \\
\hline Native Chinese & 5 & $\mathbf{2 1}$ & $\mathbf{1 2}$ & 10 & $\mathbf{1 2}$ & 0 \\
\hline Chinese Canadian & 4 & $\mathbf{1 2}$ & $\mathbf{2 9}$ & 9 & $\mathbf{1 2}$ & 7 \\
\hline Non-Chinese & $\mathbf{1 4}$ & $\mathbf{1 4}$ & $\mathbf{1 3}$ & 11 & 3 & 1 \\
\hline
\end{tabular}

Situation comedies, news, and documentaries were the three types of television shows

that native Chinese participants thought should be audio described. Documentaries, dramas, and comedies were the three types for Chinese Canadians and Non-Chinese participants who lived in Toronto. Comedies, actions, and dramas were the three types of movies that all participants thought should be audio described. Dances, plays, and opera were the three types of theatre shows that native Chinese and Chinese Canadian participants thought should be audio described. Some participants mentioned some other types of shows to be described, such as art shows, crime shows, nature shows, classics, and musicals. These types were from their own preferences. 
The factors that could influence participants' ratings of $A D$ were also the factors that participants thought should be taken into consideration in producing AD. As shown in Figure 18, 'Enjoyable', 'informative', and 'Doesn't disrupt my enjoyment of the show' were the three most important factors affecting native Chinese participants when they assessed the quality of AD. 'Informative' and 'Doesn't talk over other dialogue' were the two most important factors for Chinese Canadian participants, and 'Enjoyable', 'Doesn't disrupt my enjoyment of the show', 'Doesn't distract me', and 'Different voice' were tied for the third important one. 'Doesn't talk over other dialogue', 'Doesn't disrupt my enjoyment of the show', 'Doesn't distract me', and 'Informative' were the most important factors for non-Chinese participants. The factors affecting their ratings of $A D$ were somewhat different among nationalities, but most participants thought 'Informative', 'Doesn't disrupt my enjoyment of the show', and 'Doesn't talk over other dialogue' were important for their assessment of AD. Some participants mentioned some extra factors that might affect the ratings of $A D$. For example, two Chinese Canadian participants mentioned that if the characters in the show were talking in another language which they had no knowledge of, then it was ok to talk over characters' dialogue. Another participant mentioned that there was always too much $A D$ and left no space for her to digest the content. Some obvious sounds should not be described. One participant said that it would be better if they just left the sound there and let the audiences guess what was happening. Also, one participant argued that the producer always turned the soundtrack down to add $A D$ in the production, which overlapped with the sound effect of the production and made it more confusing. 


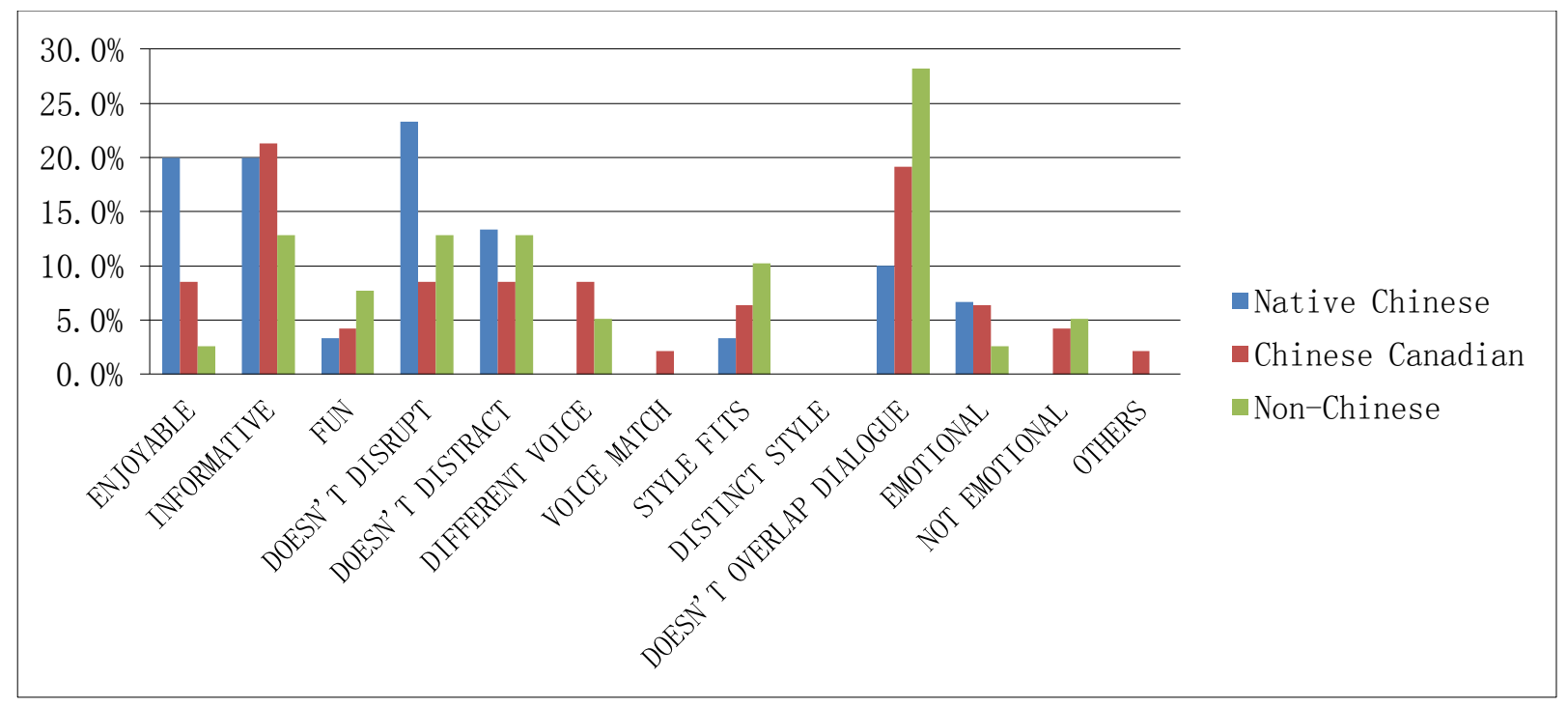

Figure 18. Factors that would influence participants' ratings of AD

In general, participants with different nationalities had slightly different expectations of $A D$, but the preferences of participants who lived in Toronto did not vary much.

\subsection{Evaluations of 'Magical Coincidence'}

In phase two, participants evaluated the AD film after watching it. A Mann-Whitney nonparametric analysis was carried out to examine differences in ratings between the two groups who viewed the film (Chinese Canadian and non-Chinese). There was a statistically significant difference between the understanding of the production in general between Chinese Canadian and non-Chinese participants $(U=36, p=0.005)$, with a mean rank of 17.23 for Chinese Canadian and 9.77 for non-Chinese. Non-Chinese participants rated their understanding of the as greater than that of Chinese Canadian participants (Figure 19). 


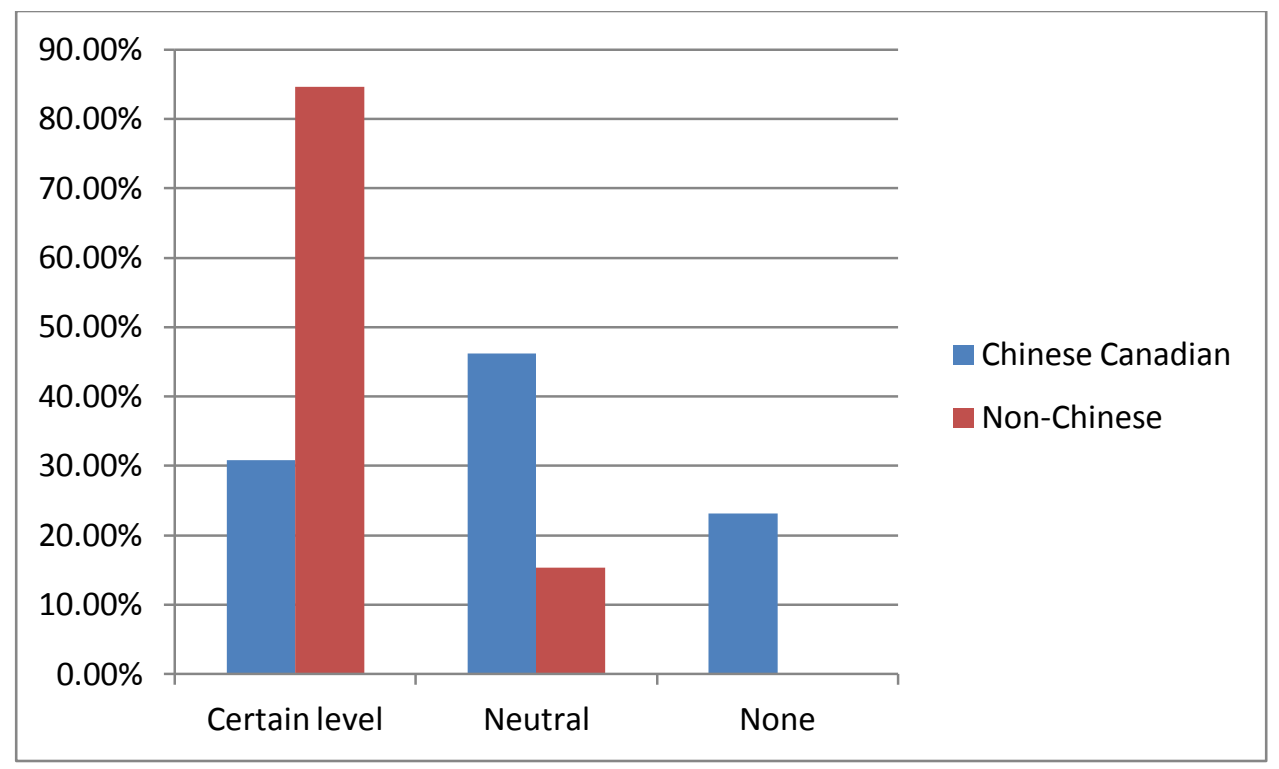

Figure 19. Level of understanding of the production

As shown in Figure 20, seventy-seven percent of Chinese Canadian and one hundred percent of non-Chinese participants said they were entertained or very entertained by the movie in general. Twenty-three percent of Chinese Canadians gave neutral ratings to the film. Generally, participants liked the film. Some participants appraised the production as very well developed. 


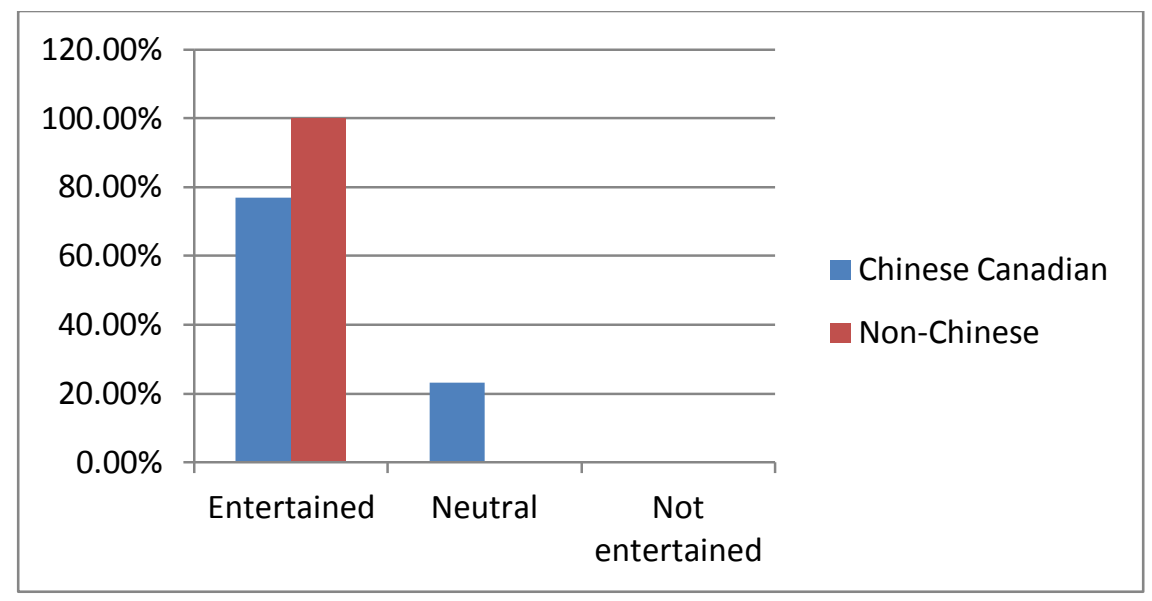

Figure 20. Entertainment of the film

There was a statistically significant difference between the entertainment of $A D$ between Chinese Canadian and non-Chinese participants $(U=45.5, p=0.032)$, with a mean rank of 16.5 for Chinese Canadian and 10.5 for non-Chinese. Chinese Canadian participants were less entertained by the AD than non-Chinese participants. As shown in Figure 21, 69.2\% of Chinese Canadian participants were entertained or very entertained by the AD of the film, and $84.6 \%$ of non-Chinese participants were entertained or very entertained. Some participants said the AD was good and it conveyed accurate information. Another participant thought there should be space for her to digest the content of AD. One participant argued that "this film, for the most part, seems like one that is tailored to AD. I would like to see more from one where the AD is likely to be difficult to fit in, i.e. a more action-packed film." Although this comment could not be considered a positive one, it can be estimated from this comment that the entertainment of $A D$ matches the film. 


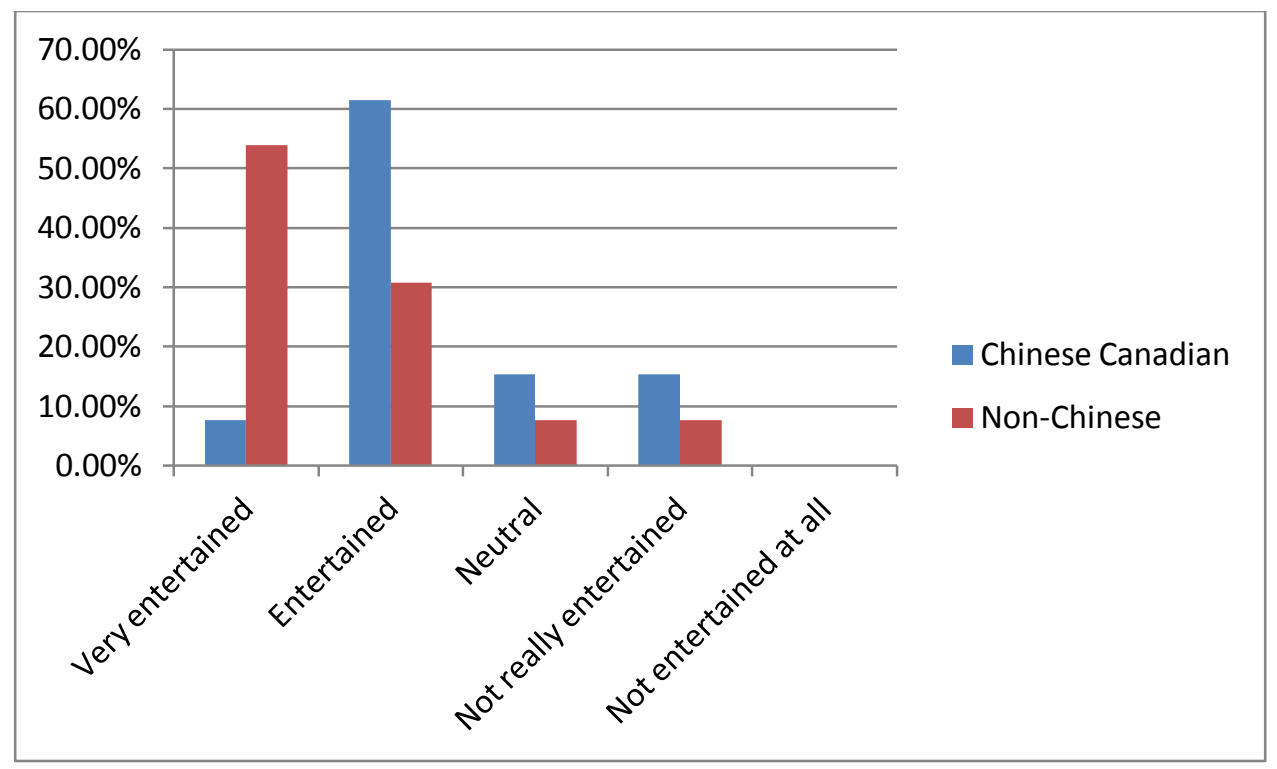

Figure 21. Entertainment of AD

During an interview, the describer mentioned that he tried to make the AD poetic because his film was a short romantic comedy. About the style of description, the director said that "I wanted to make it intimate, as if I am sitting beside a blind person, but not whispering in their ear, but filling them in on the parts they might need to know." Because there was some Chinese and Italian in this film, and the describer did not translate all of it, some participants thought all foreign languages should be translated. The director made an active decision about how to handle the non-English language used in the film:

"In "Magical Coincidence", when Amy first speaks Mandarin to the mushroom seller, the Mandarin is also not subtitled into English for sighted audiences. This is because I wanted the audience to be in Benjamin's position. Ben cannot understand what the mushroom seller is saying, but Amy can 
and she answers her in Mandarin. I felt that if this scene was not translated with subtitles, the audience would better understand the communication difficulties between the characters. For example, if someone speaks to you in a language you do not understand, a translation of what they are saying does not appear across their abdomen. So in this sense, subtitles are not realistic. I wanted to show this. In dramatic terms, the scene is self-evident and even if you do not understand the dialogue, the context is clear and the scene is still understandable. Since I chose not to translate the dialogue using subtitles, I also decided not to translate it in the AD. The B/LV audience may understand the scene in a different way. Because of this, I am curious if they needed to have the translation to understand what was happening in the scene -- or did they perhaps simply wonder why it wasn't being translated."

In rating the quality of the $A D$, there was a statistically significant difference between Chinese Canadian and non-Chinese participants $(U=33, p=0.004)$, with a mean rank of 9.54 for Chinese Canadian and 17.46 for non-Chinese. Chinese Canadian participants rated the quality of the AD lower than non-Chinese participants (Figure 22). All participants rated the quality of $A D$ above average level. As shown in Figure 23, 92.3\% of Chinese Canadians and $91.7 \%$ of non-Chinese participants stated that they would 
comfortable discussing the production with a sighted partner or friend who did not use AD. Although there were some differences in understanding and rating of the AD film between Chinese Canadian participants and non-Chinese participants, the overall evaluation of the production and its AD was high.

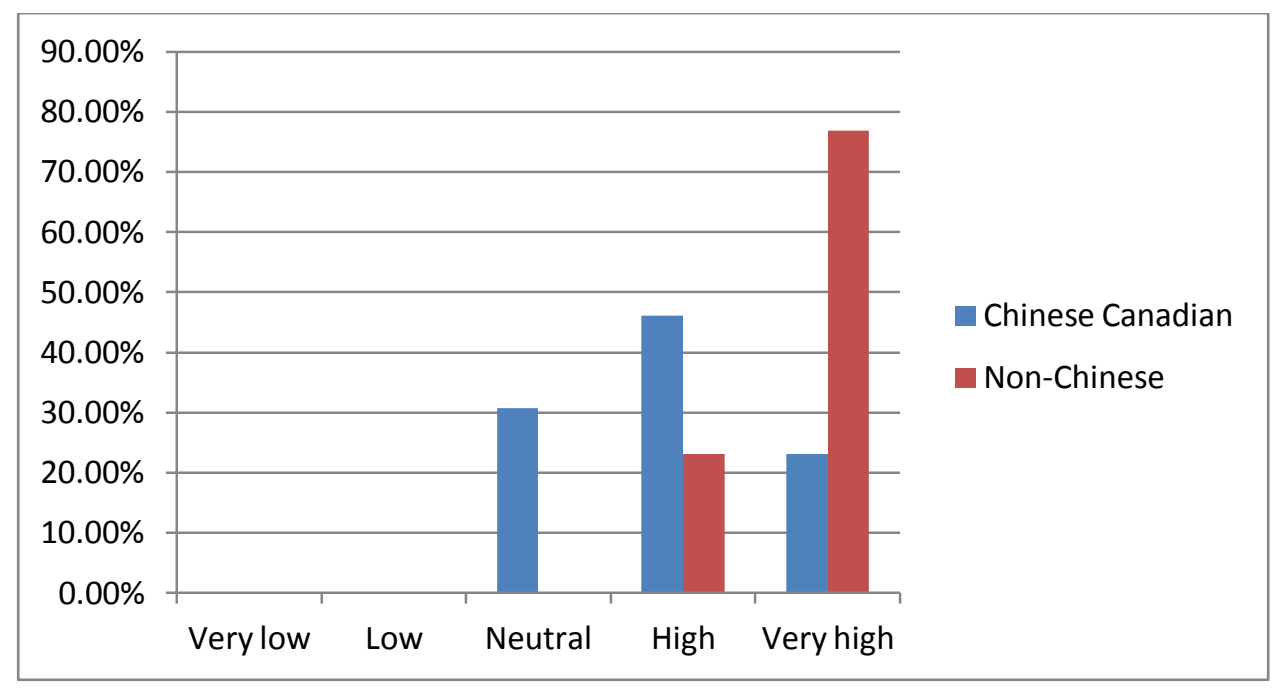

Figure 22. Ratings of the quality of $A D$

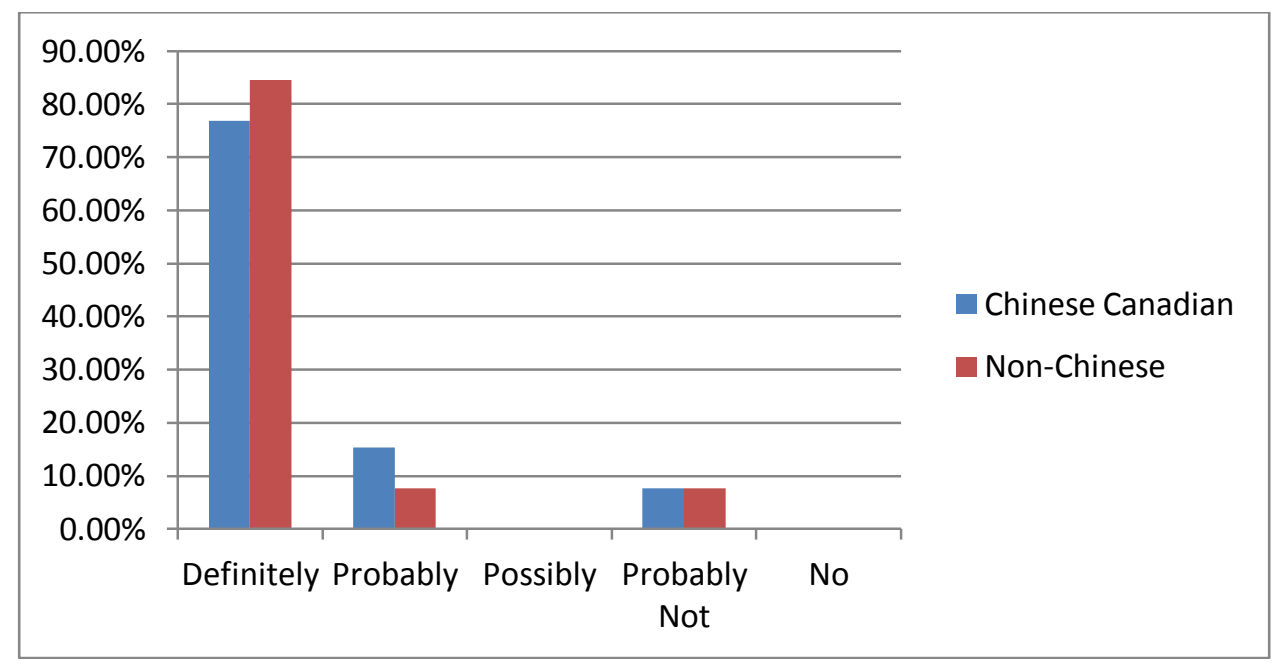

Figure 23. Comfortable discussing the production with a sighted partner or friend 
The volume level was always the controversial issue in evaluating AD. Two Chinese Canadian participants thought AD should be louder for them to catch it, and their English was not good enough to understand all of the AD. One participant quit since she could not understand English due to her poor listening skills. One non-Chinese participant said the AD was too loud in relation to the film and the other twelve said the volume was just fine and that it did not overshadow the film. All non-Chinese participants thought the volume level of $A D$ was above average, and $15.4 \%$ of Chinese Canadian participants thought it was poor (Figure 24).

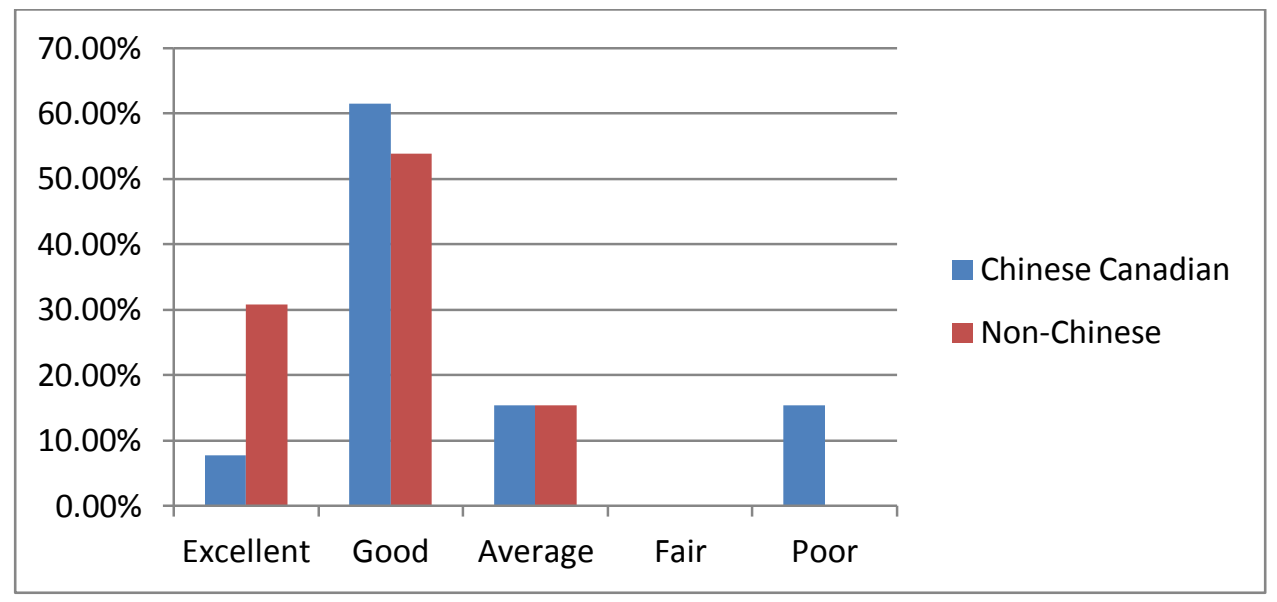

Figure 24. Volume level

In evaluating the quality of the $A D$, seven positive and twelve negative factors were listed in the questionnaire. Participants were asked to choose all the possible positive and negative factors affecting their ratings. 'Style of description' listed in positive factors means the style of $A D$ is appropriate. 'Fit of description to show' means the AD is integrated with the show in a good way. All positive factors affecting the ratings of $A D$ were chosen at similar frequencies, since seventeen participants chose all of the 
positive factors listed in the questionnaire (Figure 25). One non-Chinese participant mentioned that she loved the description of the credits before and after the film, and some initial introduction was important before the show. Another one said she would like to see the questions before the film, so she would know what to look at. Also, some non-Chinese participants said the wording of the description was perfect, they loved the way it was described, and enjoyed the mood and spirit of the film.

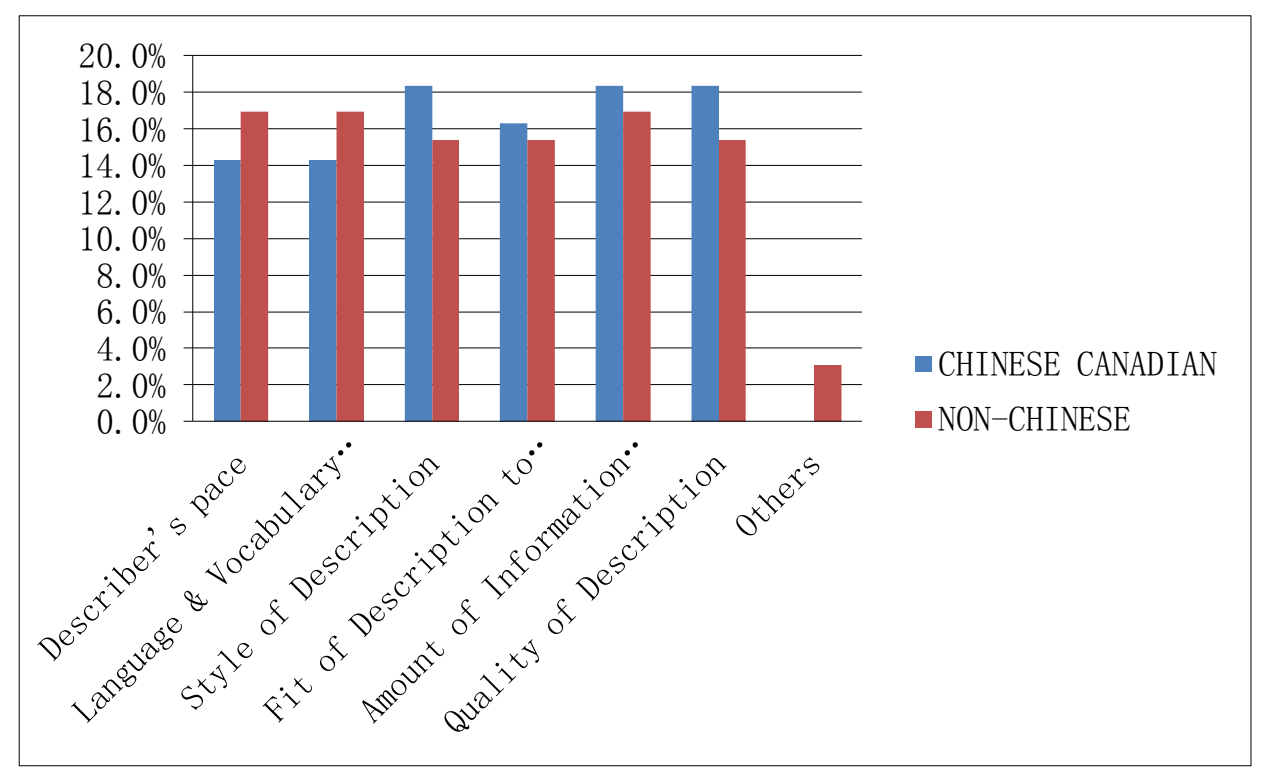

Figure 25. Positive factors that influence ratings of $A D$

The choices of negative factors that affected participants' ratings of AD did not vary much, but there was a small variation among the most-chosen one. 'Too little description' means the participant would like more description. 'Interrupted elements' means there are some interrupted elements such as dialogue or music in AD. 'Interrupted enjoyment' means the AD interrupted the participant's enjoyment of the show. For Chinese Canadian participants, 'too little description' was the most frequently 
selected negative factor (Figure 26). For non-Chinese participants, 'too simple language' and 'interrupted elements within the show' were the most frequently selected negative factors. From the phase one questionnaire, $28.2 \%$ of non-Chinese participants thought AD should not talk over other dialogues further corroborating the selection of this category in the negative factors affecting quality of $A D$ from the phase two questionnaire. One non-Chinese participant mentioned that the $A D$ of this film described obvious things a couple of times. However, most participants did not choose negative factors because they thought the AD was well developed.

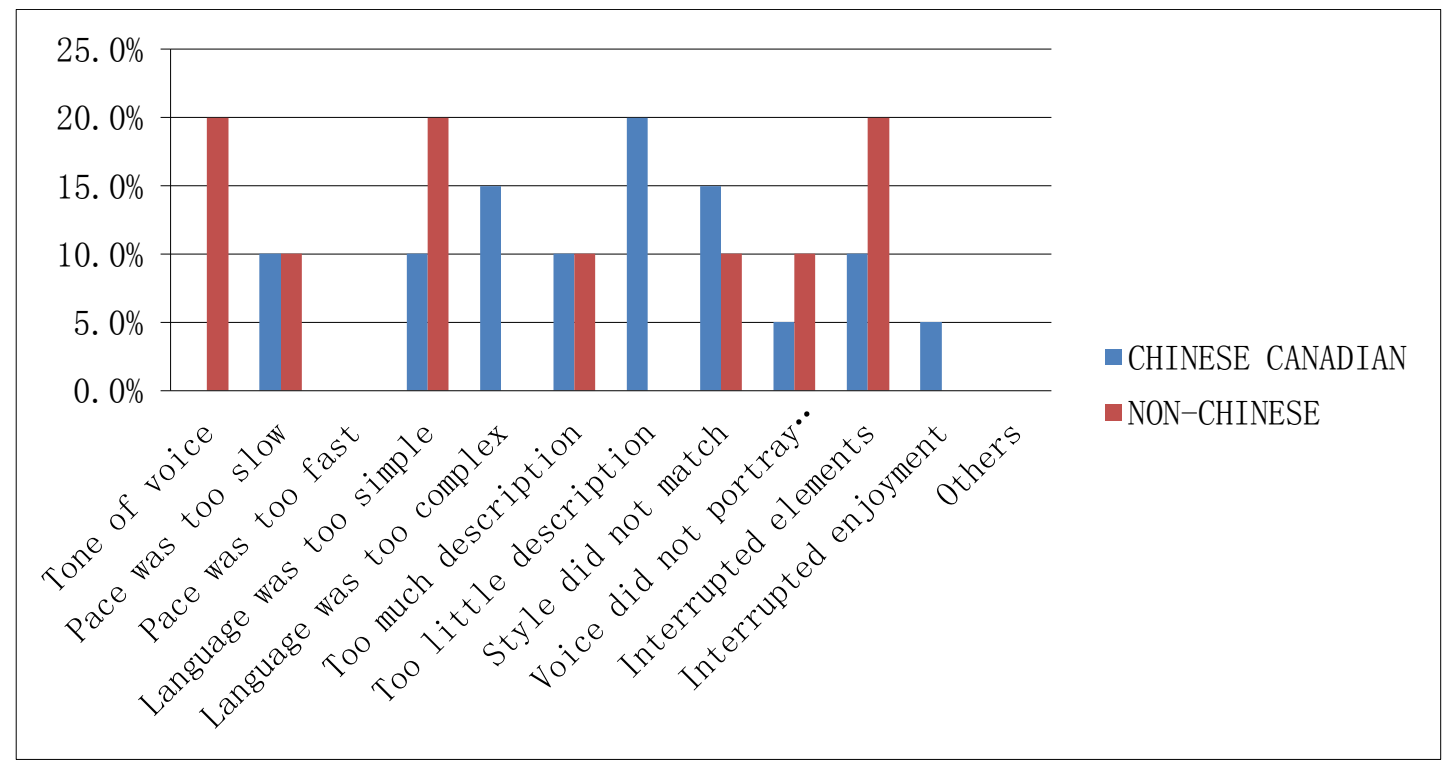

Figure 26. Negative factors that influence ratings of $A D$

The AD was divided into 4 subcategories for further evaluation of quality: onscreen action/plot, characters, costumes, and set. These categories were taken from prior researches [19]. There was a statistically significant difference in the ratings of the description between Chinese Canadians and non-Chinese participants for: 
1) onscreen action/plot $(U=40.5, p=0.031)$, with a mean rank of 10.88 for Chinese Canadian and 16.12 for non-Chinese (Figure 27);

2) characters $(U=51.5, p=0.037)$, with a mean rank of 10.96 for Chinese Canadian and 16.04 for non-Chinese (Figure 28);

3) $\quad$ set $(U=44.5, p=0.024)$, with a mean rank of 10.42 for Chinese Canadian and 16.58 for non-Chinese (Figure 29).

There was no statistically significant difference between Chinese Canadian and nonChinese participants for costume (Figure 30).

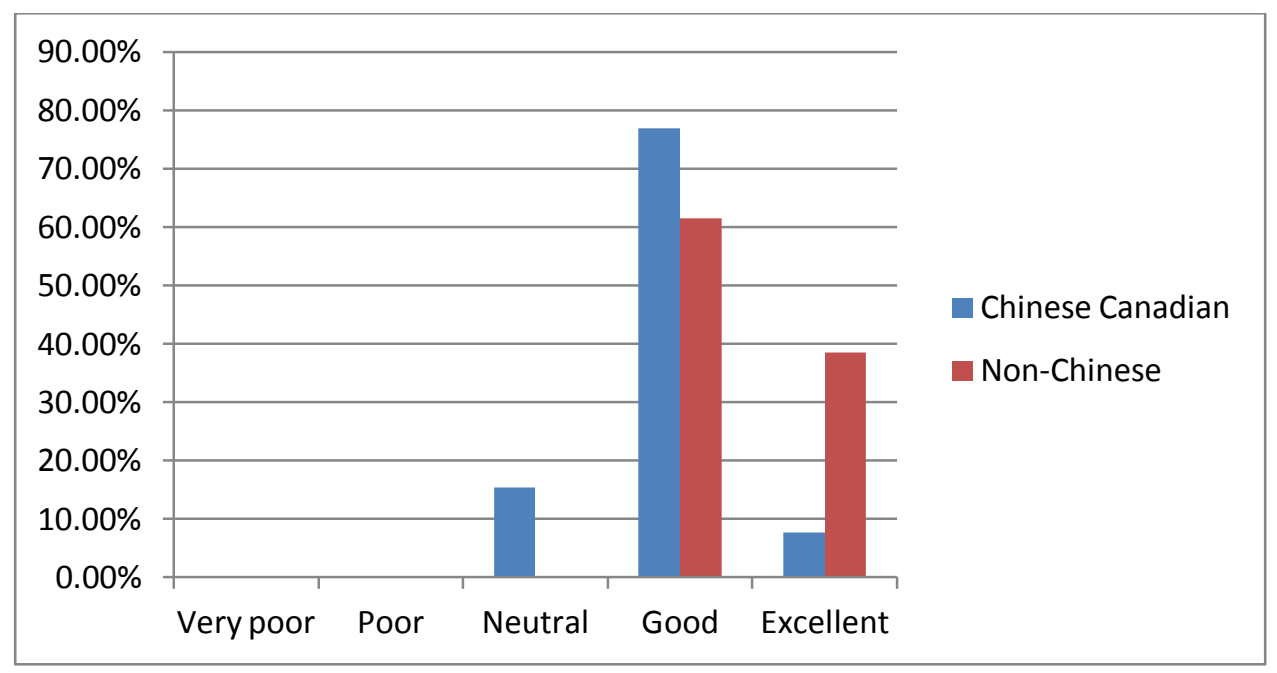

Figure 27. Quality of description for onscreen action/plot 


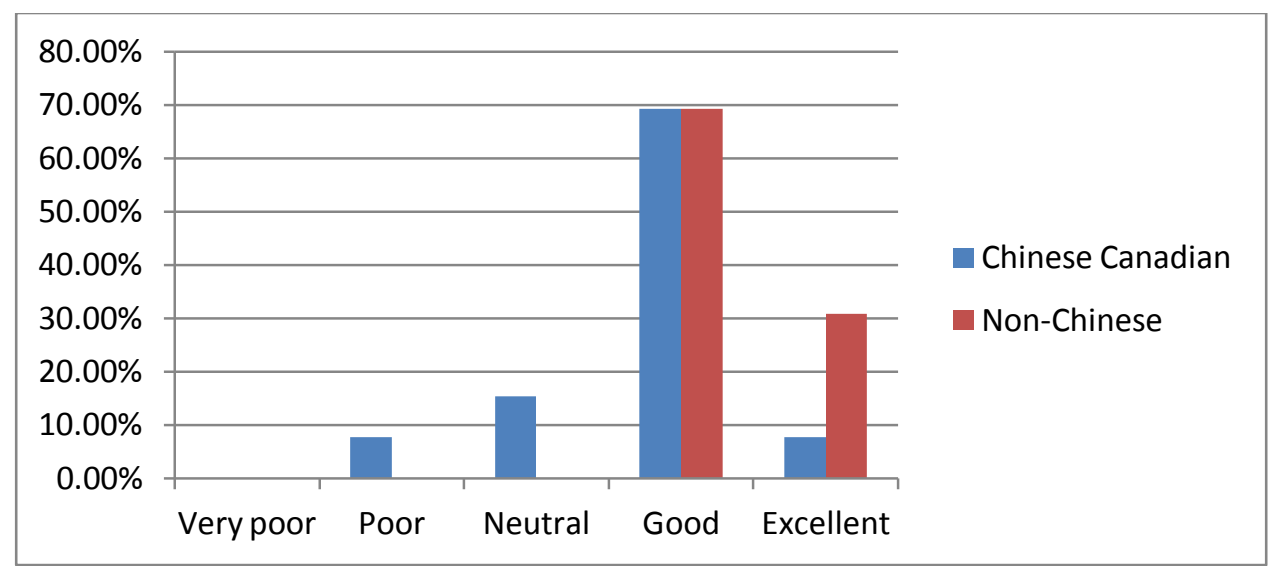

Figure 28. Quality of description for characters

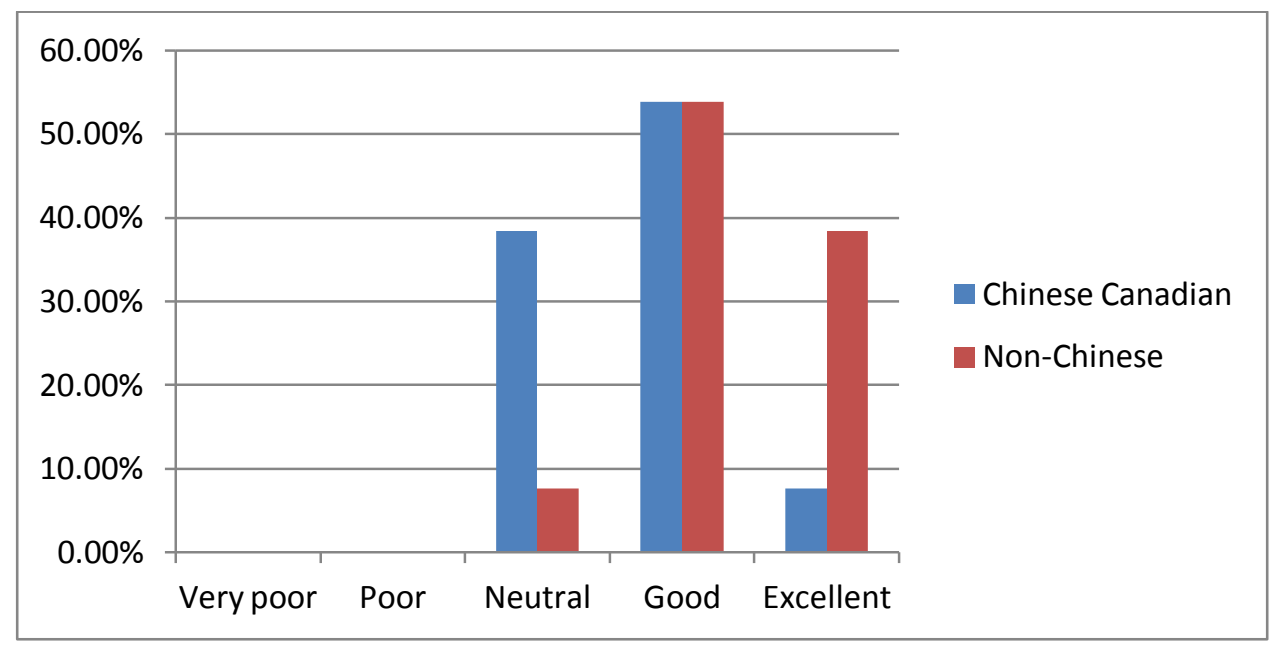

Figure 29. Quality of description for set

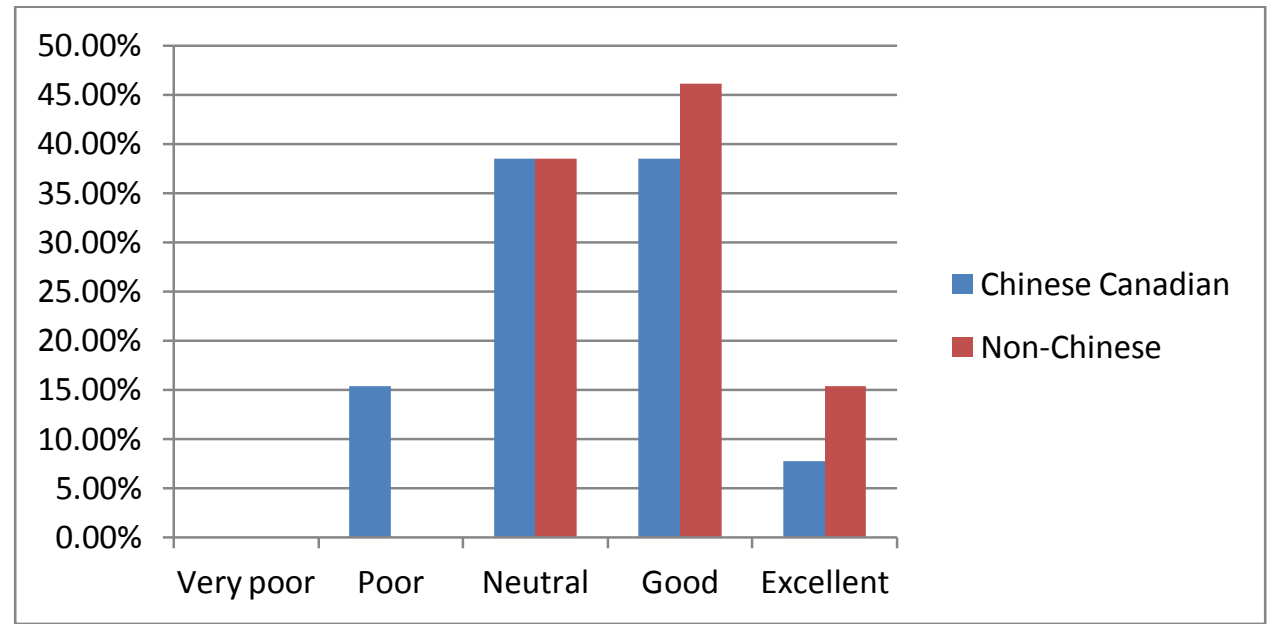

Figure 30. Quality of description for costumes 
Chinese Canadian participants rated the description for each subcategory lower than non-Chinese participants did. $92.3 \%, 88.4 \%, 53.8 \%$ and $76.9 \%$, respectively, of comments rated the quality of description for onscreen action/plot, characters, costumes and set as good or excellent separately (Figures 31-34). $80.8 \%, 65.4 \%, 26.9 \%$ and $69.2 \%$ of the comments said the descriptions of onscreen action/plot, characters, costumes and set were just enough. The describer commented later to this result that " ... this is partially due to the editing of "Magical Coincidence", which is unhurried. If the pacing had been faster there would have been less room for AD. Even so, I found in most places the amount of space for $A D$ was limited and it was quite challenging to fit the words into the scenes."

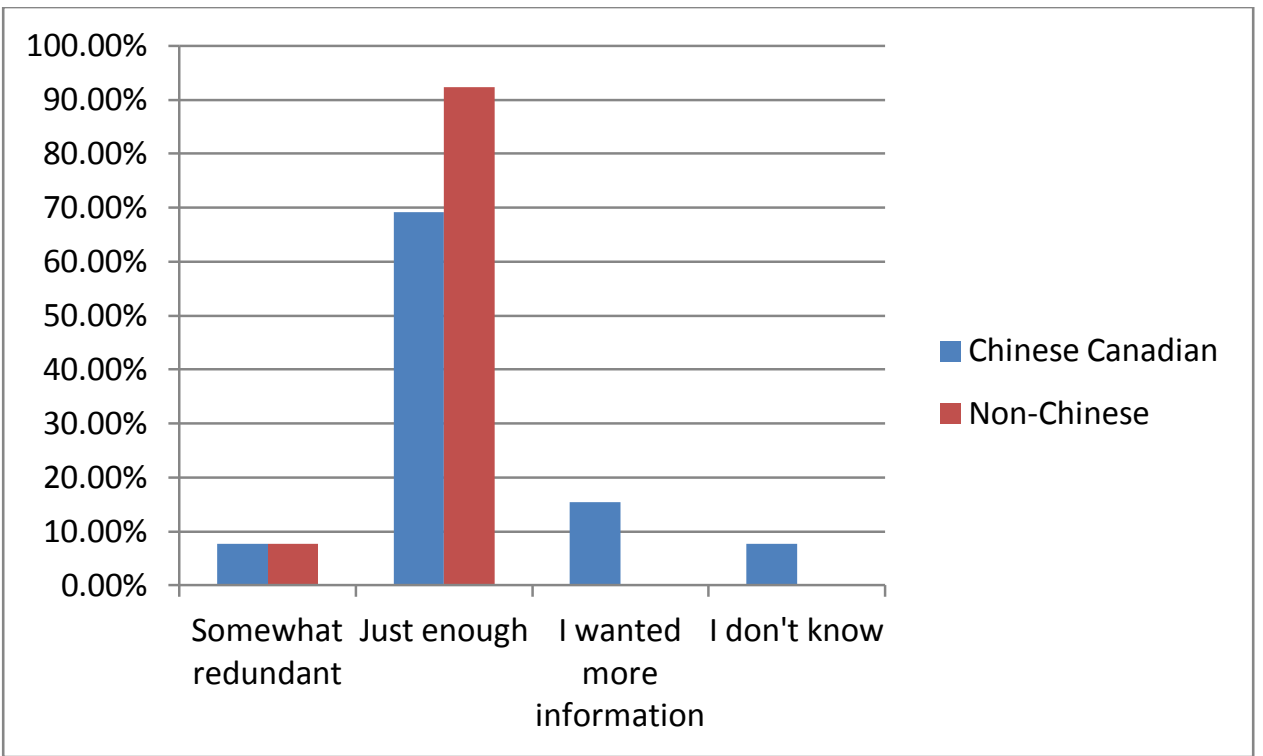

Figure 31. Enough description for onscreen action/plot 


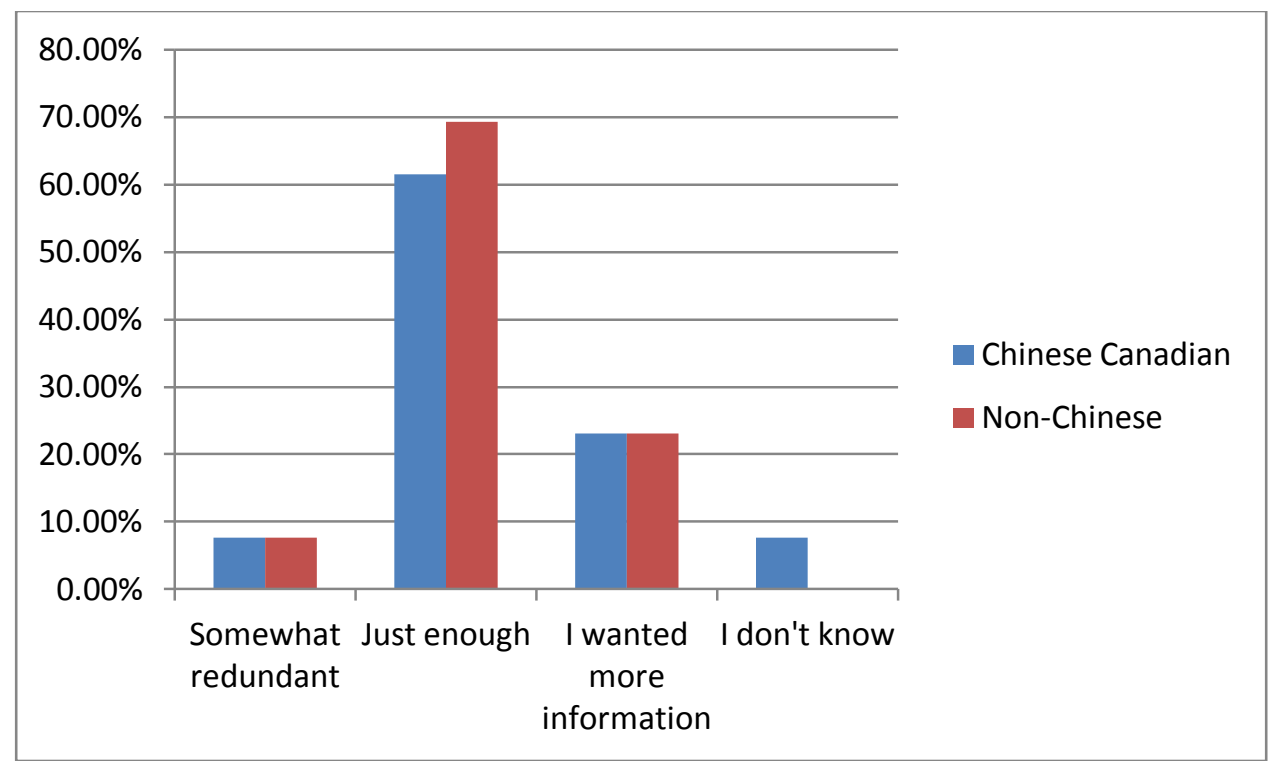

Figure 32. Enough description for characters

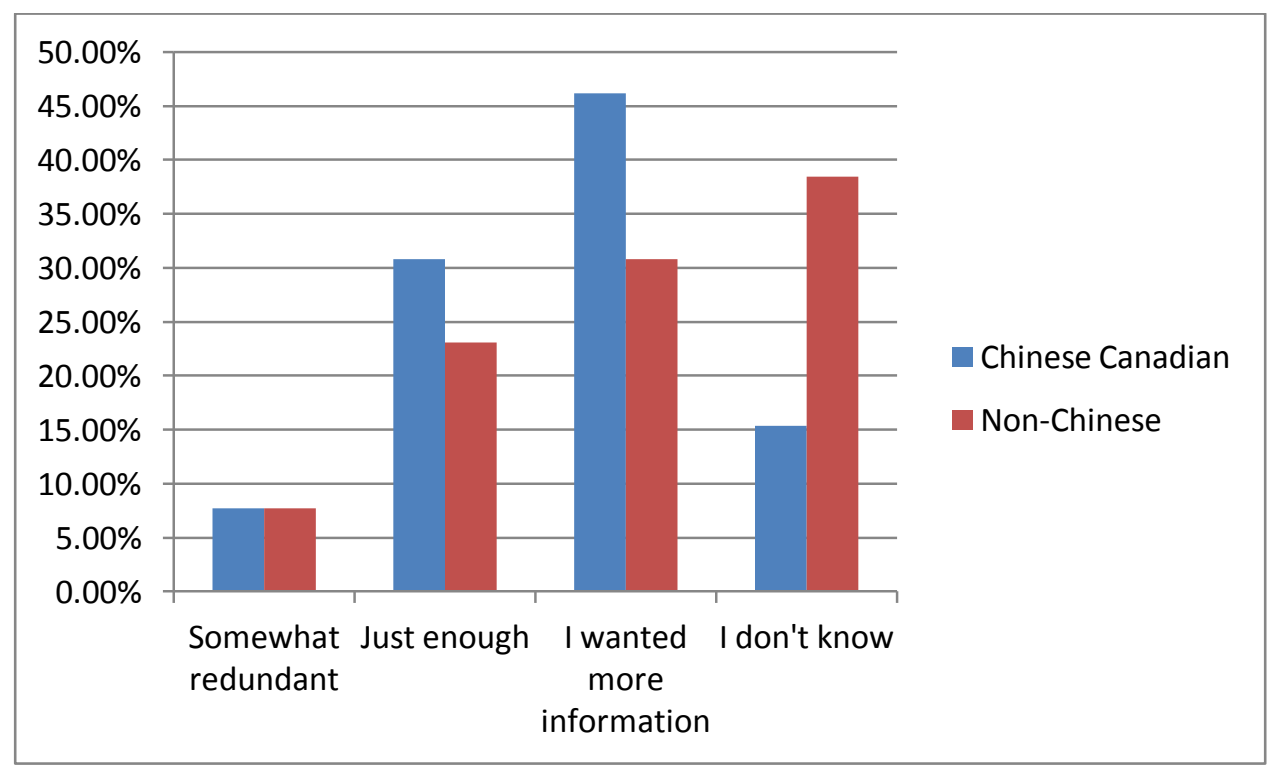

Figure 33. Enough description for costumes 


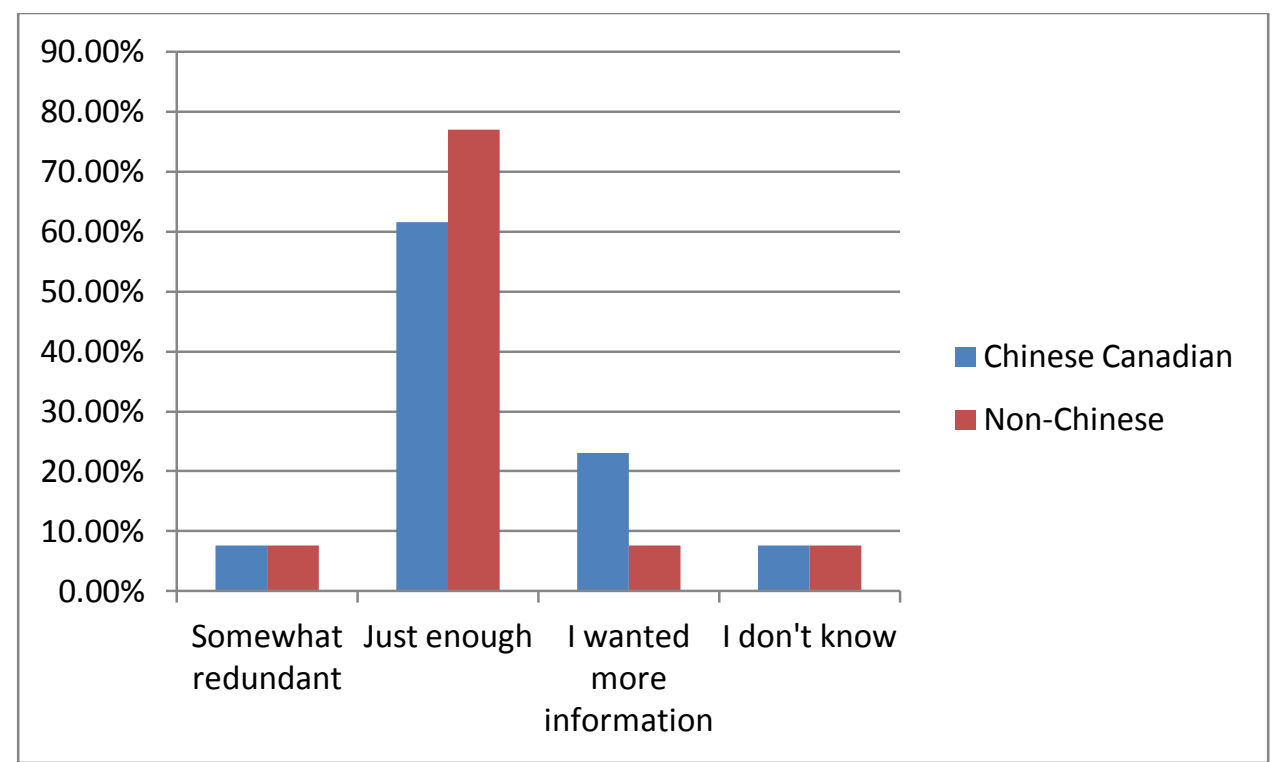

Figure 34. Enough description for set

For the description of costumes, 38.5\% said they needed more description, another $26.9 \%$ answered they did not know. Some participants said they did not remember that there was description for costumes and therefore chose "I don't know". There were only 4 instances of description for costumes in relation to other categories, so it was not surprising that participants would want more description for costumes.

To sum up, the describer tried to do his best to let B/LV people enjoy the film, and participants liked the AD film. Although there were some differences between Chinese Canadian participants and non-Chinese participants, they gave positive evaluation of this AD film.

\subsection{Other results not related to $A D$}

There were some results which were unrelated to AD, but may represent participants' daily access. There was a statistically significant difference of frequencies of accessing 
screen reader among different nationalities $(H(2)=10.268, p=0.006)$, with a mean rank of 10.67 for native Chinese, 21.67 for Chinese Canadians and 21.69 for nonChinese. Participants in Toronto had more access to screen readers than participants in Beijing. In testing the participants' expected frequency of accessing screen reader, there was a statistically significant difference among different nationalities $(H(2)=17.286, p=$ 0.000), with a mean rank of 8.22 for native Chinese, 22.87 for Chinese Canadians and 22.00 for non-Chinese. Forty-four percent of native Chinese participants would want to access a screen reader weekly, and eighty-seven percent of Chinese Canadian and eighty-five percent of non-Chinese participants would like to access a screen reader on a daily basis. Also, there was a statistically significant difference of expected frequencies of accessing audio reading services among different nationalities $(H(2)=$ 6.389, $p=0.041$ ), with a mean rank of 11.78 for native Chinese, 20.03 for Chinese Canadians and 22.81 for non-Chinese. Native Chinese participants' expected frequencies of accessing audio reading services were lower than that of Chinese Canadian and non-Chinese participants. When testing the frequencies of going to live music performances among different nationalities, native Chinese and Chinese Canadian participants had significantly lower frequencies $(H(2)=6.145, p=0.046)$, with a mean rank of 13.70 for native Chinese, 18.37 for Chinese Canadians and 24.21 for non-Chinese.

The current and expected frequencies of accessing other services were not statistically different among nationalities. Most participants had never had a guide dog, and they would not like to have one. Most participants had little access to education services, 
because most of them had passed the age of going to school. Native Chinese participants tended to have little access to audio reading services, and Chinese Canadian and non-Chinese participants had more access. Native Chinese participants had less access to entertainment than Chinese Canadian and non-Chinese participants, and most participants would want more access to entertainment.

Female participants would like more descriptions for costumes, and they had lower ratings of description quality for costumes than male participants (Figures 35 and 36). There was a statistically significant difference between male and female participants in deciding whether there was enough description for costumes $(U=36, p=0.009)$, with a mean rank of 9.50 for male participants and 16.93 for female participants Also, in comparing the ratings of the quality of description of costumes between male and female participants, there was a statistically significant difference $(U=46.5, p=0.038)$, with a mean rank of 16.13 for male participants and 10.82 for female participants. Some female participants mentioned that there was too little description for costumes, and that they would like to know what characters were wearing. Two male participants said they would not care about the description of costumes, and they thought it was irrelevant to the story telling unless it was important to the plot. When talking about how the describer decided the frequency of describing costumes in the interview, he said that: "This was a subjective decision based on my understanding of the characters and story and what I thought the audience needed to understand. Perhaps, as a male, I did not fully consider that female viewers wish to know more about the costumes. Perhaps I undervalued this important visual element in the AD." 


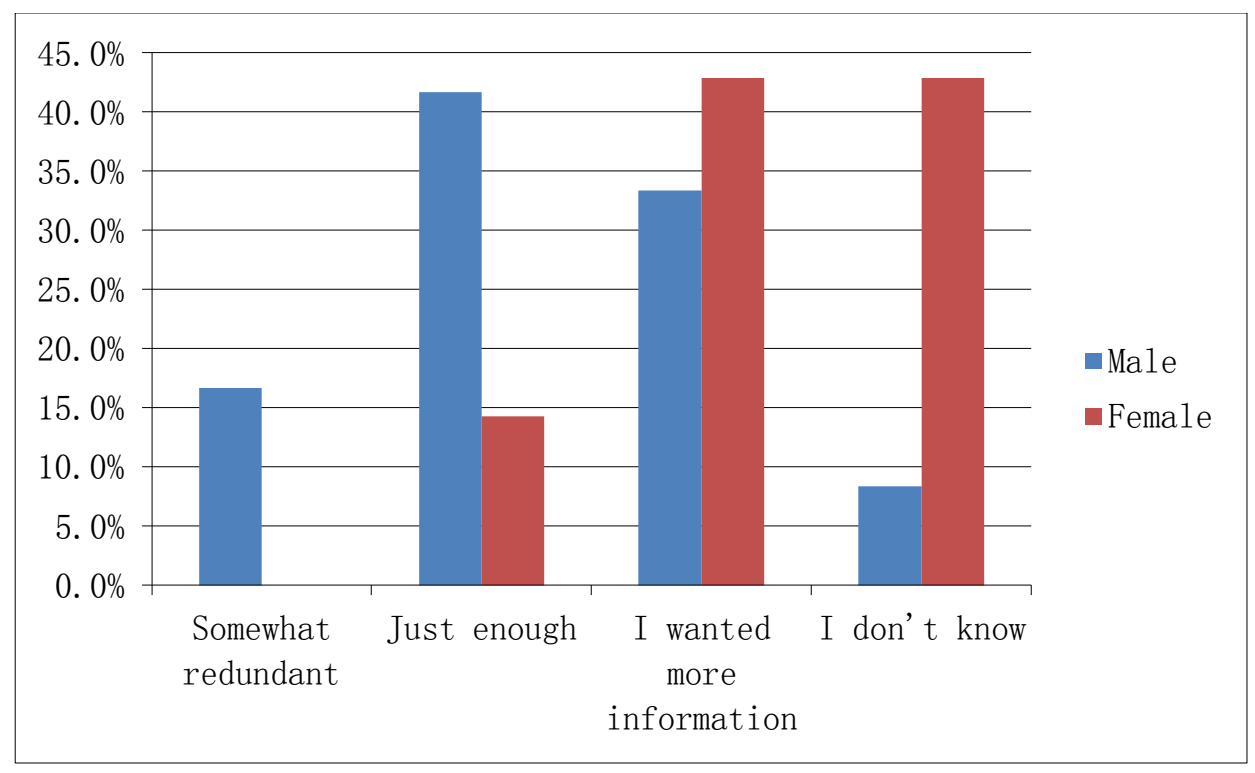

Figure 35. Enough description for costumes by gender

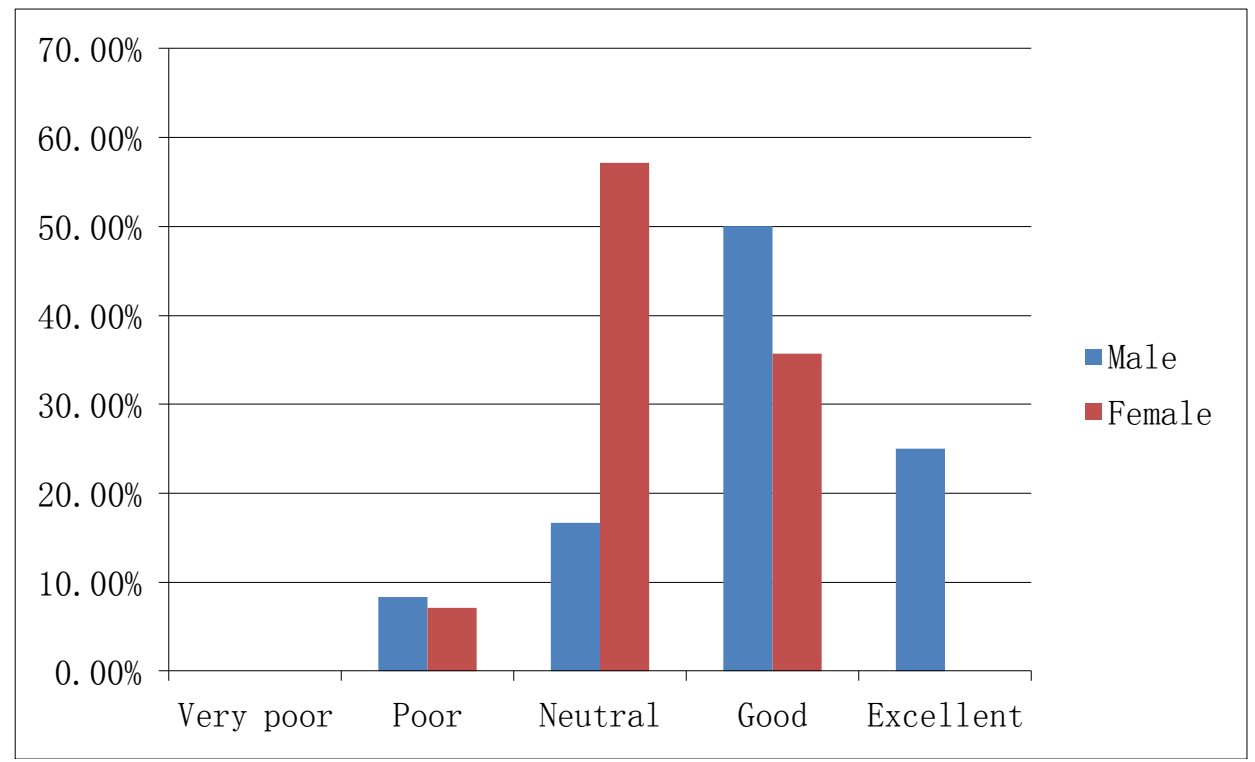

Figure 36. Quality of description for costumes by gender

As shown in Figures 37 and $38,79.69 \%$ of the comments mentioned that they would like to be able to do daily activities by themselves. $10 \%, 7.41 \%$, and $29.63 \%$ in each group said they would like to access or understand things related to AD by themselves. Non-Chinese Canadian participants were more aware of issues related to AD. Access 
to services and technological items were not usually mentioned in responses. Daily activities was the most frequently selected option that individuals wanted help with, but were usually not helped in all groups(58.33\% of comments from native Chinese, $69.23 \%$ of comments from Chinese Canadians, and $69.57 \%$ of comments from non-Chinese). $25 \%$ of comments from native Chinese said they did not need any help. $15.38 \%$ of comments from the Chinese Canadian mentioned they needed help with issues related to AD. $13.04 \%$ of comments from non-Chinese said they needed help with technology. There was not much difference among nationalities for getting help, and all participants wanted more help in daily activities.

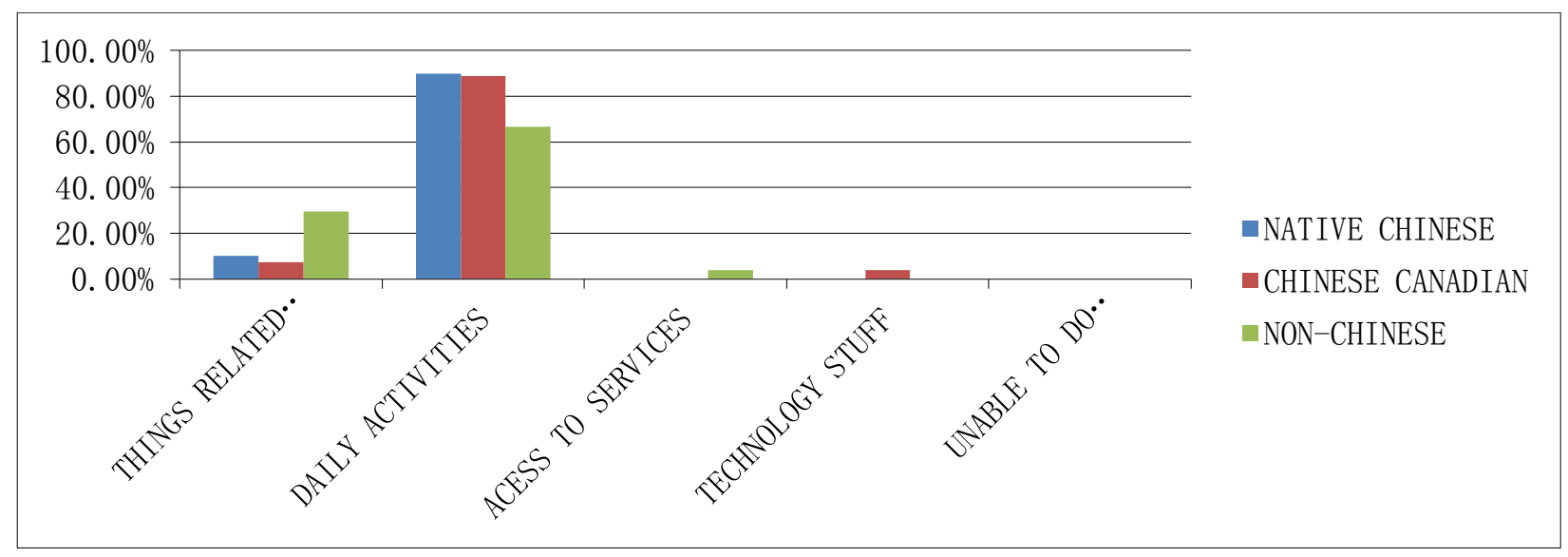

Figure 37. Things that participants would like to do on their own 


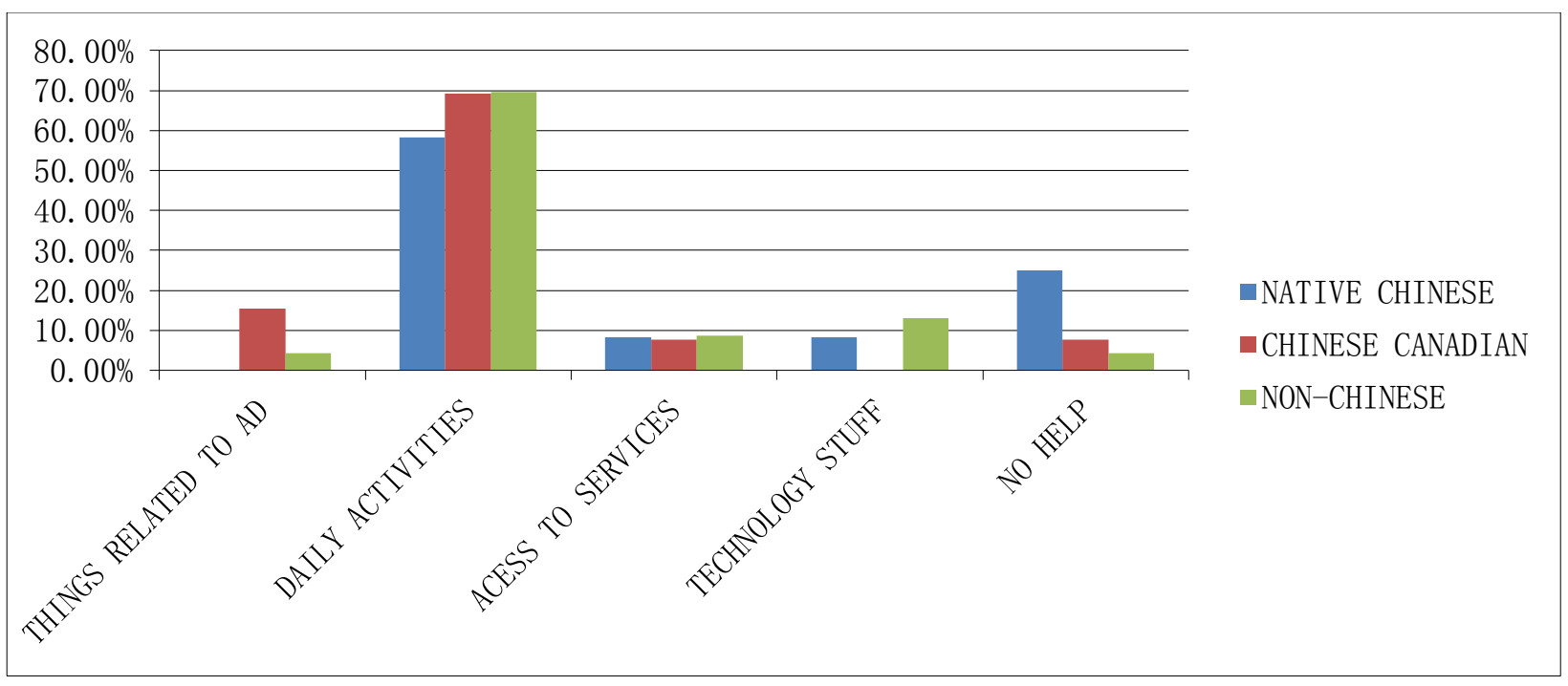

Figure 38. Things that participants would like to be helped with

\subsection{Secondary Study}

In order to better understand how each of the subcategories affected the quality ratings, a further analysis was carried out. The researcher counted the AD script by phrases and classified them into the five subcategories listed in Table 9. The AD script percentage was calculated by dividing the counting number of each subcategory by the total number.

In Table 9, all of percentages of descriptions for each category fall into the ranges that were defined by Turner (2009), which means the percentages of each category fit with other films. There was no data for the category 'Language Translation' in Turner's chart, so the percentage of this category in the AD script was compared with the film script in this research. There were 4 separate uses of foreign languages in the film script, but only 3 were translated in the AD script. 
Table 9. Percentages of AD contents

\begin{tabular}{|l|l|l|l|l|l|l|}
\hline Count/Categories & $\begin{array}{l}\text { Onscreen } \\
\text { action/Plot }\end{array}$ & Characters & Costumes & Set & $\begin{array}{l}\text { Language } \\
\text { Translation }\end{array}$ & Total \\
\hline Count & 122 & 22 & 4 & 49 & 7 & 204 \\
\hline AD Script\% & 59.80 & 10.78 & 1.96 & 24.02 & 3.43 & 100.00 \\
\hline $\begin{array}{l}\text { Gagnon and Turner } \\
(2009) \%\end{array}$ & $43-67$ & $8-37$ & $1-3$ & $13-28$ & NA & NA \\
\hline
\end{tabular}




\section{Chapter 6. Discussion}

The results presented in Chapters 5.1 and 5.2 addressed the first research question: how the expectations of AD of the Chinese community and of the Canadian community differ. The quantitative results showed that the expectations of $A D$ between the Chinese and Canadian communities are different. The Canadian communities had higher expectations of all aspects of AD compared with the Chinese communities since they already had a higher level of experiences of $A D$. Experiences of $A D$ and entertainment might influence people's reception and expectation of $A D$ [14].

There was no significant difference between nationalities in accessing entertainment as expected. The most popular forms of entertainment among participants were radio and television shows, and the least popular one was live theatre. Television was one of the most popular forms of entertainment in Canada and China [66], so it would be a logical conclusion that it would be also popular in the blind community. Radio only conveys audio, and this makes it easy for people with vision impairment to perceive it [74] which explains the popularity rating in this research. According to some participants' explanations, the reason why they seldom went to the theatre was not because they do not like theatre performances, but because they were unable to travel without assistance or was it unaffordable. As a result, theatre was the least popular form of entertainment of all kinds listed in that question.

Some participants in Canada listed other extra entertainment types not listed in this question, such as movies from CNIB and walking in the park. This result may indicate 
that there are more services provided in Canada for the blind community or that the participants in Canada are more active in participating in entertainment.

Another finding is that native Chinese and non-Chinese participants are more willing to watch television with other people and request some help than Chinese Canadian participants (Figure 11), and most participants from the three groups ( $80 \%, 46.67 \%$, and 61.54\%) want assistance when they are watching movies (Figure 12). Most Chinese Canadian participants are first-generation immigrants [79] and they do not have many relatives or friends who can offer them assistance when they are watching television. There might be other explanations for this result according to some participants' comments. After years of watching television or movies without assistance, some participants became accustomed to this situation and no longer saw a need for assistance.

Friends, relatives, and partners were the three most chosen categories in the question asking who usually describes for the participants. This result is as expected since these three kinds of people are close to the participants and are likely more willing to offer assistance in watching television or movies as these individuals likely assist in other activities, such as going from place to place. In summary, participants have some access to entertainment venues in China and Canada, and Canadian participants have slightly more access than Chinese participants although there is no statistical difference. Participants are willing to enjoy entertainment by themselves if accessibility tools (e.g. AD) are available to them. 
The results related to experiences of $A D$ show that it was significantly more popular to people from Canada than those from China. Non-Chinese participants were the most familiar with AD (Figure 6), Chinese Canadian participants were the second, and native Chinese participants are the least. The frequency of using $A D$ is arranged in the same order. Among the participants who had used AD before, most native Chinese participants rated it as poor, and most participants from Canada rated it as average or above. Part of the reason might be that in Canada, AD for television is regulated by the government [76] on how to produce qualified $A D$ and what standards should be met. However, there are few regulations or guidelines in China for AD [73] but institutions are aware of this issue and trying to provide some accessibility services, such as aural description. Implementing regulations in China could motivate the production of more $A D$ for entertainment venues and ensure the quality is at a certain level. This would increase the availability of $A D$ and likely improve access for $B / L V$ citizens which allows them to be included in the public communication environment, therefore make contributions to the society.

Chinese Canadian participants reported having less access to AD in Toronto likely because little $A D$ is provided in their native language [79]. In addition, people must be informed that this service is even available. The announcement that AD is available for a television show occurs just before the show begins. Electronic and print-based programming guides do not indicate that a show is available with $A D$. This means that any consumption of $\mathrm{AD}$ for television by $\mathrm{B} / \mathrm{LV}$ Chinese Canadians is likely in English or French. 
For $A D$ in the cinema, films that are available with $A D$ are usually indicated on the electronic or print-based movie listings. However, a B/LV person would need to know the acronyms used to indicate that $A D$ is available for a particular film or inquire in some way about whether $A D$ is available. For example, on the SilverCity Yorkdale website AD is announced with "Also with DVS for visually impaired" (http://www.cinemaclock.com) whereas for the Cineplex Odeon Yonge \& Dundas Cinemas, AD is not indicated on their website movie listings (http://www.amcyongedundas.com/) even though AD is available for some movies at this cinema. Being aware of and consuming AD for television or film then relies on an individual's comfort with and level of understanding of English or French as well as knowledge of how to access $A D$ in different venues. As outlined in universal design, it should "accommodate a wide range of literacy and language skills" [63] to achieve simple and intuitive use.

Due to the large Chinese B/LV population in China and in Toronto, there is a need to develop equivalent access to AD for the Chinese community. As stated in Habermas' communication theory [40], it is the public's rights to communicate with their social group and not be excluded from others. This participation contributes to the development of the society. To further analyse and understand the results of expectations of $A D$, this research includes questions about users' experiences of entertainment.

There are two questions in examining the expectations of $A D$ : shows expected to be described and important factors that would influence participants' ratings of quality. The 
decision-making in producing $A D$ includes which show to describe and what and how to describe it. Participants' expectations of AD regarding the two elements could help contribute to developing higher quality $A D$ for the Chinese community. Native Chinese participants preferred different types of television shows and preferred similar types of movies and theatre shows to be described compared with Chinese Canadian and nonChinese participants. Native Chinese participants' preferred shows to be described could be the most popular shows in their society, or the kinds of shows that they thought required the most effort from them to understand or enjoy without $A D$. For example, some participants said that they chose action shows to be described because without $A D$, they could not understand what is going on. Different from participants in Canada, native Chinese participants would like news to be described. News is a daily show that most people watch in China [66], and it is a major source of information regarding what is happening in the community. Chinese participants and Chinese Canadian participants preferred opera over music concerts to be described, as opera is a traditional form of entertainment in China [67].

It would seem then when not all films, televisions or live theatre productions are described, decisions about which shows or films to describe should consider user preferences. For example, efforts should be made to have AD available for Peking opera in China and in Canada as a priority for live theatre instead of other live events. In China, Peking opera is a family event which lasts for hours. Having access to Peking opera means being able to participate, and it is important for accessing traditional culture in China [67]. Whereas opera is not as popular a form of entertainment as Live 
events, television shows, and films among Canadians. Future studies could further study the preferences of forms of entertainment and offer suggestions on what types of shows to describe.

Participants from China and participants from Canada chose some similar factors and some different ones that influenced their ratings of $A D$. AD being informative is important for all participants, and this is also recommended in most AD guidelines [64, 65, 76].

In analyzing the differences, native Chinese participants would like to gain enjoyment from $A D$, and participants from Canada were more concerned about the disruption to the original work caused by AD. To further explain this result, participants who previously had little access to $A D$ expect that $A D$ would provide them with a better entertainment experience, and participants who previously had some access are more willing to consider the problems caused by $A D$, such as 'doesn't overlap the dialogue', 'doesn't interrupt other elements', and 'doesn't distract my enjoyment of the show'.

Overall, to answer the first research question, participants' expectations of $A D$ are somewhat different between the Chinese and Canadian communities. These differences might relate to their cultural backgrounds, previous experiences with $A D$ and in society, and governments' efforts. 
Section 5.3 of the results was intended to address the second research question: what are the differences in the evaluations of integrated AD for 'Magical Coincidence' between the Chinese and Canadian communities. From the interview with the describer/director, he tried to integrate the AD with the original work and he described in the way in which he wanted the audiences to understand the film. He used the approach highlighted with bold lines in Figure 1 to generate his description. The overall ratings for entertainment, understanding, and quality of this production and the $A D$ are high for most participants (Figures 19-21). All positive quality factors were chosen (Figure 25) and high evaluations were given by most participants.

As the 'Magical Coincidence' was only available in English, the researcher was unable to recruit a group from China so only Chinese Canadians and non-Chinese Canadians were available for this part of the research. There were some significant differences between Chinese and non-Chinese Canadians in the understanding of the production, entertainment of the $A D$, quality of the $A D$, and quality of three detailed categories of $A D$ content. The only non-significant result in rating the quality of detailed categories of $A D$ content was for costumes. However, in the comments from participants, female participants wanted more descriptions of costumes. The describer/director explained later that he did not notice that there was little description of costumes. This feedback could help develop AD procedures in the future. Knowing that users want more information of costumes or other content in $A D$, describers could follow this suggestion and develop more satisfying $A D$. 
Chinese Canadians and non-Chinese participants gave higher evaluations for $A D$ and the film than Chinese participants, and they rated their understanding and enjoyment for the integrated $A D$ and film higher (Figures 19-21). This result could be as a result of differences in comfort with English, lack of experience with AD, or not knowing what to expect. Although the Chinese participants could engage in basic communication in English, they are still likely more comfortable with enjoying entertainment in their native language [79]. It is better to provide Chinese AD to those users who use Chinese in daily communication, so that they could feel more comfortable and enjoy with the AD.

Also, some non-significant results showed the same trends as in the significant results. Non-Chinese participants were more entertained by the film than Chinese Canadian participants. Most non-Chinese participants thought the volume level was appropriate while Chinese Canadian participants thought it was poor. Perhaps they were less familiar with the equipment because they had never used it before.

In choosing negative factors, non-Chinese participants tended to think that the language was too simple since they wanted more vivid language, and there were some moments in $A D$ that interrupted their enjoyment of the film. Enjoyment is important when people consume entertainment [37], so questions about users' enjoyment of the show and the $A D$ were included to evaluate the production. While Chinese Canadian participants tended to think that there was too little description. They wanted more description for every category (action, set, costumes, and characters) since they expected that $A D$ would offer them a higher level of entertainment before they watched the film. Although 
some participants chose 'language' as a negative factor in this research, in general, more than half of all participants gave high evaluations of the production and they would recommend the production to their friends. Some participants voluntarily called their friends after they finished the questionnaires and told them about the study and the movie, helping in the recruiting process. Chinese Canadian and non-Chinese participants had significantly different ratings of quality for descriptions of set, action, and characters. The demands of descriptions of different category vary according to their cultural values and personal preferences.

One issue that several participants mentioned in their comments was that there were some moments in the film spoken in foreign languages that were not translated in the AD. But that this did not interrupt their enjoyment of the AD film. These same instances were also not subtitled for sighted audiences. The AD was produced by the director, and he wanted the sighted and B/LV audiences to have the same experience of confusion due to the lack of language comprehension so that people would understand the film from another character's perspective. This confusion was intended by the director to add some entertainment value to the film and the AD.

Overall, the evaluations of the AD and the film 'Magical Coincidence' were higher from the non-Chinese participants than the Chinese Canadian participants. It was assumed that the emigrant Chinese Canadian participants had lower level of comfort with the language and enjoyment of the production. However, there could be various reasons why this occurred including language issues and experience with AD. Future studies 
with larger sample sizes, different genres and different styles of $A D$ and over longer period of time could be carried out to examine each of these possible issues. Although, this study was not specifically designed to evaluate daily access but rather collect that data as part of the demographic information, there were some important and unexpected issues that were important to report and that may have had an impact on people's ability to respond to the questions on $A D$. Access to daily services could reflect the living quality of the blind community and offer some cultural or political preferences. There were four significant differences between nationalities: current access to screen readers, expected access to screen readers, expected access to audio reading services, and frequencies of going to live music concerts. Together with some non-significant results, these results showed that Chinese participants currently had less access to daily living services than Canadian participants, and they also had lower expectations of future access. All of the Chinese participants were living in a large city where awareness of possible access would be higher than in smaller cities or rural areas - the results in these communities may be even greater. Although the Chinese government had announced several regulations on improving accessibility, the digital or technical accessibility in China was still lower than that in Canada [73]. Considering the results of current access and expected access together, twenty-five percent of all participants would like to have more access to daily living services. However, $44.5 \%$ of native Chinese participants would want more frequent access to entertainment which they currently had little access to compared with $40 \%$ of Canadian participants and $23.1 \%$ of non-Chinese participants. Twenty-two percent of native Chinese participants would like more access to screen readers compared with fourteen percent of Chinese Canadian 
and eight percent of non-Chinese participants. Thirty-three percent of native Chinese participants would like to have more access to audio reading services compared with $26.7 \%$ of Chinese Canadian and $30.8 \%$ of non-Chinese participants. Although native Chinese participants would like more access to screen readers and audio reading services, their expected frequencies of accessing these services were at a lower level than Chinese Canadian and non-Chinese participants. Forty percent of Chinese Canadian participants would like to have more access to entertainment, and thirty-three percent would want more access to education services. Most of the education services they currently had access to were language learning classes. The native language of Chinese Canadian participants was Mandarin or Cantonese, so they wanted to take more language learning classes and lectures. Also, there were fewer sources of entertainment in their native language, so they wanted more entertainment. Thirty-one percent of non-Chinese participants would like to have more audio reading services and education services. It seemed that participants' expected frequencies were dependent on the current situation. For example, if an individual had no access to screen readers, he may hope for a small amount of access rather than expecting to use it on a daily basis because some access is better than no access. As they were not familiar with services to which they did not have access, they may not expect frequent access to them. Also, although most participants needed some assistance in their daily life, they wanted to be as independent as possible similar to most other individuals [24]. The blind community was not a special group, but rather a community that needs equivalent access and systems designed to include B/LV users as would be the practice if these systems were designed according to universal design theory [63]. This line of reasoning 
would also apply to the provision of $A D$ where it would be considered from the beginning of the production process rather than at the end. The results related to daily service access were not a research objective of this thesis, but it offers the demographic information of the participants.

In the secondary study results, there were some unanticipated findings related to gender bias in content. Female participants had significantly different preferences of AD contents from male participants. More and better description of costumes was preferred by female participants. Since this film was a romantic comedy, which was more femaleoriented [85], female participants might expect to have description that they consider important [85]. Similar findings on gender-oriented contents were studied in film narratives [15], the results showed that female tended to narrative a film in the form of story-telling instead of mentioning it was a film. There is little research on this issue in the AD field, except for the study conducted by Fels and Naraine [19]. This interesting finding could offer a new study direction and provide suggestions for describers.

The process of this research could be applied in future studies of other culture groups. Audio described films could be developed following the framework proposed in Chapter 3 , and the two phases or questionnaires could be adopted to collect data from different culture groups. The results and conclusions of this research are proposed based on the data collected, so those would not apply to other culture groups. The expectation and evaluation factors that are highlighted in this research could offer some insights for future studies, and more cultural contexts could be added to test the cultural differences. 
The issue about "blind culture" is vague, and little academic work exists on this topic. The Alliance for Equality of Blind Canadians (http://www.blindcanadians.ca/publications) takes the position that there is a culture for the blind since blind people have unique characteristics and behaviours. Others suggest otherwise as people who are blind people are not identified with having their own language (https://nfb.org/images/nfb/publications). From their discussions and the researcher's own observations, a blind culture may be considered as there seems to be some characteristics such as reliance on and skill of using auditory information for many tasks including wayfinding and accessing entertainment that are shared by blind people regardless of their nationalities. Future studies could be carried out to investigate the notion of blind culture and, further, its influences on AD reception.

To sum up, the expectations and evaluations of $A D$ between the Chinese Community and the Canadian community were different. It is necessary to develop a specific AD to satisfy the Chinese blind community. To apply the theoretical results in practically producing $A D$ in the Chinese Community, there are still some limitations and recommendations for future studies. 


\section{Chapter 7. Limitations}

First of all, the AD produced in this research is not in Chinese. This may influence participants' evaluations. In order to better understand the impact of AD on the Chinese community, having Chinese AD would be more appropriate for users to evaluate. As this research is conducted mainly in Toronto, it is difficult to find a Chinese director producing a Chinese film, and who is willing to integrate AD into the film. The describer/director is a second-generation immigration from Asia, which might contribute to the minimization of the cultural gap.

A second limitation is that the sample in this research is small and statistical analyses are limited as a result. The number of Chinese people in the blind community in Toronto who are willing to participate in this research and are able to understand English in the blind community in Toronto is very small. The researcher employed various approaches to recruit participants and found 40 participants in total but some are unable to go to movies, public places or the participant's home were used for interviews. There were 10 native Chinese participants recruited in Beijing since the researcher only had a month to recruit participants and conduct the interview. Although the sample size is small, it is enough to describe the situation and produce the results of this research.

A third limitation is that there may be some interrelations between variables, but these were not studied in this research. The goal of this research is to find out whether there are differences between the Chinese and Canadian communities in their expectations 
and experience of $A D$ and consider those differences, so the correlations were not explored.

Another limitation is that this research had limited sources to be examined. Only four instances of costumes were described, which could not compare a version with more costume description. No television or live events were included, and only one movie genre was presented. The researcher only used one movie in this study, whilst longitudinal study could examine how attitudes change over time and with experience. It is the director's first experience so he was learning too. A second description may be different.

Lastly, there may be various reasons that cause different expectations and evaluations of $A D$; in this research, only a few factors were examined. The questionnaires used in this research were created following previous research in this field, so some factors might be missing. However, this research is a beginning of studies conducted to apply $A D$ in the Chinese Community. 


\section{Chapter 8. Contributions}

In this research I carried out a study that examined differences between Chinese and Canadian communities regarding their expectations of AD for film, television and theatre. The results of this study provided some evidence that it is desired in both communities and that it is much less available for Chinese audiences in Canada and in China. The data collected in China and the comparison analysis adopted are another contribution in this field where there was little data and few findings related to the Chinese community. This cross-cultural comparison provides data for governments, regulators and organizations for the blind to improve access to cultural artefacts for the Chinese blind community.

I also carried out a study using a film about cultural and language differences that had been produced and described by a second-generation Chinese Canadian director. Audiences provided their perspectives on the film and the AD. This assessment of the film used questions that had been used in previous $A D$ research offering some measure of external validity. The feedback provided from this questionnaire then provides a valid feedback to the film creation team, and results in recommendations to other audiences. This feedback gives high ratings on the quality of $A D$ and film, and enjoyment of the production.

A secondary and preliminary finding from this questionnaire is that there is a gender bias for content preferences for AD; it would seem that for this film, women wanted more costume description than men. This finding provides evidence that gender could 
be an important consideration when deciding what to describe and that this is a possible new direction for research.

Another contribution is that the focus on audiences' perspectives is in line with universal design. Users could provide feedback and suggestions that designers always overlook, and make the production more friendly to users. 


\section{Chapter 9. Conclusion and Future Directions}

This research describes how the expectations and evaluations of $A D$ are different between the Chinese and Canadian communities. Participants from China are less aware of $A D$ and had lower expectations and evaluations of $A D$ and that there is a strong desire to consume AD if it was available. This suggests that more work in China and Canada is required to ensure that $A D$ is produced for Chinese films.

Regarding the integrated $A D$ that was created and narrated by the Chinese Canadian director for his film, Magical Coincidence, the overall ratings of the AD and the film by Chinese and non-Chinese Canadians were high. The inclusion of the creative team and users' feedback align with the principles of universal design because the AD was considered at the beginning of the film's production and it was designed by the director for a diverse audience. This provides one example of how accessibility can be introduced at the beginning of the media design process. Although there were some limitations in this research, it is a starting point for studies on the application of AD in the Chinese Community.

This research began with a questionnaire that attempted to gather the opinions of native Chinese, Chinese Canadians and non-Chinese Canadians on their access to technology in general and $A D$ specifically. In comparing all three groups of $B / L V$ audiences, seven conclusions arose: 1 . native Chinese participants had less access to daily living services than Chinese Canadian and non-Chinese participants; 2. Chinese Canadian and non-Chinese participants were more aware of issues related to AD; 3 . 
native Chinese participants were less likely to go to live music performances; 4. Chinese Canadian and non-Chinese participants were more familiar with AD; 5 . Participants from different groups would like different types of shows to be described; 6 . Non-Chinese participants understood the film better; 7. Non-Chinese participants assigned higher ratings to $\mathrm{AD}$. These conclusions then point to the need for considering access to $A D$ from a cultural perspective which then adds new dimensions to the concept of a diverse population in the theory of universal design. In addition, it provides some evidences for regulators and governments regarding the need to have AD for broader audiences and for more content.

Future studies in this field could focus on other factors in applying AD in the Chinese Community or continuing in the direction of this research. Chinese AD could be developed to gain Chinese B/LV people's feedback as well as provide more inclusive entertainment. Also, a comparison could be made between the aural description provided in the current Chinese blind community and the more formal AD that is developed following AD best practices. As discussed in the limitation chapter, the relationship between participants' comments and their experiences with $A D$ could be tested in future studies. For example, people who are new to AD might want more information from $A D$ than those with more experience. Other factors such as access to technology, educational background, and political and social attitudes that might influence people's evaluations could also become variables to examine future studies:. Larger sample sizes and more than one film production would provide additional evidence and support stronger conclusions, directions for AD and eventual regulations. 
Availability and access to daily living services and assistive technologies are likely important factors that would also influence participants' comments and preferences in the future.

In addition, blindness level and whether the blindness is congenital or acquired could also affect the research results.

A comparison of the film script and the AD script is another method by which to further understand the difference between film narration and AD. Also, in this direction, differences in genre-related percentages of content categories could be tested. For example, another direction in future studies is to provide multiple versions of AD for the same show that are developed according to the different possible processes shown in Figure 1. For example, providing a detailed version of AD online could offer more options to users or using a path that does not involve access to the written script or the director (a more conventional scenario in $A D$ ).

In summary, while there is a much further research to carry out for the development of AD processes and procedures, cultural considerations are a new direction. This thesis offers one example of how these considerations and possible audience reactions can be explored. 


\section{Appendix A: Ethics Approval}

\section{RYERSON \\ UNIVERSITY}

From: rebchair@ryerson.ca

To: fei.xue@ryerson.ca

Cc: rebchair@ryerson.ca

Subject: REB 2012-208 Status

Date: July 31, 2012 10:03:45 AM

\section{REB 2012-208}

Project Title: Audio Description in Chinese community: the differences of Audio

Description in Chinese and Canadian communities

Dear Fei Xue,

The Research Ethics Board has completed the review of your submission. Your research project is now approved for a one year period as of Jul 31, 2012. The approval letter is attached in Adobe Acrobat (PDF) format.

Congratulations and best of luck with the project.

Please note that this approval is for one year only and will expire on July 31,2013 . Shortly before the expiry date a request to complete an annual report will be automatically sent to you. Please complete the annual report at that time indicating if the study is completed or still ongoing. Completion of the annual report takes only a few minutes, enables the collection of information required by federal guidelines and when processed will allow the protocol to remain active for another year.

Please quote your REB file number (REB 2012-208) on future correspondence. 
If you have any questions regarding your submission or the review process, please do not hesitate to get in touch with the Research Ethics Board (contact information below).

No research involving humans shall begin without the prior approval of the Research Ethics Board.

Record respecting or associated with a research ethics application submitted to Ryerson University.

Yours sincerely,

Toni Fletcher

Research Ethics Coordinator on behalf of

Nancy Walton, Ph.D.

Chair, Research Ethics Board

Associate Professor

Ryerson University POD470B

350 Victoria St., Toronto, ON

(416)979-5000 ext. 6300

nwalton@ryerson.ca

rebchair@ryerson.ca

http://www.ryerson.ca/research

Toni Fletcher, MA

Research Ethics Co-Ordinator

Office of Research Services

Ryerson University

(416)979-5000 ext. 7112

toni.fletcher@ryerson.ca

http://www.ryerson.ca/research 


\section{INFORMATION AND CONSENT FORM \\ FOR QUESTIONNAIRE FOR THE FILM "MAGICAL COINCIDENCE".}

Study title:

Audio Description in the Chinese community: differences in expectations, needs and opinions between Chinese and Canadian communities

Purpose of the Study:The purpose of this research is to give directors some advice on their audio descriptions of films, and to compare different experiences and attitudes between Chinese and Canadian audiences with blindness or low vision. Researchers seek to assess the entertainment value and quality of description provided for the film "Magical Coincidence". Description of the Study:

Study summary:

1) We are interested in your experience with audio description and your evaluation and opinion of the audio description provided for the specific short film that will be screened. Prior to your participation, we require that you provide informed consent. As such, please read the following information about the study and what you will be asked to do.

2) Considering the subjective nature of the film topics and the time commitment involved, we realize that some participants may not watch the entire film. If you choose to stop watching the film, please fill out as much of the post questionnaire as possible. On this questionnaire, please articulate the reason why you are no longer interested in watching the film.

Phase One: Participants would be asked to complete 22 questions on your attitudes/expectations/ experiences of Audio Description for film, television and live theatre in the Chinese community, which would take no longer than 20 minutes. 
Phase Two: Participants would be asked to complete 15 questions on your attitudes/expectations/ experiences of Audio Description after seeing a film called "Magical Coincidence". The film is approximately 20 minutes long, and the questionnaire would take no longer than 15 minutes.

None of the questionnaires used in this study is experimental in nature. The only experimental aspect of this study is the gathering of information for the purpose of analysis.

Risks or Discomforts: The risks associated with the study are minimal. You might feel uncomfortable or fatigued while responding to questionnaires. You may take a break and then continue after the break. You may also discontinue participation at any time for any reason either temporarily or permanently.

Benefits of the Study: It is not foreseen that you will personally benefit from participation in this study other than enjoyment of media. However, the results from this research will contribute to the development of guidelines for the description. As such, individuals who are blind or have low-vision will be able to not only understand what is occurring onscreen but enjoy full access to the entertainment experience that films offer.

Confidentiality: All data will remain confidential and be secured at the Inclusive Media Design Centre at Ryerson University and destroyed after five years. Data will only be presented in summary form and no individuals will be identified. Data will only be accessible to people who are related to this research in the Inclusive Media Design Centre at Ryerson University. Number codes will be used to link data with personal information.

Costs and/or Compensation for Participation: There will be no compensation for participation. Voluntary Nature of Participation: Participation in this study is voluntary. If a participant decides to participate, he/she will be free to withdraw his/her consent and to stop his/her participation at any time. At any particular point in the study or while watching media, he/she may refuse to answer any particular question or stop participation altogether.

\section{Questions about the Study:}

If you have any questions or concerns, please do not hesitate to call Deborah Fels at 979-5000 ext. 7619, Fei Xue at 979-5000 ext. 7620. The Research Ethics Board should be contacted if the participant has questions about their treatment as a participant in a research study.t, c/o Office of the Vice President, Research and Innovation, Ryerson University, 350 Victoria St., Toronto, ON M5B 2K3, Tel: 416-979-5042.

Principal Investigators: Fei Xue, MMSc Candidate. Ryerson University

(416)-979-5000 ext. 7620 or fei.xue@ryerson.ca 
Faculty supervisor:

Deborah Fels, Ph.D., P.Eng. Ryerson University

(416)-979-5000 ext.7619 or dfels@ryerson.ca

\section{Agreement:}

Your signature below indicates that you have read the information in this agreement and have had a chance to ask any questions you have about the study. Your signature also indicates that you agree to be in the study and have been told that you can change your mind and withdraw your consent to participate at any time. You have been given a copy of this agreement.

You have been told that by signing this consent agreement you are not giving up any of your legal rights.

Name of Participant (please print) 
Appendix C: Questionnaires

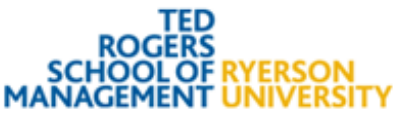

RYERSON

UNIVERSITY

\section{Audio Description in the Chinese Community}

Phase one questionnaire

The purpose of the questionnaire is to gather information about your attitude and experience with audio description for television, film or live theatre. There are a total of 22 questions in this questionnaire and it should take about 20 minutes to complete this questionnaire. Thank you in advance for your assistance.

Demographics:

1. What is your age?

ㅁ 19 to 29

口 $\quad 30$ to 39

口 40 to 49

口 50 to 59

口 60 and over

2. What is your level of vision impairment?

ㅂlind

- Low-vision

3. What is the highest level of education that you have completed?

口 Elementary School

․ High School 


\section{a College \\ ․ Undergraduate Degree \\ a Masters Degree \\ 口 Doctorate}

4. What is your gender?

口 Male

a Female

5. What kind of services do you access in your daily life?

Guide dogs

$\begin{array}{ll}\square & \text { Never } \\ \square & \text { Yearly } \\ \square & \text { Monthly } \\ \square & \text { Weekly } \\ \square & \text { Daily }\end{array}$

Education services

$\begin{array}{ll}\square & \text { Never } \\ \square & \text { Yearly } \\ \square & \text { Monthly } \\ \square & \text { Weekly } \\ \square & \text { Daily }\end{array}$

Audio reading services

$\begin{array}{ll}\square & \text { Never } \\ \square & \text { Yearly } \\ \square & \text { Monthly } \\ \square & \text { Weekly } \\ \square & \text { Daily }\end{array}$

Entertainment such as Audio Description 


$$
\begin{array}{ll}
\square & \text { Never } \\
\square & \text { Yearly } \\
\square & \text { Monthly } \\
\square & \text { Weekly } \\
\square & \text { Daily }
\end{array}
$$

Screen reader

$$
\begin{array}{ll}
\square & \text { Never } \\
\square & \text { Yearly } \\
\square & \text { Monthly } \\
\square & \text { Weekly } \\
\square & \text { Daily }
\end{array}
$$

Sports commentary

$$
\begin{array}{ll}
\square & \text { Never } \\
\square & \text { Yearly } \\
\square & \text { Monthly } \\
\square & \text { Weekly } \\
\square & \text { Daily }
\end{array}
$$

Other

$\begin{array}{ll}\square & \text { Never } \\ \square & \text { Yearly } \\ \square & \text { Monthly } \\ \square & \text { Weekly } \\ \square & \text { Daily } \\ & \\ \square & \text { I don't know }\end{array}$

6. What kind of services would you like to have access?

Guide dogs

a Never 


$$
\begin{array}{ll}
\square & \text { Yearly } \\
\square & \text { Monthly } \\
\square & \text { Weekly } \\
\square & \text { Daily }
\end{array}
$$

\section{Education services}

$$
\begin{array}{ll}
\square & \text { Never } \\
\square & \text { Yearly } \\
\square & \text { Monthly } \\
\square & \text { Weekly } \\
\square & \text { Daily }
\end{array}
$$

Audio reading services

$$
\begin{array}{ll}
\hline & \text { Never } \\
\square & \text { Yearly } \\
\square & \text { Monthly } \\
\square & \text { Weekly } \\
\square & \text { Daily }
\end{array}
$$

Entertainment such as Audio Description

$$
\begin{array}{ll}
\square & \text { Never } \\
\square & \text { Yearly } \\
\square & \text { Monthly } \\
\square & \text { Weekly } \\
\square & \text { Daily }
\end{array}
$$

Screen reader

$$
\begin{array}{ll}
\square & \text { Never } \\
\square & \text { Yearly } \\
\square & \text { Monthly } \\
\square & \text { Weekly } \\
\square & \text { Daily }
\end{array}
$$

Sports commentary 


$\begin{array}{ll}\square & \text { Never } \\ \square & \text { Yearly } \\ \square & \text { Monthly } \\ \square & \text { Weekly } \\ \square & \text { Daily }\end{array}$

Other

$\begin{array}{ll}\square & \text { Never } \\ \square & \text { Yearly } \\ \square & \text { Monthly } \\ \square & \text { Weekly } \\ \square & \text { Daily } \\ \square & \text { I don't know }\end{array}$

7. What kind of things would you like to be able to do by yourself?

8. What kind of things would you like help with but are usually not helped?

9. How often do you access the following types of entertainment?

Television

$\begin{array}{ll}\square & \text { Never } \\ \square & <1 \text { time/month } \\ \square & 1-5 \text { times/month } \\ \square & 6-15 \text { times/month } \\ \square & \text { Daily }\end{array}$

Radio broadcast
口 Never
口 < time/month
口 $\quad 1-5$ times/month
口 6-15 times/month
D Daily 
Theatre
口 Never
口 $<1$ time/month
口 $\quad 1-5$ times/month
6-15 times/month
口 Daily

Live music performance

$\begin{array}{ll}\square & \text { Never } \\ \square & <1 \text { time/month } \\ \square & 1-5 \text { times/month } \\ \square & 6-15 \text { times/month } \\ \square & \text { Daily }\end{array}$

Other (please specify: )
口 Never
口 $<1$ time/month
口 $\quad 1-5$ times/month
6-15 times/month
口 Daily

10. How often do you watch television with other people?

- Never watch television

口 Never watch television and ask for assistance

- Sometimes watch TV and don't ask for assistance

口 Sometimes watch TV and ask for assistance

口 Frequently watch TV and don't ask for assistance

ㅁ Frequently watch TV and ask for assistance

- Always watch TV and don't ask for assistance

口 Always watch TV and ask for assistance

11. How often do you watch movie with other people? 


\section{Never watch movie}

口 Never watch movie and ask for assistance

- Sometimes watch movie and don't ask for assistance

口 Sometimes watch movie and ask for assistance

口 Frequently watch movie and don't ask for assistance

- Frequently watch movie and ask for assistance

- Always watch movie and don't ask for assistance

a Always watch movie and ask for assistance

12. How often do you go to theatre with other people?

口 Never go to theatre

口 Never go to theatre and ask for assistance

口 Sometimes go to theatre and don't ask for assistance

- Sometimes go to theatre and ask for assistance

- Frequently go to theatre and don't ask for assistance

- Frequently go to theatre and ask for assistance

- Always go to theatre and don't ask for assistance

a Always go to theatre and ask for assistance

13. Who normally tells you what is going on when you go to theatre or watch television for you (Select all that apply)?

Partner or spouse

Always

口 Sometimes

口 Never

Relatives

$\begin{array}{ll}\square & \text { Always } \\ \square & \text { Sometimes } \\ \square & \text { Never }\end{array}$


Friends
Always
口 Sometimes
口 Never

Support staff
always
口 Sometimes
$\square \quad$ Never

Other (please specify: )

$\begin{array}{ll}\square & \text { Always } \\ \square & \text { Sometimes } \\ \square & \text { Never } \\ \square & \text { No one describes for me }\end{array}$

14. Please rate your level of familiarity with audio description where audio description is a verbal description of the important visual information provided as part of a show.
$\square \quad$ Very familiar
口 Familiar
口 Somewhat familiar
口 Not very familiar
$\square \quad$ Not familiar at all

15. When audio description is available, how often do you use it?

口 I do not watch television/movie/go to theatre

$\square \quad$ Never used audio description

口 Sometimes

口 Frequently 
16. What quality would you rate current audio description available for television

$\begin{array}{ll}\square & \text { Very poor } \\ \square & \text { Poor } \\ \square & \text { Don't care } \\ \square & \text { Good } \\ \square & \text { Very good } \\ \square & \text { I do not use AD }\end{array}$

17. What quality would you rate current audio description available for movies

$\begin{array}{ll}\square & \text { Very poor } \\ \square & \text { Poor } \\ \square & \text { Don't care } \\ \square & \text { Good } \\ \square & \text { Very good } \\ \square & \text { I do not use AD }\end{array}$

18. What quality would you rate current audio description available for theatre

$\begin{array}{ll}\square & \text { Very poor } \\ \square & \text { Poor } \\ \square & \text { Don't care } \\ \square & \text { Good } \\ \square & \text { Very good } \\ \square & \text { I do not use AD }\end{array}$

19. If audio description were to be available to you for television, what would be the three (3) most important types of television shows to be described? (please rank 1, 2, 3)

$\square \quad($ )News 
( )Documentaries

( ) Dramas

( ) Situation comedies

( )Comedies

( ) Mysteries

口 ( )Reality shows

ㄱ ( )Other(s), please specify:

20. If audio description were to be available to you, what would be the three (3) most important types of movies to be described? (please rank 1, 2, 3)

a ( )Dramas

口 ( )Documentaries

口 ( )Comedies

口 ( )Tragedies

a ( )Actions

口 ( )Mysteries

口 ( )Horrors

ㄱ ( )Other(s), please specify:

21. If audio description were to be available to you, what would be the three (3) most important types of live theatre shows to be described? (please rank 1, 2, 3)

a ( )Music concerts

a ( )Dance (e.g., ballet, modern dance)

a ( )Plays

口 ( ) Circus

a ( )Opera

ㄱ ( )Other(s), please specify:

22. If you were to assess the quality of a show's audio description, what three (3) factors would you consider important in your rating (check only 3 items)? 


$\begin{array}{ll}\square & \text { Enjoyable } \\ \square & \text { Informative } \\ \square & \text { Fun } \\ \square & \text { Doesn't disrupt my enjoyment of the show } \\ \square & \text { Doesn't distract me } \\ \square & \text { Is in a voice that is different from others in show } \\ \square & \text { Is in a voice that matches with the show } \\ \square & \text { Style of description fits with rest of the show's dialogue style } \\ \square & \text { Has distinct style from other dialogue in the show } \\ \square & \text { Doesn't talk over other dialogue } \\ \square & \text { Is emotional } \\ \square & \text { Is not emotional } \\ \square & \text { Other, please specify: }\end{array}$




\section{Audio Description in the Chinese Community}

Phase two questionnaire

The purpose of the questionnaire is to gather information about your opinion of the quality and quantity of audio description for the movie you just watched. There are a total of 15 questions in this questionnaire and it should take about 15 minutes to complete this questionnaire. Thank you in advance for your assistance.

1. Please indicate, in general, how entertained you were by the movies.

$\begin{array}{ll}\square & \text { Very entertained } \\ \square & \text { Entertained } \\ \square & \text { Uncertain } \\ \square & \text { Not really entertained } \\ \square & \text { Not entertained at all }\end{array}$

2. Please indicate, in general, how entertained you were by the audio description of the movies.

\begin{tabular}{cl}
\hline & Very entertained \\
$\square$ & Entertained \\
$\square$ & Uncertain \\
$\square$ & Not really entertained \\
$\square$ & Not entertained at all \\
$\square$ & I was distracted by the description
\end{tabular}

3. How well do you think you understood the production in general?

a Complete understanding of all of the elements 

$\square \quad$ Mostly understood the elements
口 Some understanding
$\square \quad$ A little
口 None

4. Out of ten, please rate the quality of the audio description of this film where 1 is very poor quality and 10 is excellent quality?

Rating out of 10:

$/ 10$

5. Was there enough description for

\begin{tabular}{|l|l|l|l|l|}
\hline & Onscreen action/plot & Characters & Costumes & Set \\
\hline Somewhat redundant & & & & \\
\hline Just enough & & & & \\
\hline $\begin{array}{l}\text { I wanted more } \\
\text { information }\end{array}$ & & & & \\
\hline I don't know & & & & \\
\hline
\end{tabular}

6. Rate the quality of the description for

\begin{tabular}{|l|l|l|l|l|}
\hline & $\begin{array}{l}\text { Onscreen } \\
\text { action/plot }\end{array}$ & Characters & Costumes & Set \\
\hline Very poor & & & & \\
\hline poor & & & & \\
\hline Neither poor nor good & & & & \\
\hline good & & & & \\
\hline excellent & & & & \\
\hline
\end{tabular}

7. How would you rate the volume level of the description?
Excellent
口 Good
口 Average 


\section{$\square \quad$ Fair \\ $\square$ Poor}

8. What factors positively affected your rating of audio description for this film? Check all that apply.

$\begin{array}{ll}\square & \text { Describer's pace } \\ \square & \text { Language \& vocabulary used } \\ \square & \text { Style of description } \\ \square & \text { Fit of description to show } \\ \square & \text { Amount of information conveyed } \\ \square & \text { Quality of description } \\ \square & \text { Other factor(s), please specify: }\end{array}$

9. What factors negatively affected your rating of audio description for this film? Check all that apply.

Describer

口 Tone of voice does not fit the show

口 Pace was too slow in relation to the show and character dialogue

口 Pace was too fast in relation to the show and character dialogue

Language \&Vocabulary

$\square$ Too simple in relation to the show's language

- Too complex in relation to the show's language

Quantity

- Too much description in relation to the amount of available space between dialogue

․ Too little description in relation to the amount of available space between dialogue

Style of description

Did not match the show's content or genre structure (e.g. show was funny 
and the description was serious)

Voice of describer did not portray a breath of emotions (such as anger, sadness, excitement)

Interrupted elements within the show such as dialogue or music

I Interrupted enjoyment of show

- Other factor(s), please specify:

10. Would you feel comfortable discussing the production with a sighted partner or friend who did not use audio description?

$\begin{array}{ll}\square & \text { Definitely } \\ \square & \text { Probably } \\ \square & \text { Possibly } \\ \square & \text { Probably Not } \\ \square & \text { No }\end{array}$

11. If you have any other comments that you would like to share, please include them here. 


\section{References}

[1] Snyder, J. (2005, September). Audio description: The visual made verbal. International Congress Series (Vol. 1282, pp. 935-939). Elsevier.

[2] Erbaugh, M.S. (1990). 'Mandarin oral narratives compared with English: The Pear/Guava Stories'. Journal of the Chinese Language Teachers Association. 25:2;21-42. Don't describe.

[3] Agnieszka, C \& Mazur I.(2009): "Towards a common European quality audio description: Final report on the Pear Tree Project". Presentation at Media for All International Conference, Antwerp, http://www.mediaforall.eu/parallel_4.html. Last visited 14 January 2010.

[4] Bartolome, H. Ana I. (2009) Cabrera Gustavo Mendiluce. How can images be translated? Audio description, a challenging audiovisual and social gap-filler Hermeneus. (11, pp. 161186).

[5] Jakobson, R. (1959). On linguistic aspects of translation. On translation, 3, 30-39.

[6] Bartrina, F. (2004). The challenge of research in audiovisual translation. Benjamns Translation Library, 56, 157-168.

[7] Orero, P. (2012). Film reading for writing audio descriptions: A word is worth a thousand images?.

[8] Benecke, B. (2012). Audio description and audio subtitling in a dubbing country: Case studies.

[9] Piety, P. (2004). The language system of audio description: an investigation as a discursive process. Journal of Visual Impairment \& Blindness (JVIB), 98(08).

[10] Salway, A. (2007). A corpus-based analysis of audio description. Media for all: Subtitling for the deaf, audio description and sign language, 151-174.

[11] Salway, A., Vassiliou, A., \& Ahmad, K. (2005, July). What happens in films?. In Multimedia and Expo, 2005. ICME 2005. IEEE International Conference on(pp. 4-pp). IEEE.

[12] Lakritz, J., \& Salway, A. (2006). The Semi-Automatic Generation of Audio Description from Screenplays. Dept. of Computing Technical Report CS-06-05, University of Surrey.

[13] Bourne, J. and Jiménez Hurtado C. (2007). From the Visual to the Verbal in Two Languages: A Contrastive Analysis of the Audio Description of The Hours in English and Spanish. In Jorge Díaz Cintas Media for All. Subtitling for the Deaf, Audio Description, and Sign Language. Eds.. Amsterdam/New York: Rodopi, 2007: 175-187.

[14] Agnieszka C and Mazur I.(2012). AD reception research: Some methodological considerations. In Elisa Perego (Ed): Emerging topics in translation: Audio description. Trieste: EUT Edizioni Università di Trieste. 57-80. 
[15] Orero, P. (2008): Three different receptions of the same film, European Journal of English Studies, 12:2, 179-193

[16] Yeung, J. (2007) Audio description in the Chinese world. Media for All: Subtitling for the Deaf, Audio Description and Sign Language. (pp. 231-244).

[17] Chao, Y. (2002) Audio Description: A Dialogue Between Translation and Representation. News Study. 70:97-134.

[18] Gagnon, L., Foucher, S., Heritier, M., Lalonde, M., Byrns, D., Chapdelaine, C., ... \& Ouellet, D. (2009). Towards computer-vision software tools to increase production and accessibility of video description for people with vision loss. Universal Access in the Information Society, 8(3), 199-218.

[19] Fels, D. I., \& Naraine, M. When audio description came to town: a longitudinal study.

[20] Bach-y-Rita, P., \& W Kercel, S. (2003). Sensory substitution and the human-machine interface. Trends in cognitive sciences, 7(12), 541-546.

[21] Lenay, C., Gapenne, O., Hanneton, S., Marque, C., \& Genouelle, C. (2003). Sensory substitution: Limits and perspectives. Touching for knowing, 275-292.

[22] Ward, J., \& Meijer, P. (2010). Visual experiences in the blind induced by an auditory sensory substitution device. Consciousness and cognition, 19(1), 492-500.

[23] Szarkowska, A., \& Jankowska, A. (2012). Text-to-speech audio description of voicedover films. A case study of audio described Volver in Polish.

[24] Chao, Y.(2002) Yan Yu Shi Jie Zhong De Liu Dong Guang Ying : Kou Shu Ying Xiang De Li Lun Jian Gou. Taibei Shi: Wu Nan Tu Shu Chu Ban Gu Fen You Xian Gong Si, Print.

[25] Udo, J. P., \& Fels, D. I. (2009). " Suit the Action to the Word, the Word to the Action": An Unconventional Approach to Describing Shakespeare's Hamlet. Ted Rogers School of Information Technology Management Publications and Research, 16.

[26] Diamond, J., Diamond, J., Fels, D., \& Udo, J. (2006). A comparison of alternative narrative approaches to video description for animated comedy. Journal of Visual Impairment \& Blindness (JVIB), (05).

[27] Udo, J. P., \& Fels, D. I. (2009). From the describer's mouth: reflections on creating unconventional audio description for live theatre.

[28] Udo, J. P., Acevedo, B., \& Fels, D. I. (2010). Horatio audio-describes Shakespeare's Hamlet Blind and low-vision theatre-goers evaluate an unconventional audio description strategy. British Journal of Visual Impairment,28(2), 139-156.

[29] Whitfield, M., \& Fels, D. I. (2013). Inclusive Design, Audio Description and Diversity of Theatre Experiences. The Design Journal, 16(2), 219-238.

[30] Branje, C., Marshall, S., Tyndall, A., \& Fels, D. (2006). LiveDescribe. 
[31] Whitfield, M., \& Fels, D. (2013). Mary Poppins, the musical, brought to life through alternative audio description (AD) for blind and low vision (B/LV) theatre goers.

[32] Udo, J. P., \& Fels, D. (2009). The Development of a New Theatrical Tradition: Sighted students audio describe school play for a blind and low-vision audience. International Journal of Education \& the Arts, 10(20), n20.

[33] Fels, D. I., Udo, J. P., Ting, P., Diamond, J. E., \& Diamond, J. I. (2006). Odd Job Jack described: a universal design approach to described video. Universal Access in the Information society, 5(1), 73-81.

[34] Konstantinidis, B. M., Price, E., Diamond, J., \& Fels, D. I. (2008). Described video information and animation: a case study of Odd Job Jack. International Journal of Social and Humanistic Computing, 1(1), 108-122.

[35] Udo, J. P., \& Fels, D. I. (2010). Re-fashioning fashion: an exploratory study of a live audio-described fashion show. Universal Access in the Information Society,9(1), 63-75.

[36] Udo, J. P., \& Fels, D. I. (2009). The Rogue Poster-Children of Universal Design: Closed Captioning and Audio Description.

[37] Vorderer, P. (2003). Entertainment theory. Communication and emotion: Essays in honor of Dolf Zillmann, 131-153.

[38] Vorderer, P. (2011). What's Next?. Journal of Media Psychology: Theories, Methods, and Applications, 23(1), 60-63.

[39] Airman, R. (1983). Television/Sound. Studies in Entertainment: Critical Approaches to Mass Culture, 39-54.

[40] Habermas, J. (1991). The structural transformation of the public sphere: An inquiry into a category of bourgeois society. The MIT Press.

[41] Habermas, J., Lennox, S., \& Lennox, F. (1974). The public sphere: An encyclopedia article (1964). New German Critique, (3), 49-55.

[42] Garnham, N. (1992). The media and the public sphere. Habermas and the public sphere, 359, 76.

[43] Goode, L. (2005). Jürgen Habermas: Democracy and the public sphere. Pluto Pr.

[44] Graham, G. (2012). Public Option and the Public Sphere. Beyond Habermas: Democracy, Knowledge, and the Public Sphere, 29.

[45] Born, G. (2012). Mediating the public Sphere. Beyond Habermas: Democracy, Knowledge, and the Public Sphere, 119.

[46] Bohman, J. (2004). Expanding dialogue: The Internet, the public sphere and prospects for transnational democracy. The Sociological Review, 52(s1), 131-155. 
[47] Dahlgren, P. (1995). Television and the public sphere: Citizenship, democracy and the media. SAGE Publications Limited.

[48] Kluge, A., Levin, T. Y., \& Hansen, M. B. (1981). On film and the public sphere. New German Critique, (24/25), 206-220.

[49] Kellner, D. (2000). Habermas, the public sphere, and democracy: A critical intervention. Perspectives on Habermas, 259-288.

[50] Hansen, M. (1993). Early cinema, late cinema: permutations of the public sphere. Screen, 34(3), 197-210.

[51] Curran, J. (1991). Rethinking the media as a public sphere. Communication and citizenship, 27-57.

[52] Michael DeLuca, K., \& Peeples, J. (2002). From public sphere to public screen: Democracy, activism, and the" violence" of Seattle. Critical studies in media communication, 19(2), 125-151.

[53] Craig, R. T. (1999). Communication theory as a field. Communication theory,9(2), 119161.

[54] Holmes, D. (2005). Communication theory: Media, technology and society. Sage.

[55] Eco, U. (1979). Theory of semiotics (Vol. 217). Indiana University Press.

[56] Leeds-Hurwitz, W. (2012). Semiotics and communication: Signs, codes, cultures. Routledge.

[57] Story, M. F. (1998). Maximizing usability: the principles of universal design. Assistive technology, 10(1), 4-12.

[58] Gill, J., \& Perera, S. (2003, March). Accessible universal design of interactive digital television. In Proceedings of the 1st European conference on interactive television: from viewers to actors (pp. 83-89).

[59] Nicolle, C., \& Abascal, J. (2001). Inclusive design guidelines for HCl. CRC Press.

[60] Clarkson, J. (2003). Inclusive design: Design for the whole population. Springer Verlag.

[61] Erlandson, R. F. (2010). Universal and accessible design for products, services, and processes. CRC Press.

[62] Emiliani, P. L., \& Stephanidis, C. (2000, October). From adaptations to user interfaces for all. In 6th ERCIM workshop CNR-IROE, Florence, Italy.

[63] Story, M., Mueller, J., \& Mace, R. (1998). The Universal Design File: Designing for people of all ages and abilities. Design Research and Methods Journal, 1(1).

[64] Audetel Consortium. (2000). ITC guidance on standards for audio description. Retrieved from 
http://www.ofcom.org.uk/static/archive/itc/itc_publications/codes_guidance/audio_description/l ndex.asp.html

[65] Milligan, B., Fels, D., \& Dumochel, P. (2011). The Descriptive Video Production and Presentations Best Practices Guide for Digital Environments (Version 1). Unpublished manuscript. from http://www. mediac. ca/proj-ACBPG. Asp.

[66] Scotton, J. F., \& Hachten, W. A. (Eds.). (2010). New media for a new China. Wiley. Com.

[67] Vorderer, P., Klimmt, C., \& Ritterfeld, U. (2004). Enjoyment: At the heart of media entertainment. Communication theory, 14(4), 388-408.

[68] Ke Hu. (2010). The history, situation and future of Chinese film theory. Contemporary Cinema, 6, 40-44.

[69] Yijun Liu. (2008). Establishing the system of Chinese film theory. Contemporary Cnema, 8, 85-87.

[70] Klimmt, C., \& Vorderer, P. (2003). Media psychology "is not yet there": Introducing theories on media entertainment to the presence debate. Presence: Teleoperators and Virtual Environments, 12(4), 346-359.

[71] Proulx, M. J., Stoerig, P., Ludowig, E., \& Knoll, I. (2008). Seeing 'where'through the ears: effects of learning-by-doing and long-term sensory deprivation on localization based on imageto-sound substitution. PloS one, 3(3), e1840.

[72] Auvray, M., Hanneton, S., \& O Regan, J. K. (2007). Learning to perceive with a visuoauditory substitution system: Localisation and object recognition withThe vOICe'.

PERCEPTION-LONDON-, 36(3), 416.

[73] Wei, Z., Lirong, S., \& Chunming, L. (2012). An analysis of the development of China Digital Library for Visual Impairment website. Electronic Library, The,30(6), 756-763.

[74] Zheng, G. (2007). Zhong Guo Can Ji Ren She Hui Bao Zhang De Hong Guan Si Kao. Journal of Henan Normal University (Philosophy and Social Sciences), 34(6).

[75] Leitch, T. (2009). Film adaptation and its discontents: from Gone with the Wind to The Passion of the Christ. JHU Press.

[76] Canadian Radio-television and Telecommunications Commission. (2004). Broadcasting Public Notice CRTC 2004-2. Retrieved from http://www.crtc.gc.ca/archive/ENG/Notices/2004/pb2004-2.htm

[77] World Health Organization. (2012). Visual impairment and blindness. Retrieved from http://www.who.int/mediacentre/factsheets/fs282/en/

[78] Heart \& Eye Theatre. (2010). Retrieved from http://www.hongdandan.org

[79] Christian Aid \& Relational Evangelism (CARE) Inc. Retrieved from http://careministries.ca 
[80] Field, S. (2007). Screenplay: The foundations of screenwriting. Random House Digital, Inc..

[81] Stephanidis, C., \& Emiliani, P. L. (1999). Connecting to the information society: a European perspective. technology and disability, 10(1), 21-44.

[82] Udo, J. P., \& Fels, D. I. (2010). Universal design on stage: live audio description for theatrical performances. Perspectives: Studies in Translatology, 18(3), 189-203.

[83] WordNet Dictionary (online): Definition of "narration".

[84] Holden, W., \& Beaufoy, S. (1998). The full monty. HarperCollins.

[85] Rubinfeld, D. (2001) Bound to Bond: Gender, genre, and the Hollywood romantic comedy. Praeger Publishers. 